\title{
EXCAVACIONES ARQUEOLÓGICAS EN LA LADERA SUR DE FUENTE ÁLAMO: CAMPAÑA DE 1999
}

\author{
ARCHAEOLOGICAL EXCAVATIONS AT THE SOUTHERN \\ SLOPE OF FUENTE ÁLAMO. 1999 CAMPAIGN
}

\author{
por \\ VOLKER PINGEL \\ HERMANFRID SCHUBART \\ OSWALDO ARTEAGA \\ ANNA-MARIA ROOS \\ MICHAEL KUNST
}

\begin{abstract}
Se presentan en este informe los resultados arqueológicos obtenidos en la última campaña de excavación realizada en el otoño de 1999 en el poblado prehistórico de Fuente Álamo (Cuevas del Almanzora, Almería). El corte mas occidental de la ladera oeste (corte 42) confirma en plantas y perfiles, en parte aquí presentadas, que también allí como en las laderas sur y este del cerro hay que contar con un hábitat intensivo y con sepulturas relativamente frecuentes. En la ladera sur se excavaron las tumbas femeninas 111 y 112, las dos en pithoi y la 111 con un ajuar especialmente relevante -hasta ahora desconocido en esta forma de la ladera sur-, rico en cerámica, con 16 anillos y brazaletes de bronce y plata, con más de 30 cuentas de collar de piedra, algunas importadas, y también 12 cuentas de plata de diferentes tipos. Destacan las evidencias estratigráficas recabadas en los tramos altos de la ladera sur del cerro, apuntando notables diferencias arquitectónicas respecto de los singulares edificios excavados en la cima y abriendo cuestionamientos previsibles en comparación con las diversidades constructivas que se pueden esperar integradas en otros distintos sectores del mismo asentamiento. Se ha confirmado con creces la continuidad poblacional durante el Bronce Tardío Antiguo. Por lo que partiendo del concepto 'post-argárico' y de la fragmentación política del Estado territorial precedente, quedan planteadas unas nuevas expectativas explicativas para la definición de dicho período prehistórico, por un lado en relación con el parangón del llamado Mundo Micénico, y por el lado principal en relación con el proceso atlántico-mediterráneo que concierne a la 'formación' del Mundo Tartesio.
\end{abstract}


ABSTRACT In this study we report the archaeological results of the excavation of the prehistoric settlement Fuente Álamo (Cuevas del Almanzora, in Almería) carried out in the autumn of 1999. Plans and sections of trench 42 situated on the most western slope, some of which are illustrated in this article, confirm that there, as observed on the south and east slopes, had been intensive habitation which relative frequently contained graves. On the south slope two graves, number 111 and 112 , both female and both buried in pithoi, have been excavated. Grave 111 contained particularly rich grave goods, unusual for the south slope. It was rich in pottery, contained 16 rings and bracelets of bronze and silver, 12 silver beads of different types and finally more than 30 beads of stone, some of which were imported. It is appropriate to underline the importance of the stratigraphic sequence obtained in the upper area of the south-facing slope, which illustrates a considerable architectural difference when compared to the important buildings excavated on the top of the site. Moreover, it poses many questions about the variety of buildings in other areas of the settlement. Continuous habitation during the early Late Bronze Age has clearly been confirmed. Thus, accepting the post-Argaric concept and the political fragmentation of the previous State, we will obtain a definition of this prehistoric period, in relation to the Mycenaean world and to the Atlantic-Mediterranean process involved in the formation of the Tartessian world.

Palabras claves Fuente Álamo. El Argar. Bronce Tardío post-argárico.

Key words

Fuente Álamo. El Argar. Post-Argaric Late Bronze Age.

\section{INTRODUCCIÓN}

La séptima campaña de excavación arqueológica realizada en el poblado de la Edad del Bronce de Fuente Álamo ubicado en el término municipal de Cuevas del Almanzora (prov. Almería), ha sido efectuada durante las fechas comprendidas entre el 17 de septiembre y el 31 de octubre de 1999 de acuerdo con las expectativas científicas formuladas en función de los resultados obtenidos en las intervenciones de un largo y fructífero proyecto de investigación (Arteaga y Schubart 1980; 1981; Schubart, Arteaga y Pingel 1985; 1988; 1989; Schubart, Pingel y Arteaga 1991; 1993; Pingel et al. 1998). Ha sido esta campaña concebida como una colaboración entre el Instituto Arqueológico Alemán de Madrid y las Universidades de Bochum (Alemania) y Sevilla, bajo la dirección de V. Pingel (Bochum), H. Schubart (Rauschenberg, Alemania), O. Arteaga (Sevilla) y M. Kunst (Madrid). La clasificación y catalogación de los materiales ha sido efectuada por un equipo de colaboradores de la Universidad de Sevilla coordinado por A.M. Roos.

Los autores firmantes quieren expresar su especial agradecimiento al Primer Director del Instituto Arqueológico Alemán de Madrid, Prof. Dr. Tilo Ulbert, y al Director General de Bienes Culturales de la Consejería de Cultura de la Junta de Andalucía, Dr. Julián Martínez García, por su inestimable interés y apoyo, cabiendo resaltar que sin su particular empeño esta campaña no podría haber sido realizada.

En la campaña de 1999 participaron las siguientes personas: Dra. Corina Liesau (Universidad Autónoma de Madrid), Dr. Alfredo Mederos Martín (Universidad Complutense de Madrid); los licenciados D. Daniel Barragán Mallofret (Universidad de Sevilla), D ${ }^{a}$ Elena Morán Hernández (Sagres, Portugal), Da Manuela Pérez Rodríguez (Universidad de Cádiz) y Da Olga Sánchez Liranzo (Universidad de Sevilla); los estudiantes D. Sven Beba (Universidad de Bochum, Alemania), D. José Ángel Contreras Arqué, D. Ignacio Fernández Estevan, D. Joaquín Fernández Pérez y D. Raúl Madueño Cortés (todos de la Universidad de Sevilla). Además participaron como dibujante D. José Fernández Pérez (Madrid) y como fotógrafo D. John Patterson (Instituto 
Arqueológico Alemán de Madrid). El personal obrero procedente de Cuevas del Almanzora y sus alrededores llegó a contar hasta diez personas, entre hombres y mujeres. Los autores quedan muy agradecidos a todos los integrantes del equipo. Es de lamentar que en función de la limitación programática del trabajo previsto esta vez otros investigadores de ciencias afines no pudieron colaborar directamente en la campaña. No obstante, como visitantes participaron temporalmente el Dr. Rui Parreira (Sagres, Portugal) y la Dra. Beate Schuler (Ashford, Irlanda), cuyas ayudas son de agradecer ${ }^{1}$.

Puesto que esta campaña fue concebida por parte del Instituto Arqueológico Alemán de Madrid y de la Junta de Andalucía de momento como la última a realizar antes de la publicación de la 'Memoria Científica' de los trabajos iniciados en 1977, la autorización concedida abarcaba exclusivamente la culminación de algunos trabajos en la zona de los cortes 38 a 41 ubicados en la ladera sur, para proceder luego a su cubrición inmediata siguiendo las instrucciones dictadas por la Comisión Andaluza de Arqueología (Sevilla). La proposición original de continuar una investigación más amplia de la ladera sur, como se había efectuado en el ámbito de la cima, no tuvo la fortuna de verse aprobada. Por lo que después de haberse trazado un gran eje de varios cortes bajando la ladera, la previsión de ampliar su extensión hacia los lados, por lo pronto ya no se pudo llevar a cabo; obligando el criterio de la cubrición de los cortes de dicha ladera a suspender también la restauración de las estructuras arquitectónicas de esta parte del poblado prehistórico, que en caso contrario podría haberse efectuado, para dejar a la vista del público visitante el contraste de la 'acrópolis' (ahora conservada) y la comparación de otro sector habitado de Fuente Álamo (ahora nuevamente sepultado).

También en esta campaña, como en las anteriores, debido a los problemas de almacenamiento por los que vienen pasando las instalaciones del Museo Arqueológico Provincial, los hallazgos materiales se depositaron de acuerdo con la Dirección General de Bienes Culturales en el propio Ayuntamiento de Cuevas del Almanzora. El traslado de todos los materiales depositados a unas nuevas dependencias de la misma Casa Consistorial, que fueron habilitadas para tales efectos, ofrecería a los excavadores la oportunidad de acometer una reordenación funcional de más fácil acceso, bajo la dirección de A.M. Roos, contando con la eficaz ayuda de los estudiantes participantes de las Universidades de Sevilla y Cádiz. Al actual Alcalde de Cuevas del Almanzora, D. Jesús Caicedo Bernabé, y a sus colaboradores, en especial a D. Eusebio Gómez Gambín, queremos expresar nuestro agradecimiento por la gran ayuda prestada.

La campaña autorizada en la ladera sur tenía que concentrarse por lo dicho en algunos puntos especialmente relevantes; ya que entonces apremiaba el tiempo disponible, y se tenía que hacer compatible el reducido número del personal obrero, a su vez con la previsión de los movimientos de tierras necesarios para cubrir los cortes. Sobre todo era, cuando menos, obligado acabar de documentar en el espacio limitado de aquellos cortes una mayor extensión posible de las construcciones parcialmente visibles, e investigar las secuencias estratigráficas hasta la roca. Además, se tendría que intentar completar la relación comparativa del gran perfil oeste, y realizar en la misma una ampliación de pequeñas dimensiones hacia el oeste. Algunas zonas de los cortes, y sobre todo de los perfiles, estaban relativamente dañadas a causa de las lluvias, de manera que repetidas veces surgían problemas a la hora de conectar con los contextos anteriormente documentados. Han sido excavados por completo en extensión los cortes 38 -éste, en particular, sin aportarnos contextos estratigráficos-y el 41. En la zona norte del corte 41, estas investigaciones finales no suministraron nuevos resultados, en comparación con las anteriores campañas, excepto los relativos a completar el seguimiento de algunos pocos vestigios murales (Schubart, Pingel y Arteaga 1993: 3 ss., fig. 2).

Así pues, los trabajos de esta campaña se concentraron principalmente en los cortes 39 y 40 , así como también en los potentes testigos que les separan de los cortes 38 y 41, e igualmente en el testigo 39/40 situado entre ambos. No podían ser excavadas algunas partes de las capas inferiores de la zona meridional del corte 39

1. Las ilustraciones fueron realizadas por: figs. 1-4. 13. 14 A. Kuczminski (Bochum); figs. 5. 7-12. 15. 16 J. Fernández(Madrid); figs. 17-24 O. Arteaga y A.M. Roos (Sevilla). 
y del testigo 39/40, así como de la mitad este y la zona meridional del corte 40, y del testigo 40/41. Los dos testigos mencionados se rebajaron hasta alcanzar los niveles investigados en los cortes, respectivamente. Además, en el corte 40, delante del perfil oeste, se profundizó hasta la roca, consiguiendo de esta manera una documentación completa de amplias partes del perfil oeste, excepto del ámbito ocupado por el testigo 39/40. Había de conformarse con estas restricciones adicionales, para poder realizar una ampliación limitada del corte 39 hacia el oeste (corte $39 \mathrm{~W}$ ), hasta aproximadamente la coordenada $x+32 \mathrm{~m}$, abriendo un espacio abarcado entre las coordenadas y - $6 \mathrm{~m} / \mathrm{y}-11$ m en dirección norte-sur, hasta llegar al primer plano de excavación.

Aparte, durante esta campaña se documentaron gráficamente los restos de construcciones de la Edad del Bronce y de la época romana que afloran en la superficie de las zonas más bajas de la ladera sur. En suma, esta campaña nos aportó importantes conocimientos adicionales sobre las edificaciones existentes en la ladera sur durante la Edad del Bronce, que al menos en el área investigada, en comparación con las edificaciones conocidas en la cima, muestran una notable variedad en la manera de construir y en las funciones asignadas a las estructuras arquitectónicas. También se ampliaron nuestros conocimientos sobre los enterramientos argáricos de Fuente Álamo por el descubrimiento de las tumbas 111 y 112, en el ámbito del testigo $39 / 40$ y del corte 40 , respectivamente. Y como veremos especialmente, se obtuvieron unas importantes evidencias mostrativas de la continuidad poblacional del asentamiento durante el período post-argárico relativo a los comienzos del Bronce Tardío en el sudeste de la Península Ibérica.

(V.P.)

\section{LAS ESTRUCTURAS ARQUITECTÓNICAS DIFERENCIADAS EN LA LADERA SUR DE FUENTE ÁLAMO}

En el corte 39, en primer lugar se desmontaron los muros lt y lv excavados en 1996 en la zona norte del corte (Pingel et al. 1998: fig. 1).Desde el perfil oeste el muro lt seguía durante un trayecto de $2 \mathrm{~m}$ a un escalón artificial cortado en la roca en dirección nordeste. Luego, por debajo del muro ls, este escalón dobla hacia el norte creando otro ángulo artificial de terraza hasta el perfil este, con una profundidad de unos $80 \mathrm{~cm}$. Este ángulo se insinuó ya en 1996 (Pingel et al. 1998: fig. 1, véase las líneas esquemáticas de la roca). Su espacio seguramente debería ocupar un edificio, del cual no se conservaron ningunos restos constructivos. Más bien hacia el sur, el escalón estaba relleno con materiales rocosos estériles y paquetes de filitas.

La antes mencionada ampliación oeste del corte 39 (corte $39 \mathrm{~W}$ ) ahora se proyectaría con el propósito de poder observar el ángulo entre los muros ka y kc, conocido desde hace tiempo, consiguiendo de esta manera la documentación de su límite oeste, y con ello el conocimiento de la anchura completa de un edificio de la ladera sur por primera vez (Pingel et al. 1998: fig. 2; Schubart, Pingel y Arteaga 1993: fig. 2). Finalmente, esto fue posible, ya que el muro kc que no tiene una verdadera cara exterior porque está adosado en su mayor parte a la ladera, podía ser observado durante un trayecto de unos $2,5 \mathrm{~m}$ en dirección oeste doblando luego en ángulo recto hacia el sur (fig. 1, lám. I). Así pues, este edificio X tenía una anchura interior de unos 3,0-3,5 m y unas dimensiones exteriores de unos $5,0 \mathrm{~m}$. Su límite sur no se conserva, pero se puede inferir que el edificio tenía que contar con una profundidad interior de al menos $2,5 \mathrm{~m}$. Según los contextos estratigráficos del perfil oeste, el edificio $X$ pertenece a las últimas construcciones argáricas de la ladera sur. Por primera vez nos ofrece, como hemos dicho, la medida de la anchura de una habitación o de un edificio, y al mismo tiempo la planta en sus dimensiones exteriores abarcando unos $5,0 \mathrm{~m}$ por al menos $3,5 \mathrm{~m}$. Además se podía confirmar que se trataba de un edificio de planta exenta y que no formaba parte de una hilera de 'habitaciones' construidas paralelas siguiendo la curva de nivel de la ladera. Otras investigaciones adicionales no se pudieron realizar en esta zona, como hubiera sido deseable para completar su información. Una importante concentración de hallazgos, sin embargo, se va a tratar más adelante, cuando se presenten las tumbas excavadas durante esta campaña. 


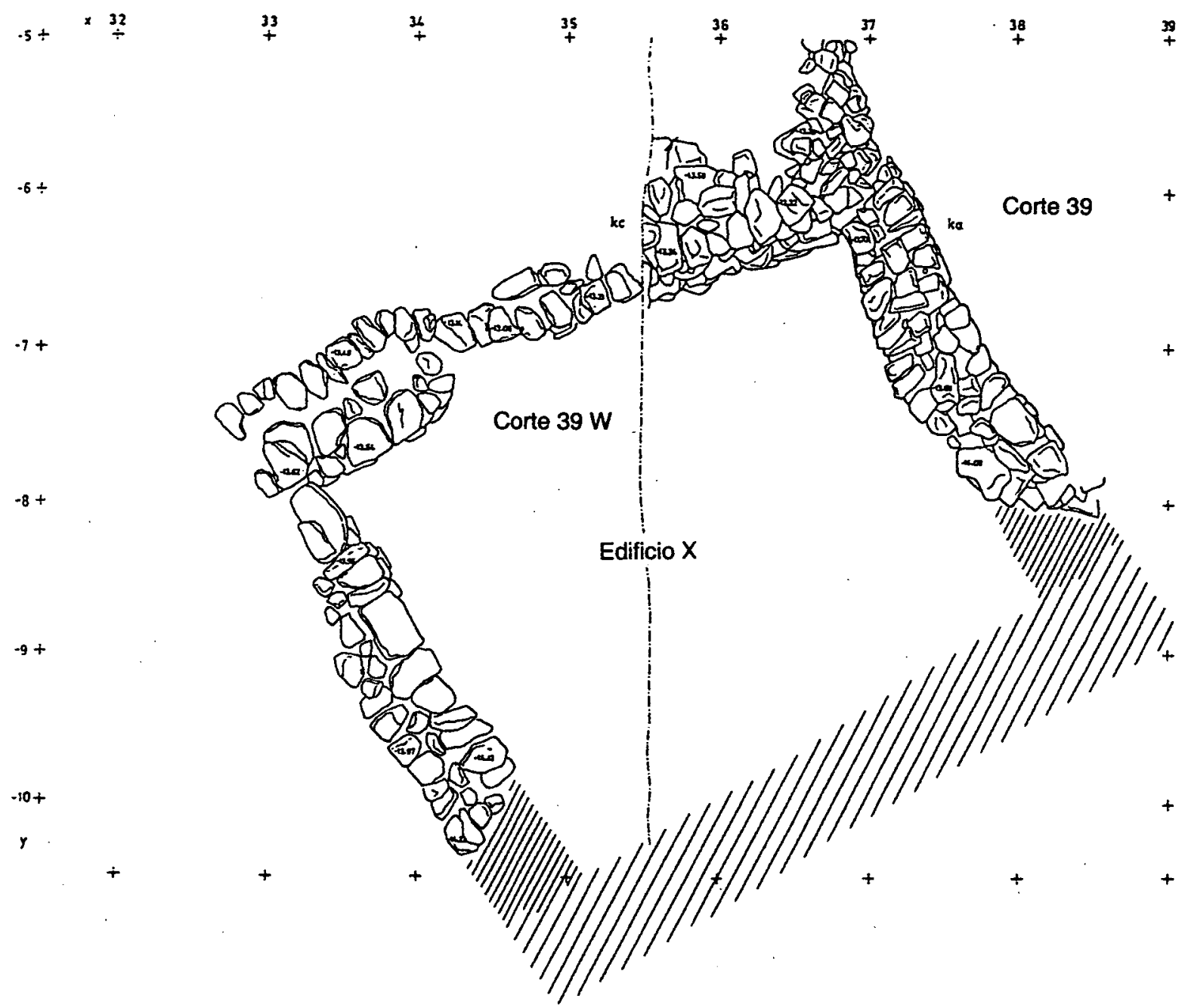

Fig. 1. Fuente Álamo 1999. Corte 39 y ampliación oeste (39W). Planta del edificio X de época argárica reciente. Los muros se completan mediante líneas rayadas: densas = deducido; amplias = supuesto.

Desmontando el muro kg del corte 39, se comprobó que en su mayor parte estaba 'relleno' de tierra de color marrón grisáceo. Además, especialmente en el perfil oeste se podía observar, cómo dicho muro estaba fundamentado en una fosa de construcción que había sido profundizada en los anteriores estratos argáricos de filitas y rellenada con la misma tierra marrón grisácea. En algunos puntos del muro, se colocaron bajo su frente unos trozos murales evidentemente de apoyo. En el ámbito del perfil este del corte 39 el mismo se asienta directamente sobre la roca. Este muro (¿de terraza?) de la época del Bronce Tardío sigue más o menos la dirección de un escalón más antiguo excavado en la roca durante la época argárica, con una profundidad de hasta $3 \mathrm{~m}$, el cual atraviesa en diagonal el corte 39 y el testigo 39/40. Contra este potente escalón, documentado por completo sólo delante del perfil este, se colocaron otros dos muros (mc, mf), en parte algo desviados uno contra el otro (fig. 2). 


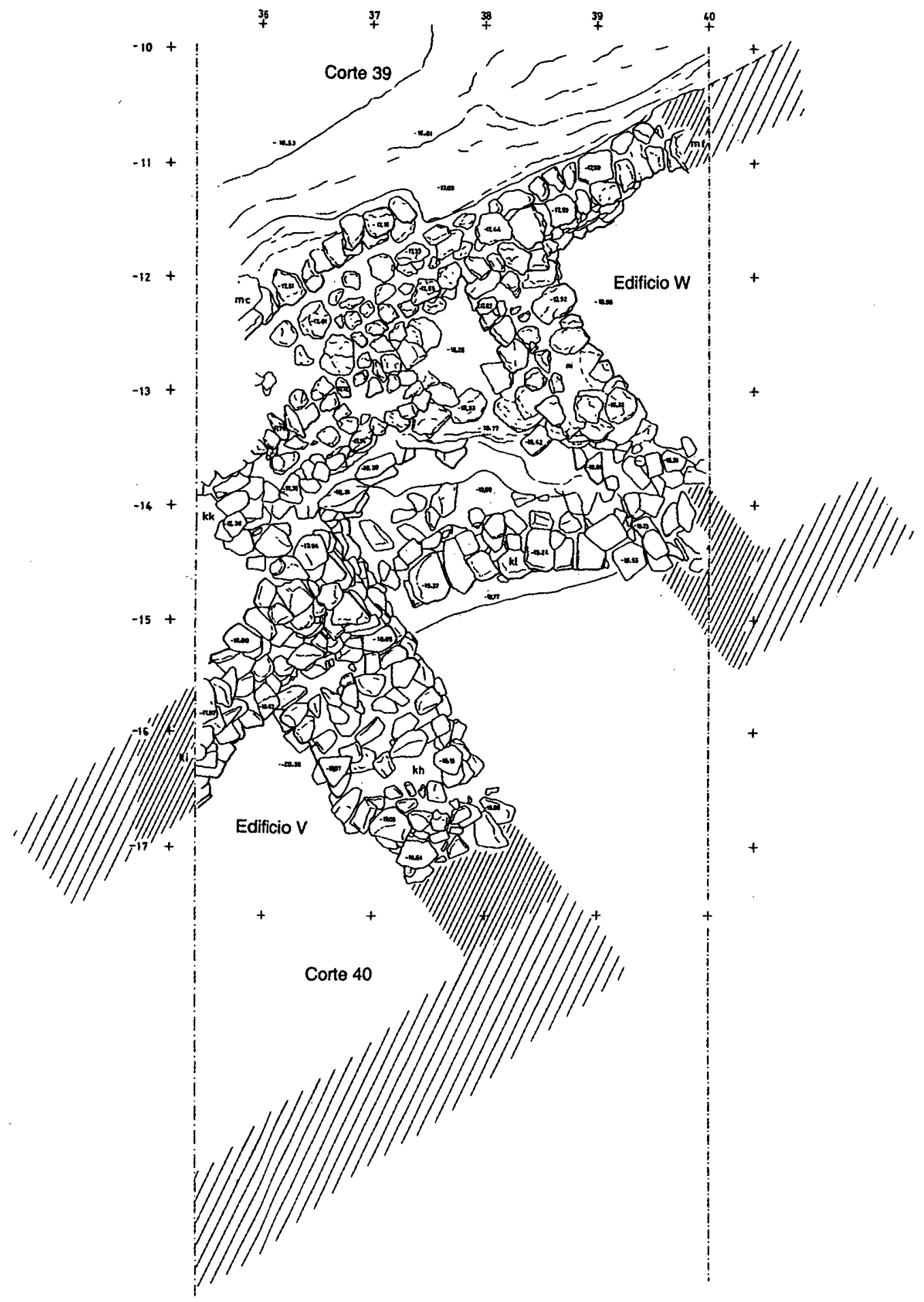

Fig. 2. Fuente Álamo 1999. Cortes 39 y 40, con el testigo 39/40. Plantas de los edificios V y W de época argárica antigua. Rayado véase fig. 1. 
El mencionado muro mf de buena construcción resultó ser la pared norte de un edificio que hacia el oeste está delimitado por el muro mi, el cual forma un ángulo recto con el muro mf (fig. 2). Esta esquina noroeste del citado edificio se conservaba todavía con una altura de más de un metro. Lamentablemente, las dimensiones oriental y meridional de este edificio $\mathrm{W}$ se salen del ámbito del corte, por lo que no podían ser averiguadas (lám. II). Pero es evidente, que el mismo se levantó sobre una superficie plana de la terraza que se extiende en el pie del potente escalón rocoso, unos $3 \mathrm{~m}$ hacia el sur, hasta entrando en el corte 40; y que incluye la terraza más septentrional situada en y -15 m (Pingel et al. 1998: figs. 4 y 5). De todo ello se puede inferir que el edificio W tendría que haber presentado hacia la ladera una profundidad interior mínima de $3 \mathrm{~m}$, lo que coincide del todo con las anteriores observaciones en la ladera sur sobre las edificaciones argáricas. Según el orden de sucesión de las terrazas definido ya en 1996, el edificio W debería pertenecer a un momento no precisado de las construcciones argáricas más antiguas conocidas en la ladera sur.

Es de lamentar, que no se podía excavar la gran cantidad de piedras que forman un bloque de muros y derrumbes en el ámbito del testigo $39 / 40$ hasta el perfil oeste. Aquí, al oeste del edificio W, hay indicaciones de unas filas de piedras atravesando el corte, en paralelo con la ladera, como se observaron anteriormente durante la excavación de la zona norte del corte 40 . Además, salta a la vista que el ángulo formado por los potentes muros kh y ki, ya conocido desde hace varias campañas, puede estar en correlación con el edificio W (fig. 2) (Pingel et al. 1998: fig. 4; Schubart, Pingel y Arteaga 1993: fig. 2). Este ángulo que es la esquina nordeste del edificio $\mathrm{V}$, está situado a una distancia de $2 \mathrm{~m}$ del edificio $\mathrm{W}$ y orientado de la misma manera, es decir, de un modo exactamente paralelo. Ya en la campaña de 1988 se tomaba en consideración que podría haber existido una subida parecida a una escalera de unos $2 \mathrm{~m}$ de ancho en el espacio entre la esquina del ahora denominado edificio V y un muro paralelo observado entonces (ahora el edificio W) (Schubart, Arteaga y Pingel 1988: 175 ss.; 1989: 82). También la base del muro ki se asienta sobre la terraza rocosa, de manera que no se puede excluir la contemporaneidad de ambos edificios. Se debe sin duda a la topografía del cerro, el que ambos edificios no coincidan estrictamente en sus orientaciones, para seguir respectivamente los contornos de la ladera.

También del edificio $V$ falta la pared que le delimita hacia el sur, la cual ha sido destruida a más tardar durante la época del Bronce Tardío cuando se construyó el edificio U (véase infra). Puesto que el edificio V se sale en sus dimensiones del ámbito del corte, no se podía investigar su límite oeste. No obstante, en analogía con el edificio $\mathrm{W}$ y con otras construcciones, se podrán estimar unas dimensiones parecidas como se indica en la figura 2.

Por encima de estos dos edificios, en el espacio de la 'subida' y al lado de la esquina noroeste del edificio W, se descubrió la tumba 111 sobre la cual vamos a insistir más adelante. Esta sepultura es claramente más reciente que los mencionados edificios de la época argárica 'antigua'. Detrás del muro mc se acumularon varios paquetes estratigráficos argáricos, por lo que todos son al menos más recientes que el edificio $X$, que se describió más arriba en el texto, y al parecer por consiguiente más antiguos que la tumba 111.

En el corte 40, en primer lugar se excavó el gran edificio U del Bronce Tardío (fig. 3) (Pingel et al. 1998: figs. 4 y 5 , lám. 4 b). Se comenzó con el desmonte del paramento contra el escalón rocoso de la pared norte que ya se había derrumbado en parte. Luego, en el interior del edificio se profundizó unos $20 \mathrm{~cm}$ por debajo del nivel alcanzado en 1996, hasta llegar al filo inferior del suelo del edificio U. Este paquete estratigráfico relativamente homogéneo contenía varios hogares, muchos recipientes típicos del Bronce Tardío, fragmentos cerámicos de mayor tamaño, etc. Tanto la losa de color verdoso hallada delante de la pared norte, como otra losa que se encontró en posición horizontal sobre el suelo del edificio $\mathrm{U}$, al parecer proceden de tumbas ubicadas más arriba en la ladẹra sur (no de la tumba 99) cayendo al interior del edificio al inicio de su colmatación (fig. 5). El propio derrumbe de grandes cantidades de piedras halladas dentro del edificio U tendrá que haberse formado aún durante el Bronce Tardío, p.ej. a causa de la caída de una construcción completa de terraza o algo parecido desde arriba hacia adentro de la casa. 


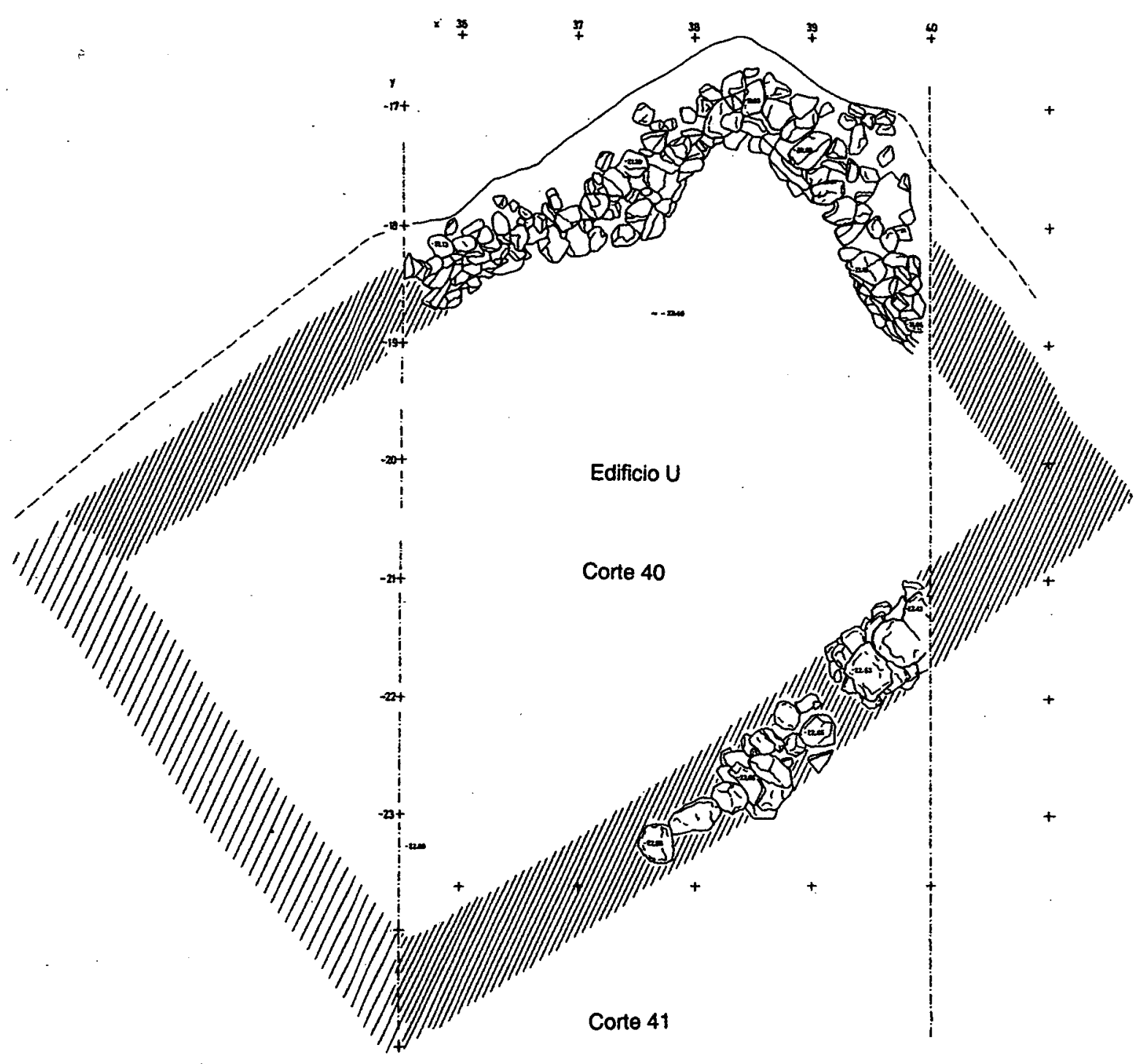

Fig. 3. Fuente Álamo 1999. Corte 40 y testigo 40/41. Planta del edificio U del Bronce Tardío. Rayado véase fig. 1.

En el sur del corte 40 y en el ámbito del testigo $40 / 41$ se encontró delante del perfil este un muro que se orienta desde dicho perfil hacia el suroeste siguiendo la curva de nivel de la ladera (fig. 3). A pesar de que este muro se pierde hacia la mitad del corte, eventualmente puede ser identificado más adelante con algunas piedras que se encuentran cerca de la superficie dentro del perfil oeste del corte 41 en y $-24,50 \mathrm{~m}$. La construcción de este muro se llevaría a cabo profundizando en estratos argáricos de filitas, por lo que resulta ser del Bronce Tardío. Aunque no se podía excavar su conexión con el muro este del edificio U, la cual tiene que hallarse algo al este del corte 41 , todo habla a favor de que se trata del muro sur de dicho edificio. Puesto que en el espacio del corte 40 no se encontró el muro oeste de la casa, y dado que el muro meridional al parecer llegaba hasta el perfil oeste, puede inferirse que el límite occidental del edificio U 
tiene que hallarse al oeste de los cortes 40 y 41 . Así pues, el edificio U de la época del Bronce Tardío era considerablemente mayor que las casas argáricas de la ladera sur, ofreciendo unas dimensiones exteriores de al menos $8,5 \mathrm{~m}$ por $5,5 \mathrm{~m}$ y unas medidas interiores de aproximadamente $6,5 \mathrm{~m}$ por $4,5 \mathrm{~m}$ (fig. 3, lám. III).

Por debajo del nivel de suelo del edificio U, en el corte 40 apareció un paquete de estratos de filitas de época argárica que ocupa un espacio aproximado desde y $-18 \mathrm{~m}$ en el este y desde y $-20 \mathrm{~m}$ en el oeste; lo que significa que el edificio U estaba excavado aproximadamente un metro en la roca sólo en su parte norte, mientras que en el sur se asienta sobre unos estratos argáricos más antiguos. En la zona este del corte, en estos estratos argáricos se profundizaba la tumba 112, desde algo por debajo del suelo del edificio $U$ hasta dentro de la roca (fig. 4, lám. III). Como no fue posible investigar toda la superficie ocupada por el edificio $\mathrm{U}$, se excavó únicamente delante del perfil oeste un espacio de unos $2 \mathrm{~m}$ de ancho hasta la roca. Se comprobó que el paquete estratigráfico argárico tenía aún una potencia de $60-80 \mathrm{~cm}$ siendo posible subdividirlo en parte en dos paquetes. Todo el paquete estratigráfico se depositó igualmente sobre una terraza artificial instalada en época argárica, la cual se extiende de norte a sur en el perfil oeste aproximadamente desde y - 20 m hasta y -24 m (figs. 4 y 5). En este espacio reducido excavado se encontraron distintos restos de construcciones, en parte hasta entonces desconocidas, cuyas interrelaciones concretas o incluso funciones no se podían averiguar. La terraza argárica se delimita hacia el sur por un potente muro $(\mathrm{mh})$ de un metro de ancho, levantado directamente sobre el reborde de la roca. También en el norte de la terraza, delante del escalón rocoso en y $-20 \mathrm{~m}$, se hallaron restos constructivos (me) asentados sobre la roca. No obstante, era evidente que en el caso de estos restos no se trata de un muro continuo, sino que tanto delante del perfil oeste, como en el perfil este del espacio investigado, los trozos murales se acaban. Además resulta que el muro me no constituye una unidad, sino que se compone de dos bloques de muros algo desviados en su orientación uno contra el otro (me1, me2), con unas dimensiones aproximadas de un metro de largo y $60 \mathrm{~cm}$ de ancho, respectivamente. En su orientación difieren algo del muro meridional $(\mathrm{mh})$. Otro pequeño resto de un muro argárico (mg) se halló entre la tumba 112 y el límite este del edificio U. Se construyó igualmente sobre la roca, dentro de una excavación de la misma (lám. III).

Sin embargo, el resultado más sorprendente quedaría referido a la existencia de varias excavaciones realizadas en la superficie rocosa de la terraza argárica. Directamente paralelo con el muro meridional $(\mathrm{mh})$, y a una distancia de unos $30-40 \mathrm{~cm}$, había un 'canalillo' algo irregular excavado en la roca, con una anchura de $40-50 \mathrm{~cm}$ y una profundidad de $10-20 \mathrm{~cm}$ (fig. 4, lám. IV). Este canalillo continúa hacia el este y se termina redondeado directamente delante del perfil oeste. Tiene que quedar sin resolver, si después de una interrupción el canal eventualmente continuaba o si el mismo cambiaba de dirección. En el espacio limitado investigado, dentro del canal no se constataron otros elementos constructivos, ni un relleno fuera de lo normal, etc. El estrato argárico superior, compuesto de filitas, va por encima de este canal; mientras que al menos en el perfil oeste en el ámbito del canal que, sin embargo, no conecta con dicho perfil, el paquete estratigráfico inferior que en parte topa contra los muros me o se superpone a ellos, se termina.

Al norte del canal, aunque junto a él y en paralelo, se encontró una fila de al menos tres hoyos, más o menos redondeados. Han sido excavados en la roca con una equidistancia de un metro profundizando unos $10 \mathrm{~cm}$. Su distancia respecto del canal es de unos $30-40 \mathrm{~cm}$. Así mismo, en el escalón rocoso del extremo norte de la terraza argárica y al otro lado de los muros me, se halló al menos un hoyo similar excavado en la roca (fig. 4, lám. IV). En el perfil oeste, dichos hoyos son cubiertos por el paquete estratigráfico inferior, por lo que son más antiguos que el canal.

Ha de quedar pendiente esclarecer mejor, cuáles de estos elementos formaban parte de los diferentes conjuntos. No obstante, las desviaciones en la orientación y también los contextos estratigráficos evidencian que pertenecen a unas construcciones de distinta antigüedad. De la mejor manera, por lo menos los hoyos podrán ser interpretados como vestigios de unas construcciones sustentadas mediante postes. Pero como no se trata en este caso de unos verdaderos hoyos de postes, como también se conocen esporádicamente 


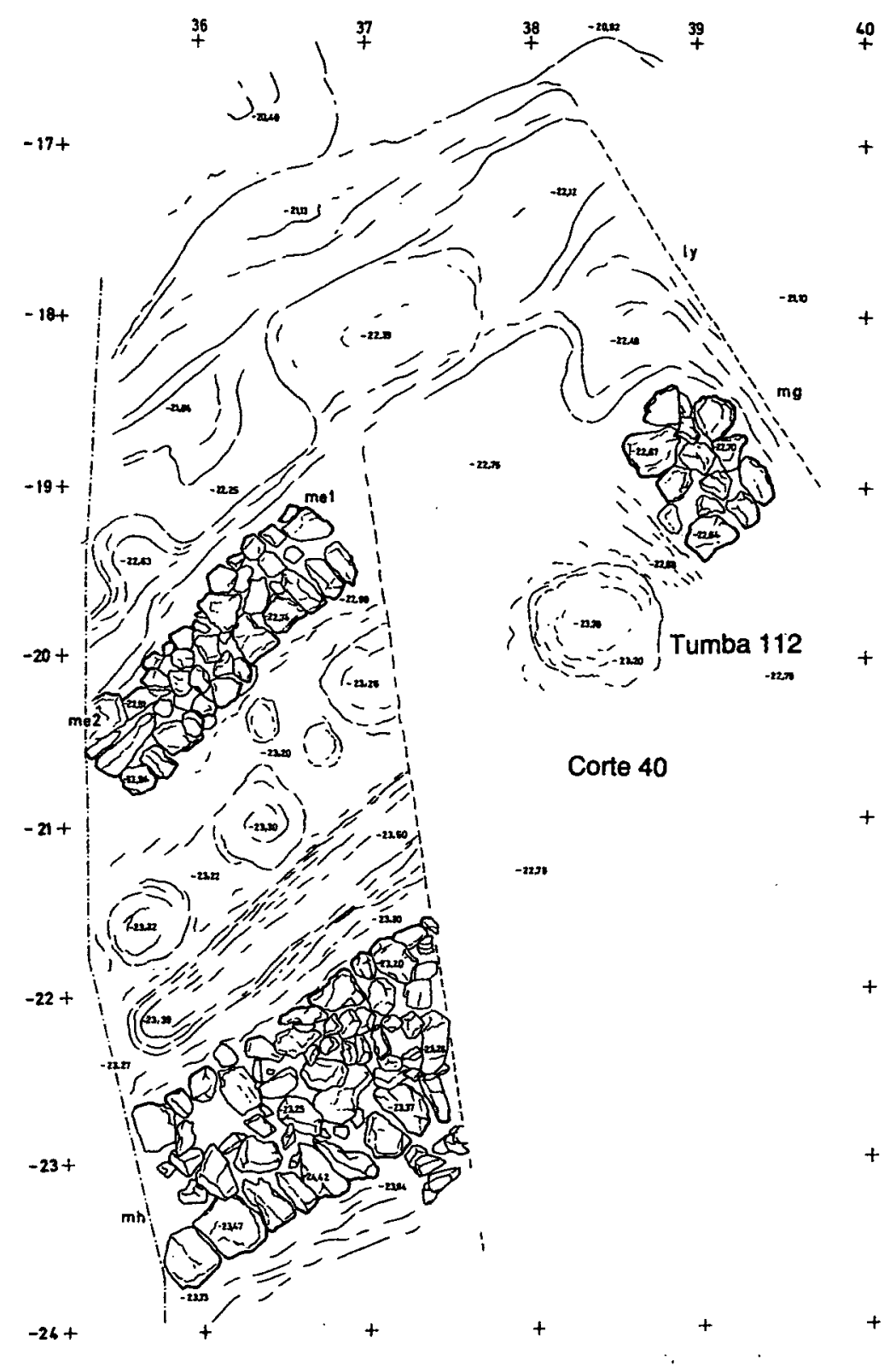

Fig. 4. Fuente Álamo 1999. Corte 40 y testigo 40/41. Plano parcial más profundo delante del perfil oeste con los contextos argáricos.

en Fuente Álamo (véase infra las explicaciones sobre el corte 42), hay que suponer que existía una superestructura conectando tales postes que en los hoyos mismos no hallarían la suficiente estabilidad. En cambio, la función del canal (¡discontinuo!), eventualmente en unión con el muro mh, queda sin resolver. A causa del espacio limitado investigado, pues, no se puede aclarar, cómo hay que imaginarse estas construcciones: si constituyeran un edificio, una instalación técnica para alguna actividad artesanal, un pasillo cubierto, etc. No obstante, las observaciones sobre la arquitectura argárica enseñan que al lado de las casas erigidas en 


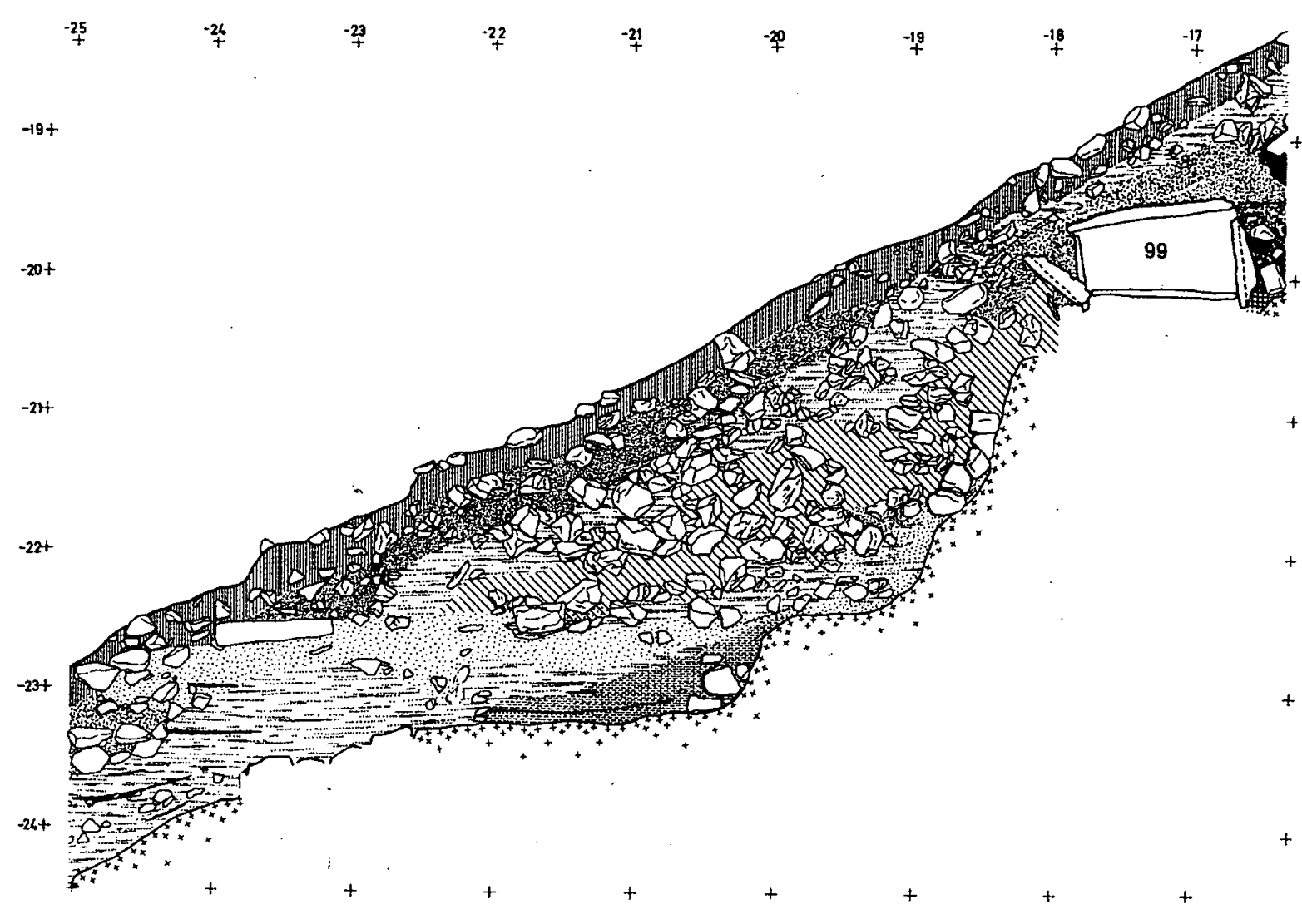

Fig. 5. Fuente Álamo 1999. Corte 40 y testigo 40/41. Sector del perfil oeste. Relleno y niveles de suelo del edificio U del Bronce Tardío (hasta una profundidad de -22,5/-23,0 m, aproximadamente). Por debajo aparecen los estratos argáricos.

base a limo de filitas sobre zócalos de piedra, hay que contar con otros modos de edificar, p.ej. con construcciones de postes, y que es de suponer que existieran también otros tipos de edificios aparte de las casas de planta rectangular.

Según los datos estratigráficos, estas construcciones argáricas sobre la terraza rocosa son las más antiguas en esta zona. Por lo visto, después se abandonan y fueron cubiertas por el antes citado paquete de estratos de filitas, desde el escalón rocoso en el norte hasta por encima del muro mh en el sur. De este paquete estratigráfico proceden varios fragmentos de copas pertenecientes al período de El Argar B, que fechan estos estratos no asociados a estructuras arquitectónicas y que también son de importancia para la datación de la tumba 112.

La situación estratigráfica de los cortes realizados en la ladera sur de Fuente Álamo podía ser aclarada a grandes rasgos, sobre todo a base del perfil oeste; el análisis completo se reserva para el estudio definitivo de la ladera sur. Las profundas excavaciones constructivas de las terrazas (edificio U, edificio X, etc.), así como los muros que se distribuyen en el perfil oeste más o menos en vertical, dividen la ladera sur en diferentes zonas que no pueden ser conectadas entre sí de una manera estratigráfica. En estas zonas se documentan varios paquetes estratigráficos argáricos, respectivamente, así como también sedimentos del Bronce Tardío que en parte presentan una gran potencia. En suma, de ello resulta que de momento la ladera sur se 
divide en cinco sectores con secuencias relativamente 'independientes', con diferentes superposiciones múltiples de paquetes estratigráficos, sin que se pudiera percibir el comienzo, el final y las relaciones entre los distintos sectores, y a su vez con la secuencia documentada en la cima de Fuente Álamo.

Como iniciativas complementarias a la excavación arqueológica, en el tramo inferior de la ladera sur se tomaron las medidas topográficas de varios restos de muros que afloran en la superficie y de dos sepulturas de cista (tumbas 97 y 98). Con todo se podían constatar poco más de una docena de muros que en parte conservan una longitud de varios metros y también una altura de varias hiladas de piedras (una altura máxima de 5 hiladas en la zona escarpada de la ladera que mira al precipicio sobre la fuente). En su orientación, algunos muros siguen las curvas de nivel de la ladera, mientras que otras están erigidas en dirección perpendicular a ella (fig. 6). Por consiguiente, parece evidente, y se insistió ya en otro lugar en ello, que hasta el pie del cerro existiría una edificación en principio parecida a la conocida en los tramos superiores de la ladera, en la cual se incluyen todas las sepulturas hasta ahora observadas, inclusive las descubiertas por Siret (Pingel et al. 1998: 21 s., fig. 6, lám. 4c; Schubart y Pingel 1995: 150 ss., fig. 2) ${ }^{2}$.

Desde luego, hay que plantear aquí una vez más la cuestión de hasta cuánta extensión las distintas maneras de construir, las formas arquitectónicas, las estructuras, etc., observadas en los cortes hasta ahora realizados en la ladera sur podrán ser generalizadas, respecto de otros sectores habitados. La superficie excavada hasta el momento en la ladera sur mide unos $140 \mathrm{~m}^{2}$, lo que no llega a un $10 \%$ comparado con lo excavado en la cima de Fuente Álamo que ha sido investigada casi por completo en unos $1600 \mathrm{~m}^{2}$; mientras que resulta evidente que la superficie habitada durante la época del Bronce es todavía muchas veces mayor en la ladera sur que en la cima (fig. 6).

De todos modos, en los cortes excavados en la ladera sur se manifiestan unas características que tanto para las edificaciones argáricas, como para la arquitectura del Bronce Tardío, merecen ser destacadas. En cuanto concierne a la época argárica, han aumentado las referencias de las plantas de casas de menor tamaño, documentándose en un caso (edificio X) un edificio exento de planta cuadrada. Por lo visto, estos edificios se erigieron con alguna frecuencia sobre las zonas delimitadas de las terrazas, que para tales efectos se perfilaron repetidas veces mediante unos recortes realizados en ángulo. No se constatan muros de terrazas argáricos de mayor tamaño, que atraviesen los cortes o excedan sus límites. Así pues, más bien habrá que contar con edificios exentos que en su orientación difieran algo unos contra otros, y que sigan los contornos de la ladera, poco más o menos, como lo demuestran p.ej. los edificios $\mathrm{V}$ y $\mathrm{W}$. No obstante, parece que el margen de variación que se daba para encontrar una solución adecuada en las edificaciones era bastante mayor, como lo indican los recortes de la roca y los muros del corte 40 delante del perfil oeste, sin que se pudieran aventurar por ahora unas interpretaciones más precisas y unas reconstrucciones más completas. Para ello hubiera sido preciso realizar una ampliación lateral de los cortes.

Ya en las anteriores excavaciones arqueológicas quedaba patente que durante la época del Bronce Tardío las edificaciones eran bastante distintas. Ahora, el edificio U nos ofrece unas dimensiones mínimas para intentar analizar estos imponentes edificios, i.e. unas medidas que son comparables a las de la cima, aproximadamente (Schubart y Pingel 1995: 150 ss., fig. 7). En cualquier caso, por causa del reducido espacio investigado no era posible determinar si los edificios del Bronce Tardío fueron erigidos en la ladera sur sobre unas terrazas continuas, como se las podría reconstruir tal vez en base al muro kg del corte 39 , o si fueron construidos en unos recortes angulares propios de la roca, respectivamente, como se constata en la esquina nordeste del edificio $\mathrm{U}$.

2. Véase también el plano en Arteaga y Schubart 1980: fig. 4. Las tumbas 97 y 98 se mencionan ya en Schubart, Arteaga y Pingel (1989: 84). 


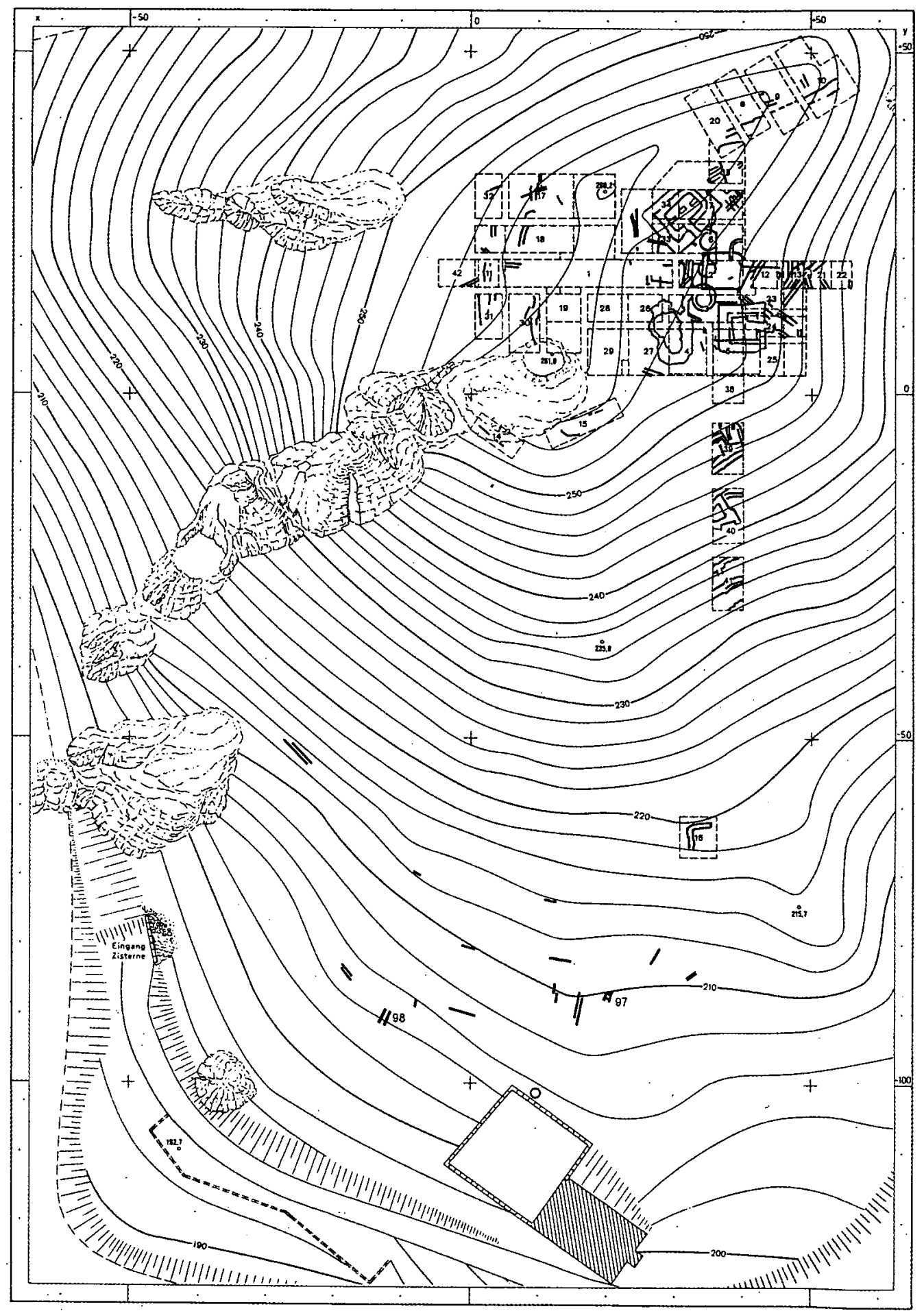

Fig. 6. Fuente Álamo. Plano topográfico con indicación esquemática de los muros detectados en los cortes, así como de restos constructivos y sepulturas en el pie de la ladera sur. Círculo = hundimiento de tierra de 1996 con estratos argáricos. 
La variedad y también las diferencias de los primeros resultados observados en la superficie muy limitada que podía ser estudiada, en el fondo no permiten generalizar estas características para las edificaciones de toda la ladera sur, ni tal vez para las laderas escarpadas en el norte y el oeste, ni tampoco en los tramos inferiores de la ladera este. Aquí hubiera sido indispensable abrir también unas mayores extensiones.

En este mismo sitio hay que insistir una vez más en el problema de la fortificación de Fuente Álamo (Arteaga y Schubart 1980: 262). Era de esperar que un asentamiento de este tamaño, con su situación estratégica, siendo edificado densamente y estando habitado de una manera intensa durante siglos, tuviera una protección y un límite señalado, fuera hacia el valle, fuera contra los montes vecinos. Pero, por otra parte, lo cierto es que hasta ahora no se puede dar ninguna prueba verdadera de la existencia de fortificaciones en los poblados argáricos de esta región (Pingel 1991: 1 ss.; en particular 16 ss.).

Ni en la cima de Fuente Álamo, ni en los tramos superiores de la ladera sur, las excavaciones arqueológicas aportaron posibles indicios de unas murallas, torres, etc. No obstante, los grandes edificios $\mathrm{H}$ y $\mathrm{O}$ de la cima demuestran que los habitantes de Fuente Álamo eran del todo capaces de construir edificios con muros de considerable potencia. Puestoque en un tiempo inmediato no será posible realizar excavaciones arqueológicas en los tramos inferiores de la ladera sur, o en las otras laderas, queda pendiente la posibilidad de que existiera una línea de fortificación en el pie del cerro, incluyendo tal vez a la fuente. Sin embargo, quedan sin respuesta varias preguntas: cómo, en su caso, pudo estar construida una tal fortificación; dónde estaría situada, si realmente existía; y cómo se puede comprobar arqueológicamente.

Las reiteradas prospecciones arqueológicas, realizadas sobre todo en los tramos inferiores de la ladera sur, no aportaron ningún dato positivo al respecto. Pero hay que hacer constar que justamente en aquel área se efectuaron múltiples transformaciones posteriores y en parte de una gran envergadura: la construcción del cortijo moderno, la instalación del acceso a la fuente, la creación de las terrazas de cultivo, etc.

Además, a propósito de esto, hay que tomar en consideración que las mismas terrazas de las laderas empinadas así como las casas erigidas sobre ellas, cuyas paredes de varios metros de alto presentaron unos frentes dispuestos escalonados gradualmente, de forma que en parte darían la vuelta al cerro, podrían haber servido al mismo tiempo de fortificación para el núcleo del poblado, sin que hubiera sido preciso construir una verdadera fortificación. Finalmente, en lo que concierne al estado actual de la investigación, también esta problemática ha de quedar en tela de juicio.

\section{LOS CONTEXTOS ESTRATIGRÁFICOS EN LA LADERA OESTE DE FUENTE ÁLAMO}

Conforme al programa formulado después de la campaña de 1996 efectuada en Fuente Álamo, respecto de los futuros trabajos (Pingel et al. 1998: 33), se proyectaba cumplir con los siguientes objetivos en la próxima campaña a realizar: continuación de las excavaciones arqueológicas en la ladera sur; conclusión de las investigaciones en el corte 35 de la ladera este, así como en la ladera oeste sobre todo en el corte 42 (Schubart, Arteaga y Pingel 1989: 77, 84 ss., figs. 5, 6a-c, láms. 5c, 6b). No obstante, a causa del escaso número de la mano de obra disponible, y dentro del margen de la autorización restringida concedida de acuerdo con la resolución acordada por la Comisión Andaluza de Arqueología, en la expectativa de una última campaña ya no fue posible poner en práctica este programa en 1999, por lo que había que desistir del esperado término planteado para las excavaciones iniciadas en estos cortes.

En lo que concierne al corte 42 de la ladera oeste, en 1999 con todo fue posible documentar, más allá de la profundidad de excavación alcanzada en 1988, la roca que ahora afloraba en un espacio bastante amplio, y proyectar la superficie rocosa en los perfiles norte y sur (fig. 8) de dicho corte como límites inferiores. La zona intermedia de los dibujos, muy afectada por la erosión, se sombreó con un amplio rayado previsto 


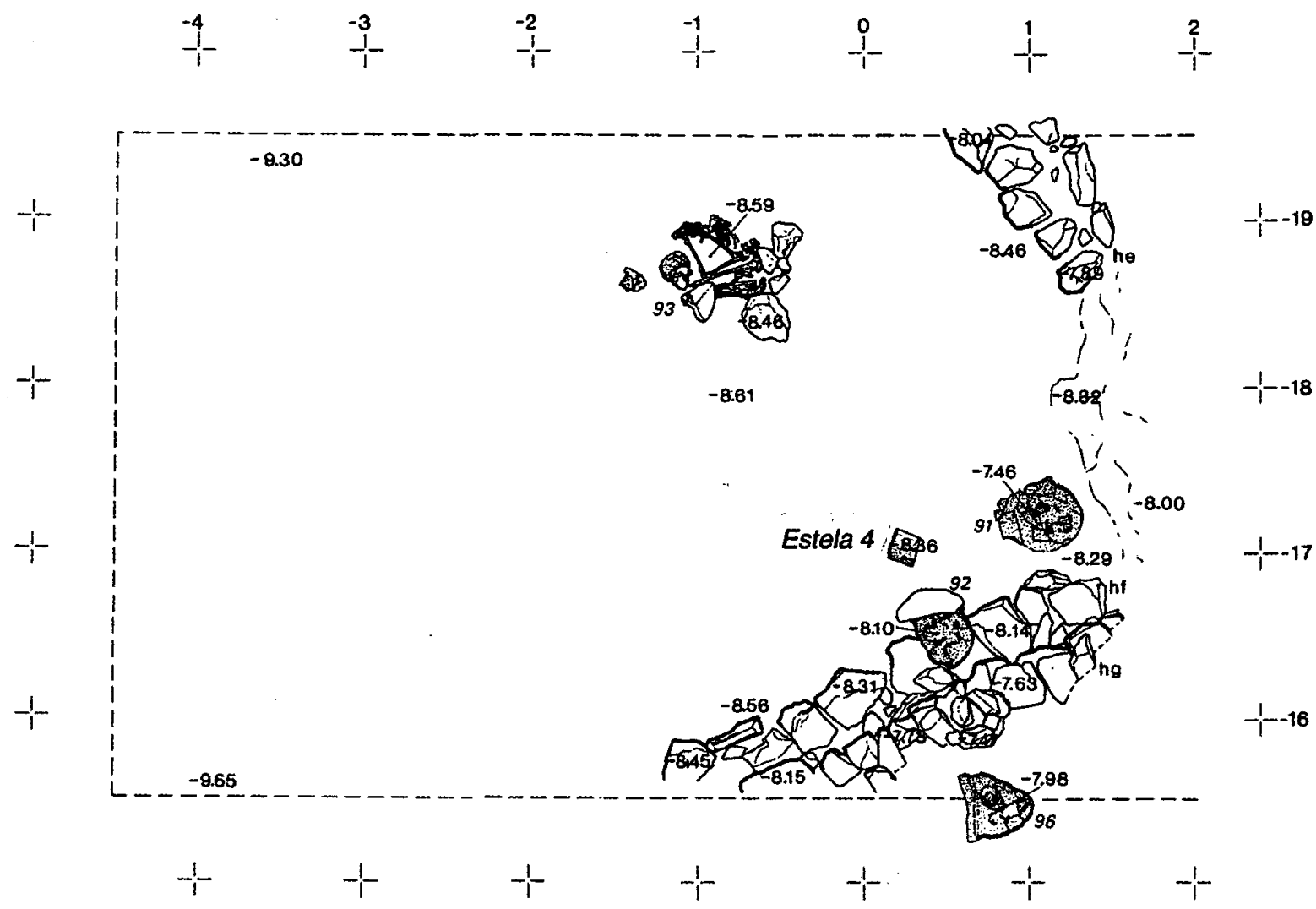

Fig. 7. Fuente Álamo 1988. Corte 42. Plano de los muros más antiguos y de las tumbas 91, 92, 93 y 96 más recientes.

en la nomenclatura de las tramas utilizadas en Fuente Álamo, para indicar alteraciones secundarias, de modo que se pudieran concluir tales perfiles, aunque en su parte inferior fuera de una manera provisional ${ }^{3}$. Así pues, a los planos y perfiles de las excavaciones efectuadas en Fuente Álamo entre 1977 y 1991 que se publican en la correspondiente monografía (Schubart, Pingel y Arteaga 2000: anexos 1,2,13, 14), se añaden aquí una planta (fig. 7) y el perfil sur (fig. 8) del corte 42. Al mismo tiempo, se presentarán a continuación los resultados de las investigaciones en este corte, para no dejar un vacío en el aspecto general de la ocupación poblacional de la ladera oeste ${ }^{4}$.

En el corte 42, la superficie rocosa documentada en la zona este del corte (fig. 8) tiene de este a oeste una caída de unos $1,30 \mathrm{~m}$ sobre un trayecto de algo más de $3 \mathrm{~m}$ (entre $\mathrm{x}+1,20 \mathrm{~m}$ y $\mathrm{x}-1,70 \mathrm{~m}$ ), lo que coincide con la situación conocida de la ladera oeste. El firme de la roca no se registró solamente en la franja descubierta por la erosión en y $+17,00 \mathrm{~m}$, sino también en la zona este del corte, tanto en el perfil norte como en el

3. Puesto que las excavaciones del corte 42 no habían concluido y estaba previsto continuar con las investigaciones (Pingel et al. 1998: 33), no se publicaron los perfiles norte y sur del corte 42 junto con los grandes perfiles de la cima de Fuente Álamo (Schubart, Pingel y Arteaga 2000: anexos 1 y 2), con los cuales hubieran conectado en el oeste, respectivamente. Por tanto, la presentación aquí del perfil sur del corte 42 (fig. 8) completa el gran perfil sur en su margen derecha (ibídem: anexo 1).

4. Por las causas indicadas supra en la nota 3 , las investigaciones realizadas en el corte 42 no se incluyeron en la citada monografía y tampoco se presentan en las publicaciones proyectadas sobre Fuente Álamo en un tiempo inmediato. 


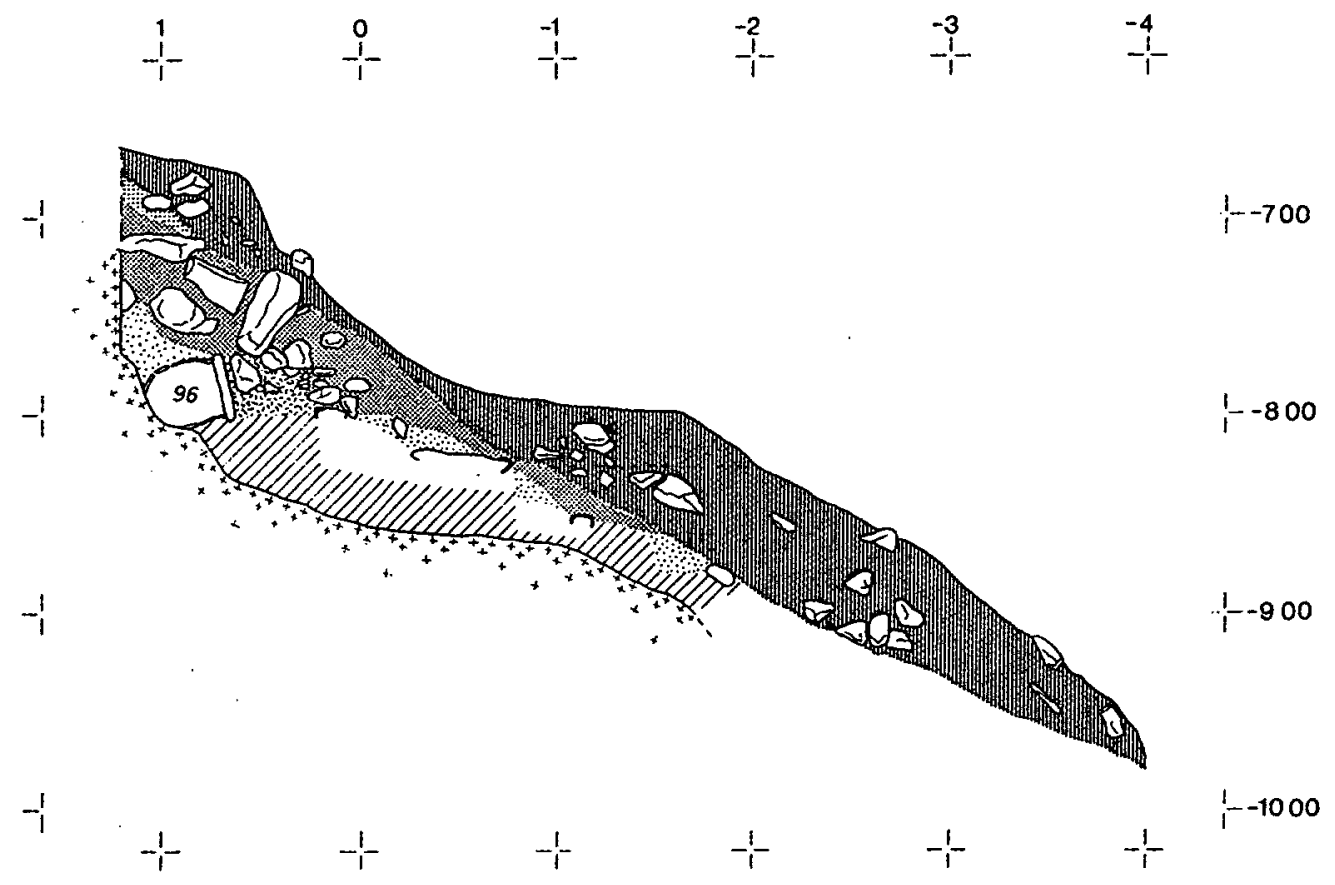

Fig. 8. Fuente Álamo 1988/1999. Corte 42. Perfil sur con la tumba 96.

perfil sur (fig. 8), respectivamente. En el perfil norte, las filitas aparecen ya a una profundidad de $-1,40$ $\mathrm{m}$ por debajo de la superficie, y en el perfil sur a una profundidad de $-1,00 \mathrm{~m}$. Por lo visto, en el perfil norte, aquí se cortó un escalón en la roca para la construcción del muro he (fig. 7). Así mismo, en el perfil sur, en la preparación de la tumba 96 se recortó la roca para poder depositar la respectiva urna de inhumación en un hueco de fondo llano (fig. 8).

Los muros excavados en el corte 42 , o sea el antes citado muro he en el nordeste y los muros hf y hg en el sudeste del corte (fig. 7), forman un ángulo recto, aproximadamente, si no se hace caso de las irregularidades del muro he y si se parte del supuesto de que las piedras del frente suroeste de dicho muro que se encuentran en el sudeste, están in situ. El perfil norte hace ver que el muro he ha sido profundizado en la roca esquistosa que aflora en el nordeste del corte. Hacia el sudeste termina sobre el firme, como puede observarse en la planta. No se puede determinar, si el muro he se asentaría sobre la roca en todo su trayecto hacia el noroeste, ya que pasa el límite del corte dado por el perfil norte, aparte de que se interrumpieron las excavaciones arqueológicas en este sector. No obstante, la construcción del muro en un recorte de la roca, observado en el perfil norte, y la terminación de dicho muro sobre el firme hacia el sudeste evidencian de todos modos que en el ámbito del corte 42 el muro he debe pertenecer a una construcción muy antigua.

En el sudeste del corte, el muro hf que atraviesa el corte en diagonal es superpuesto por el muro hg más reciente. Ambos frentes miran hacia el noroeste, aunque el frente del muro hf está desplazado unos 30-40 $\mathrm{cm}$ hacia el sudeste. No parece que el muro hf pudiera ser un zócalo más ancho sobre el cual se levantaría el muro hg. Más bien parece que después del abandono del muro hf más antiguo, éste hubiera sido sustituido por el muro hg. Según las alturas el muro hf podría corresponder al muro he, si es que ambos constituían una misma habitación. 
Parece que el muro hf termina aún delante el perfil este, lo que tiene que estar relacionado con el hecho de que sólo $20 \mathrm{~cm}$ más allá, hacia el nordeste, a la misma altura se documentó la roca. Se trata de una situación como la que ha sido observada ya en relación con el extremo sudeste del muro he, igualmente muy cerca del perfil este. En lo que concierne al resto del muro hf en dirección suroeste, ya no se podía comprobar por la excavación, si se asienta directamente sobre la roca o sobre un estrato más antiguo.

Mientras que el muro hf conserva solamente una hilada o raras veces dos hiladas de piedras, igual que el muro he, en el caso del muro hg se cuentan entre dos y tres hiladas superpuestas, en particular en su tramo nordeste donde el filo superior de dicho muro es $50-60 \mathrm{~cm}$ más alto que el muro hf. En el tramo suroeste donde el muro hg cuenta con menos hiladas, la diferencia es menor de sólo $20-30 \mathrm{~cm}$. También parece que el muro hg pasa el límite del perfil este del corte 42 hacia el nordeste. Los frentes posteriores de ambos muros que con gran probabilidad eran de dos paramentos adosados, se encuentran por detrás del perfil sur.

En el perfil sur, los muros hf y hg están representados sólo por algunas piedras precisamente allí donde sus frentes salen del perfil y donde los filos superiores de las piedras pertenecientes a estos muros emergen del límite de la excavación (fig. 8). Junto a estas piedras, y en parte por encima de ellas, se depositó un estrato de color marrón amarillento constituido de un material suelto con grava. Este estrato que cae hacia el oeste siguiendo la pendiente, se conserva solamente por tramos. Por encima hay un estrato de derrumbe de limo de filitas de color azul grisáceo, que se observa en la pendiente desde los cortes 1 y 11 , y que en su tramo superior incluye numerosas piedras, en parte de gran tamaño. Hacia arriba, esta secuencia de relativamente pocos estratos acaba con uno cobertor de color gris parduzco que contiene tierra vegetal y piedras én mayor cantidad. Estratos horizontales, p.ej. en el ámbito de los muros, no se observaron en el perfil sur. Pero en cambio, esto sí parece darse en el perfil norte, como se constata al oeste del frente del muro he, sin que se manifieste un horizonte de suelo propiamente dicho. En una profundidad de $-8,10 \mathrm{~m}$ y $-8,30 \mathrm{~m}$ se perciben unos sedimentos horizontales sobre algunos trayectos cortos.

A la misma altura, aproximadamente, que las piedras del frente del muro hf, pero con su centro situadas $45 \mathrm{~cm}$ delante de dicho frente, se hallaron unas piedras puestas alrededor de un hoyo de poste. Como este hoyo de poste se encuentra por debajo de la tumba 91, no aparece en el plano (fig. 7). El poste que entonces estaba aquí en pie difícilmente podrá ser explicado en relación con el muro mismo. No obstante, podrá haber pertenecido a una división interior de la supuesta habitación o servido de soporte para una superestrucutra.

Un segundo hoyo de poste cuyo lugar se indica igualmente por las piedras puestas en circular, se sitúa directamente en el trayecto del muro hg, es decir con el centro del antiguo poste $27 \mathrm{~cm}$ por detrás del frente del muro (fig. 7). En este caso, la vinculación del poste con el muro hg es muy probable. Se trataría de un modo de construcción bastante usual en la arquitectura argárica; situando los postes en el interior de los muros mismos y profundizándoles hasta dentro del zócalo de piedra de las paredes, e incluso hasta por debajo del zócalo, como se observa p.ej. en la casa I de Fuente Álamo durante la fase 11 (Schubart, Pingel y Arteaga 2000: anexos 5,9).

A una distancia de $40 \mathrm{~cm}$ al norte del muro hf, y a un nivel algo más bajo, se halló el fragmento de una 'estela' cilíndrica de sección ovalada, hecha de arenisca de color blanco amarillento. Esta estela 4 fue objeto de estudio ya en relación con la publicación de varias estelas argáricas antiguas de Fuente Álamo (Risch y Schubart 1991: 193 ss., fig. 6, lám. 4). Considerando que por lo visto se trata de un fragmento de la parte inferior de una estela, posiblemente de su extremo, es de suponer que la pieza se encontró en un contexto de deposición secundaria. Es de lamentar que a causa de la interrupción de las excavaciones arqueológicas en el corte 42 queda en tela de juicio, si la estela ha sido colocada en relación con una sepultura, como es de suponer. La respectiva sepultura podría haber estado quizás en el escalón rocoso situado algo al este del corte 42.

Según los complejos materiales asociados a los muros he, hf y hg se trata de unas construcciones argáricas con sus estratos pertinentes, sin que hubieran unas piezas características y bien datadas que nos permitieran 
afinar mejor la cronología dentro de este período. No obstante, las tumbas descubiertas en el corte 42 que son más recientes aunque todavía pertenecientes a la época argárica, nos ofrecen unas referencias cronológicas respecto de la fase constructiva más antigua en dicho corte. Por encima de los muros y de los estratos asociados o todavía desde más arriba se profundizaron en el corte 42 cuatro sepulturas, alcanzando en lo máximo el nivel de los muros. Las tumbas 91,92 y 96 son inhumaciones en urnas, mientras que la tumba 93 pertenece a un enterramiento en fosa con protección de piedras (fig. 8) (Pingel et al. 1998: 33; 2001: fig. 13).

Una descripción detallada de estas cuatro sepulturas y su estudio se presentará en relación con la publicación de todos los enterramientos de Fuente Álamo en una monografía específica (Schubart e.p.), de manera que aquí el texto puede ser sucinto limitándose a lo esencial, respecto del corte 42 y de su situación en la ladera oeste. Todos los tres enterramientos en urnas contenían los restos óseos de sujetos infantiles de corta edad como sigue: a lo máximo dos meses en el caso de la tumba 91; de nueve a doce meses en el de la tumba 92; y de doce a dieciocho meses en el de la tumba 96 (Kunter 2000: 265 ss., en particular 268). Los recipientes funerarios se depositaron en horizontal y en su interior los difuntos infantiles en una posición fetal, siendo ello lo que puede decirse de cuanto los escasos restos óseos permiten analizar. Como de costumbre, se rodeaban a las urnas de piedras; en el caso de la tumba 92 casi por completo. Para asegurar la posición del recipiente se le acuñaron piedras de mediano tamaño rodeándolo luego con otras más grandes. Delante de la boca de la vasija se encontró un molino que con su cara plana servía de tapadera (Schubart, Arteaga y Pingel 1989: lám. 6b). Las tres sepulturas infantiles en urnas no contenían ningún ajuar.

La tumba 93 es una inhumación en posición fetal depositada en una fosa con fuerte protección de piedras (Schubart, Arteaga y Pingel 1989: 86 ss., figs. 5, 6a-c) ${ }^{5}$. En el curso de las investigaciones llevadas a cabo en Fuente Álamo, esta sepultura era en 1988 la primera de un total de sólo tres enterramientos en fosa descubiertos; aunque este tipo de tumba no se desconoce en la cultura argárica, como en especial en el mismo asentamiento de El Argar ${ }^{6}$. A la difunta, una mujer mayor (Kunter 2000), la acompañaba el siguiente ajuar: una vasija de carena baja, una pequeña hoja de puñal con tres agujeros para los remaches, un punzón y una cuenta de hueso. La vasija presenta una carena particularmente baja, con el cuerpo superior de fuerte tendencia cónica, por lo que pertenece al período de El Argar B, incluso posiblemente ocupando una época tardía dentro de este período (Schubart 2000b: 107 ss.).

Ahora bien, si la tumba 93 posiblemente es propia de un momento avanzado del período de El Argar B, y si los tres difuntos infantiles de acuerdo con el tipo de sus sepulturas, como en general los enterramientos en urna, son adscritos al período de El Argar B, entonces las cuatro tumbas constituyen un horizonte más reciente, así y todo comprobado también estratigráficamente en un espacio donde anteriormente se erigieron unas casas atestiguadas por los muros analizados más arriba. Así mismo, parece que este hábitat más antiguo era de cierta duración, como muestra la sucesión de dos muros en el sudeste del corte. Si de esta manera a una primera fase de hábitat le sucede una segunda fase en la cual el mismo espacio ahora tiene una función funeraria, de momento solamente en lo que concierne al espacio limitado del corte 42 se puede suponer un cambio en la función.

Sin embargo, no se puede saber cuál era el aspecto del terreno cuando se instalaron las sepulturas, porque en ningún lugar se ha conservado el nivel desde donde se profundizaron las tumbas. Por lo visto, no era un nivel de hábitat, aunque los respectivos estratos pudieron haber sido víctimas de la erosión. En otros sectores del poblado se podía dar la prueba de que determinadas superficies antes habitadas se desocuparon después quedando a la merced de la erosión, a la par que se erigieron nuevos edificios en otro lugar. Sirve de ejemplo la instalación de las cistas de las tumbas 52 y 65 durante la fase $10 \mathrm{~b}$ de Fuente Álamo en una zona de la ladera este desocupada ya en la fase 10a. Contiguo a esta zona al sur se construyó el gran edificio $\mathrm{H}$

5. El punzón no está ilustrado.

6. Véase p.ej. E. y L. Siret 1890, álbum: texto de las láms. 41, 329; 50, 89; 54, 707. 
de planta cuadrada. Por lo visto, los espacios dejados descubiertos por el hábitat se aprovecharon para la instalación de las sepulturas. Algo parecido podría manifestarse en el corte 42, donde un primer estrato de color marrón amarillento que aún pertenece a los muros o al momento de su abandono está superpuesto por un estrato de derrumbe de color gris azulado el cual, sin embargo, al parecer pasa por encima del enterramiento en urna de la tumba 96 (fig. 8).

El corte 42 que es el más occidental de los cortes realizados en la ladera oeste de Fuente Álamo, confirmó la suposición de que, como ocurre en las laderas este y sur del poblado, igualmente en el oeste de la cima del cerro hay que contar con un hábitat intensivo, lo que ya aparentaba por el afloramiento en la superficie de los restos de numerosos muros en los tramos mediano e inferior de la ladera oeste. Además es de esperar que también aquí en determinadas zonas, en especial debajo de los escalonamientos de la roca que en parte con seguridad son artificiales, se abran unas nuevas perspectivas para la realización de estudios estratigráficos, aunque no en la misma medida, ni con una potencia estratigráfica como la encontrada en la ladera este y en parte en la ladera sur de Fuente Álamo. La relativa densidad de las sepulturas observadas en la ladera oeste, así como sus tipos y ajuares, permiten hacer unas afirmaciones que no pueden ser abordadas aquí dentro del margen expositivo limitado al corte 42.

\section{LAS NUEVAS SEPULTURAS DE LA LADERA SUR DE FUENTE ÁLAMO}

Si en el espacio reducido del corte 42 se encontraron en suma cuatro sepulturas, esto debe ser contrastado con la relativa frecuencia de los enterramientos aparecidos en la ladera oeste. Por lo que, a pesar de algunos hallazgos nuevos, el número de las sepulturas descubiertas en la ladera sur sigue siendo relativamente pequeño. Durante las campañas de 1988, 1991 y 1996 se podían investigar sólo cinco tumbas en total, a las cuales se añadieron en 1999 otras dos sepulturas, a saber los enterramientos en urna de las tumbas 111 y 112 (Pingel et al. 2001: fig. 13).

La tumba 111 fue descubierta en el ámbito del testigo entre los cortes 39 y 40 ; y la tumba 112 en la zona sur del corte 40. En ambos casos, las fosas de los enterramientos han sido excavadas desde unas superficies en cualquier caso aún argáricas atravesando otros estratos argáricos más antiguos. Es difícil determinar el nivel preciso desde donde profundizaron las fosas. El análisis de los estratos que atraviesan y que se hallan en parte más arriba que las tumbas, o al mismo nivel que ellas, será de importancia para la cronología de la estratigrafía de la ladera sur.

La fosa de la tumba 112, con un diámetro aproximado de un metro, profundiza hasta el suelo virgen compuesto de una arcilla de color amarillo, producto de la descomposición de las dolomías. El espacio entre la urna y el borde de la fosa se rellenó cuidadosamente con piedras de distinto tamaño entre las cuales se encontró también un molino. En el este de la tumba, otro gran molino se colocó en la fosa de modo que podía servirle a la boca del pithos como apoyo (fig. 11, lám. VIII).

La fosa de la tumba 111 era mucho mayor presentando una longitud de unos 2,20 $\mathrm{m}$ y una anchura de $1,50 \mathrm{~m}$, pero no llegó hasta la roca que en el testigo 39/40 se encuentra aún a mayor profundidad, sino que fue excavada en los restos constructivos y estratos de derrumbe más antiguos de la época argárica. El tamaño de la fosa no era previsto sólo para la urna, sino también para albergar una construcción en forma de túmulo que rodeaba a la propia tumba de grandes piedras colocadas con mucho cuidado (fig. 9, láms. V y VI). Hasta ahora, no se conoce nada parecido en Fuente Álamo.

En ambas tumbas las bocas de las respectivas urnas estaban orientadas hacia el este. Los pithoi se depositaron en las fosas con una leve inclinación de modo que la boca quedaba más alta que el fondo redondeado (figs. 9 y 11). Las difuntas fueron introducidas en las urnas con la cabeza por delante y quedaron enterradas en una posición fetal, casi extrema, de decúbito lateral derecho. Por tanto, hay grandes coincidencias en 


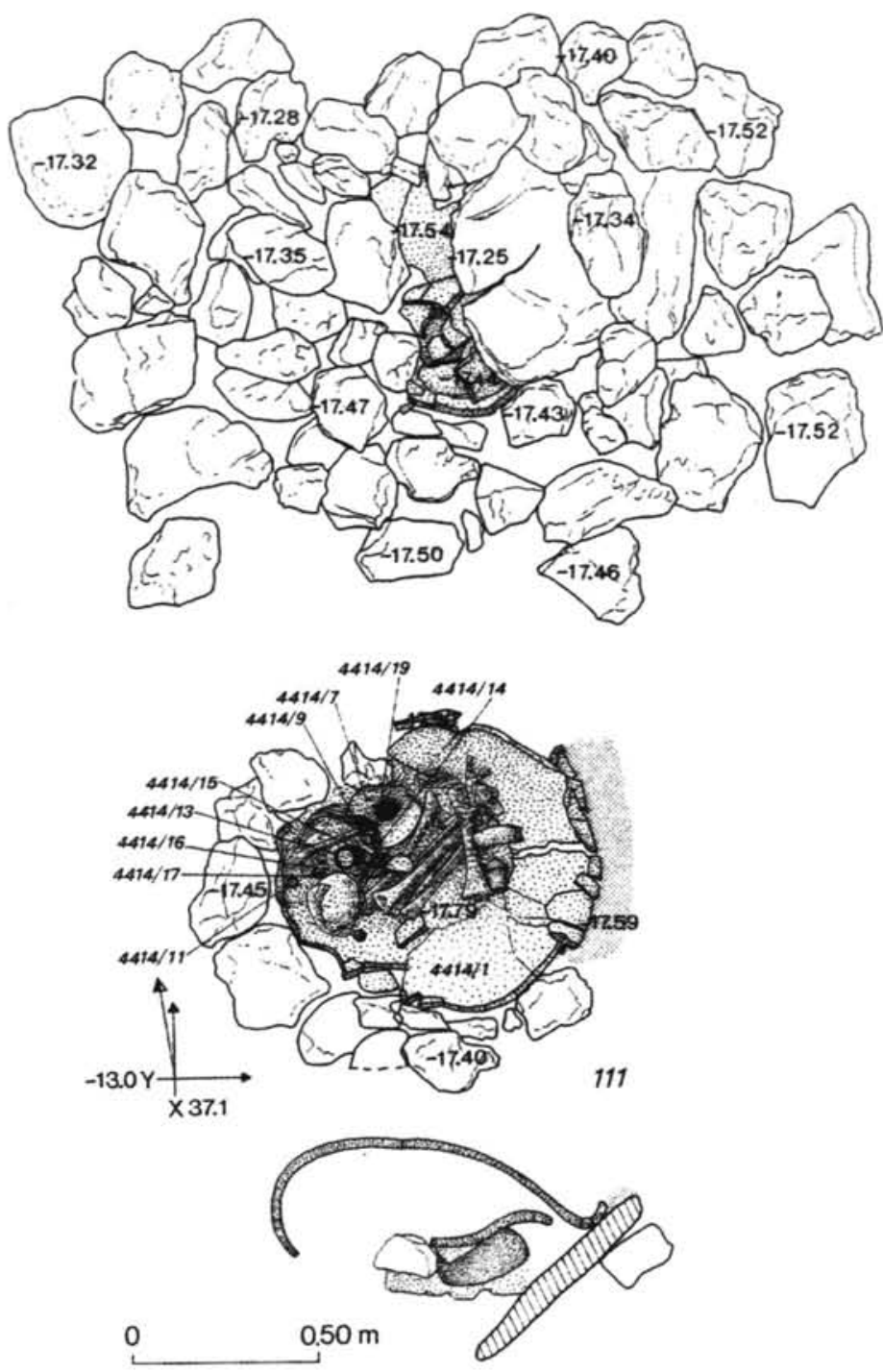

Fig. 9. Fuente Álamo 1999. Corte 39. Tumba 111. Plantas y sección.

El esqueleto de la tumba 112 causaba la impresión de estar in situ, mientras que en la tumba 111 el cambio de sitio de partes del cuerpo o bien de los huesos se debe a la descomposición del cuerpo, al desmoronamiento de la pared superior de la urna y posiblemente a la actividad de animales como un factor añadido; lo mismo hay que suponerlo también para la ubicación de algunos objetos de menor tamaño hallados en dicha sepultura.

Según la posición fetal de decúbito lateral derecho que adoptan las difuntas, las caras deberían estar orientadas hacia el sur. No obstante, los cráneos estaban girados de modo que en el caso de la tumba 112 la cara estaba orientada hacia abajo, de soslayo. Y en el caso de la tumba 111 totalmente sesgada hacia abajo. En la tumba 112 el brazo derecho estaba doblado de tal manera que la mano quedaba situada junto a la barbilla, mientras que el brazo izquierdo estaba detrás del cuerpo. En la tumba 111 la posición de los brazos era diferente: aquí se dobló el brazo izquierdo, llevando tres brazaletes en el antebrazo, y el brazo 
derecho estaba por debajo del cuerpo de modo que la mano derecha, con una sortija de bronce colocada en un dedo, se encontraba próxima a la boca del pithos.

Parece que la boca del pithos de la tumba 112 quedaba cerrada, al menos en parte, por la pared de otra gran vasija. Los fragmentos de este segundo vaso se hallaron delante de la boca de la urna, en parte colocados en vertical y precisamente dibujando un arco que correspondería a la curvatura de dicha pared antes de romperse. Se trata de una vasija carenada de la forma 5, con un tamaño especialmente grande (fig. 12b) (Arteaga y Schubart $2000^{7}: 99$ ss., fig. 2). Unos formatos tan grandes de vasijas carenadas se encontraron en Fuente Álamo ya otras veces, y han sido utilizadas reiteradamente como urnas, p.ej. en las tumbas 55 y 64 (Arteaga y Schubart 1981: láms. 9a, 9b). De todos modos, en el caso de este gran fragmento de pared de un vaso carenado no se trata de un ajuar en sentido estricto. Delante de la boca del pithos y de este gran fragmento cerámico se hallaron huesos de un bóvido que al parecer son los restos de una ofrenda de carne.

Fuera de la urna, y precisamente a la altura de la boca, aunque desplazado unos $20 \mathrm{~cm}$ hacia el sur, se encontró colocada en parte por debajo de las piedras del enterramiento (fig. 11), como ajuar, una vasija en forma de cuenco que resultó ser la parte superior de una copa (fig. 12a). En las sepulturas de Fuente Álamo y de otros yacimientos argáricos se depositaron repetidas veces tales partes superiores de copas, utilizadas como un 'cuenco'. En la tumba 60 de Fuente Álamo, p.ej., entre el ajuar se cuentan un cuenco de este tipo y además un 'vaso' que era el pie reutilizado de otra copa. Más adelante vamos a insistir en un 'vaso' semejante entre el ajuar de la tumba 111 (fig. 10x).

En el cuenco procedente de la tumba 112 se percibe el arranque del pie de la copa, hueco por su interior, y que ahora constituye el fondo en forma de anillo de un cuenco. Lo poco que le queda de la antigua peana ha sido claramente retocado en la zona de la fragmentación, y quizás rebajado aún más por el uso. De todos modos puede ser considerado como un fondo reelaborado de una forma secundaria. Por lo visto se trata del arranque de un pie esbelto que podía pertenecer a una copa de la forma $7 \mathrm{c} 1$, en la cual la esbelta peana suele estar hueca en toda su longitud. No obstante, puesto que el pequeño resto del pie es claramente entrante, tampoco se puede exceptuar una reconstrucción de la forma $7 \mathrm{~b} 2$, en la cual un pie ancho y hueco está unido a la parte superior mediante un anillo de relativamente poco diámetro. Ahora bien, en nuestro caso el cuenco se corresponde más bien con la parte superior de la forma $7 \mathrm{c}$, con un corto borde entrante, y no con la forma $7 \mathrm{~b}$ que generalmente se describe por un perfil oval. Luego, como hemos dichó, parece que está justificado reconstruir una forma $7 \mathrm{c} 1$, aunque la copa estará todavía cercana a la forma $7 \mathrm{~b} 2$. Aparte de este cuenco el enterramiento de la tumba 112 no contenía ningún otro ajuar ${ }^{8}$.

En la tumba 111 la boca del pithos estaba tapada por una losa de pizarra de color gris azulado que mide unos $60 \times 60 \mathrm{~cm}$ y tiene un grosor de $7 \mathrm{~cm}$ (fig. 9). Conforme a la posición inclinada de la urna, esta placa de pizarra ha sido colocada de la misma manera, también inclinadamente, de modo que tapaba la boca del pithos por completo. De hecho se quería cerrar herméticamente el enterramiento en el interior de la urna, como lo muestra la obturación con limo amarillo que se encontró sobre y por debajo del borde de la vasija. El mismo material limoso ha sido utilizado en el cierre de la cista de la tumba 68 de Fuente Álamo, llenando la junta entre el reborde de la cista y la laja de la cubierta. La tumba 68 quedó cerrada tan herméticamente que no penetró tierra en el interior como pasa en la mayoría de las cistas, por lo que después de levantar la losa de la cubierta el enterramiento con su ajuar quedó al descubierto (Arteaga y Schubart 1981: lám. 8etumba 68; Schubart y Arteaga 1983: 54). Solamente respecto de la tumba 69 de Fuente Álamo era factible

7. De ahora en adelante se remite a esta publicación para la clasificación de las cerámicas argáricas.

8. Durante un viaje por España en el mes de septiembre de 2000, el profesor Manfred Kunter (Gießen, Alemania) estudió los restos humanos procedentes de las campañas de 1996 y 1999 efectuadas en Fuente Álamo; se le agradece la comunicación preliminar de los resultados y la autorización de poder remitirlos aquí. Según ello la tumba 112 contenía el enterramiento de una mujer madura de entre 50 y 60 años. El estudio completo realizado por M. Kunter se incluirá en la monografía sobre todas las sepulturas de Fuente Álamo (Schubart e.p.). 

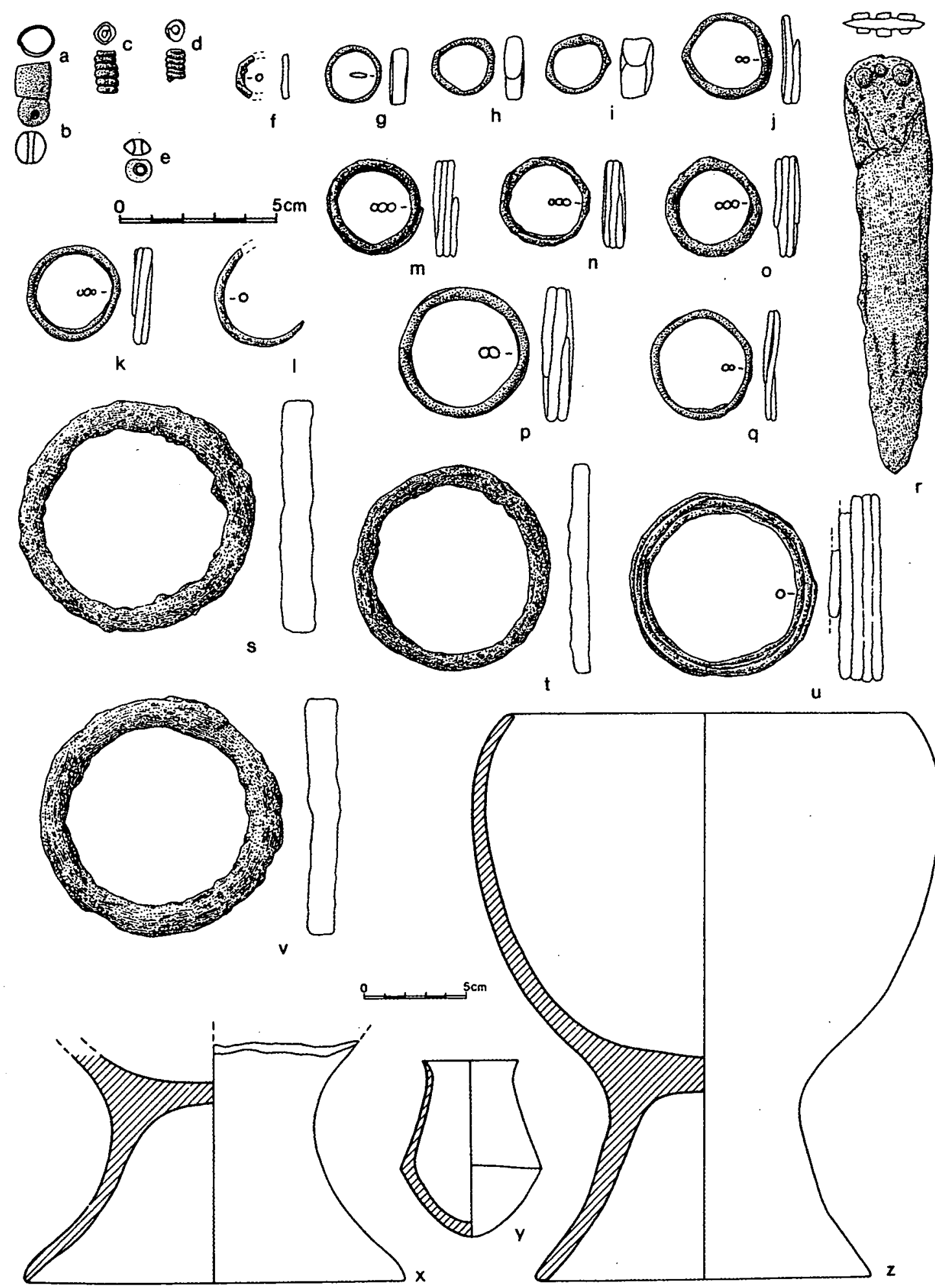

Fig. 10. Fuente Álamo 1999. Tumba 111. Ajuar (FA 99/4414). Las cuentas en una pequeña selección. 


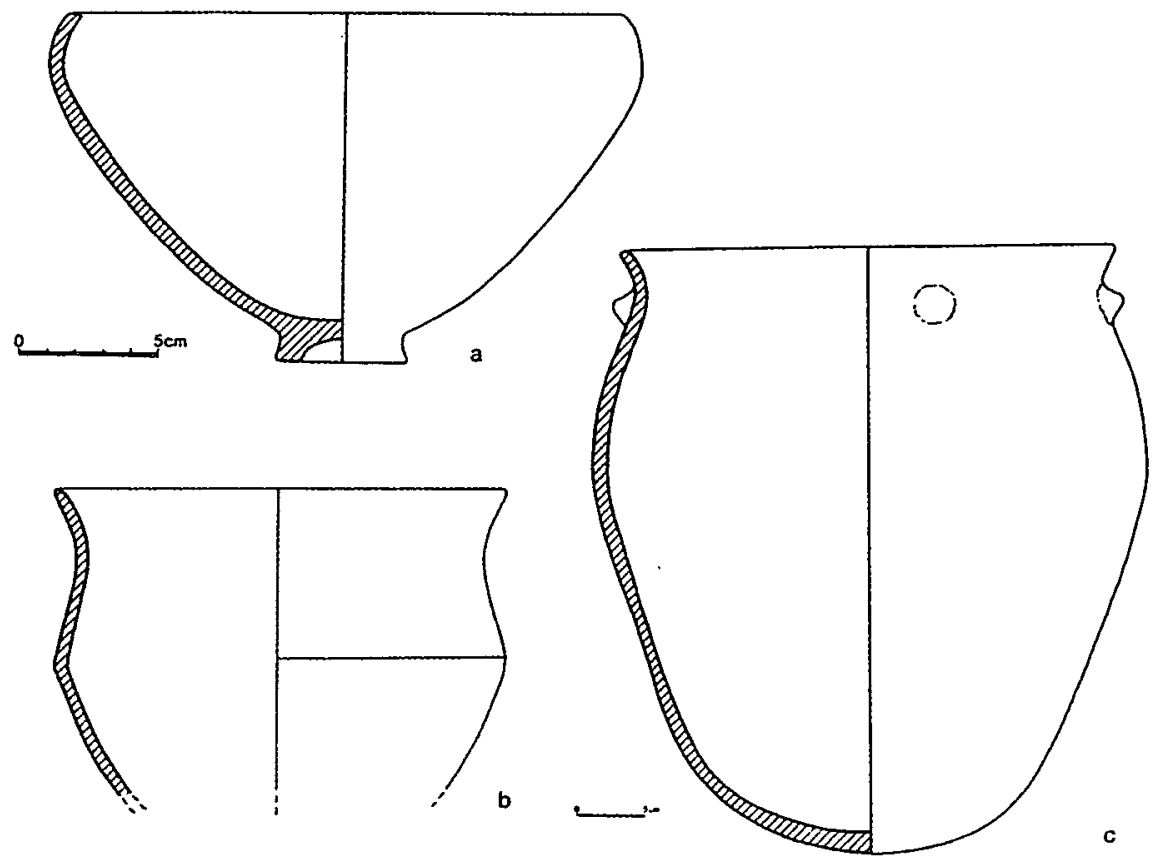

Fig. 12. Fuente Álamo 1999. Tumba 112. a Ajuar; b Gran fragmento usado como tapadera; c Urna.

hacer unas observaciones análogas (Arteaga y Schubart 1981: lám. 7-tumba 69). En cambio, era frecuente tapar la urna con una losa de piedra (p.ej. Arteaga y Schubart 1981: láms. 9b-tumba 55; 9c-tumbas 60 y 61). En la Colección Siret de Bruselas se conserva un dibujo de este significado investigador, hasta entonces inédito (Schubart y Ulreich 1991: lám. 65 abajo), donde la urna de la tumba 23 de Fuente Álamo queda cerrada por una losa y una segunda losa horizontal cubriendo la sepultura. En la tumba 111 el peso sobre la losa inclinada de cierre causó que la misma cediera. Y de ahí resultó una fuerte presión sobre la boca del pithos, por lo que finalmente se provocaría el derrumbamiento de la pared superior de la vasija.

Como de costumbre, la losa de tapadera estaba acuñada por el exterior mediante piedras de mayor tamaño. Por debajo de la piedra más superior se hallaba atravesado un bloque de más de $40 \mathrm{~cm}$ de largo, en cuyo lado inferior se conservaron adheridas a la arcilla las improntas de un tejido. Por lo visto se trata de una tela basta de un paño o vestido. Queda por saber, cómo esa tela habría llegado a este sitio y para qué podría haber servido, ya que a pesar de observar con detenimiento todos los detalles del hallazgo, no se detectaron otros indicios. Se puede considerar la posibilidad de que durante el entierro se desdobló un gran paño en el interior de la urna extendiéndose algo más allá de su boca, al exterior, y sobre el cual al término de la inhumación se acuñaron las piedras ${ }^{9}$.

El ajuar de la tumba 111 llama la atención por su riqueza. Directamente en la parte de la boca del pithos, y solamente $4 \mathrm{~cm}$ por detrás de la losa de cierre que, sin embargo, ha sido empujada hacia el interior (fig. 9), se depositó una copa de la forma $7 \mathrm{~b} 2$ (fig. 10z). Con una altura de $27,90 \mathrm{~cm}$ esta pieza es particularmente grande. Tanto la pasta de la copa como el acabado de la superficie son de una gran calidad; igual que en el caso de una pequeña vasija de la forma $5 \mathrm{c}$ hallada algo al noroeste (figs. 9 y $10 \mathrm{y}$ ). Entre el ajuar de la

9. La piedra con las huellas de tejido (FA 99/4414/8) se conserva en el almacén provisional del Ayuntamiento de Cuevas del Almanzora. Se preparó una impronta en silicona. 
tumba 111 se cuenta todavía una tercera vasija: un vaso elaborado a partir de la reutilización de la peana de una copa de la forma $7 \mathrm{~b} 2$ (figs. 9 y 10x). A juzgar por el pie conservado esta segunda copa era sólo algo más pequeña que la pieza entera antes mencionada y también se le asemeja mucho en cuanto a la forma. La vasija fue colocada en la sepultura con el pie hacia arriba, y la fragmentación hacia abajo, de modo que también aquí, como en otros casos, se puede inferir que cumplía con la función de un 'vaso' (Arteaga y Schubart 2000: 104, fig. 3; Schubart 2000b: 112).

Con tres ofrendas cerámicas la tumba 111 contiene un rico conjunto cerámico. Si es que las sepulturas argáricas cuentan con vasijas entre su ajuar, lo que respecto de los conjuntos funerarios publicados por Siret éste es el cas̀o en apenas un cuarto, contienen uno o dos recipientes (Schubart 1975: 81). Así ocurre también en Fuente Álamo, donde cerca de la mitad de los enterramientos intactos poseían vasijas cerámicas depositadas como ofrendas. No obstante, conjuntos funerarios con más de dos recipientes son también aquí excepcionales (fig. 13). Respecto de las tumbas 7, 9, 23 y 68 de Fuente Álamo, tratándose en el caso de las tumbas 9 y 23 de enterramientos dobles, llama la atención que siempre hay una o también dos copas, de las cuales algunas son de la forma $7 \mathrm{~b}$, aunque en todas las cuatro tumbas se encuentra también la forma tardía 7c que en Fuente Álamo aparece por lo visto no antes de fines del horizonte III siendo luego típica en el horizonte IV (Schubart 2000b: 112). Así pues, en lo que concierne a los enterramientos que en Fuente Álamo contienen un rico ajuar cerámico siempre se trata de unas sepulturas tardías.

Bajo este aspecto se tendrá que remarcar ante todo la importancia de las copas en estos inventarios funerarios. Reiteradas veces representan unas ofrendas adicionales; a veces se hallan fuera de la propia sepultura e incluso, como en el caso de la tumba 102 de Fuente Álamo, la copa se partió por la mitad, al parecer dentro de un ritual, depositándola a los dos lados de la urna ${ }^{10}$. Por eso se ha considerado que las copas quizás han sido utilizadas para realizar libaciones, o como incensarios, aunque estos recipientes no fueron fabricados exclusivamente para el mundo funerario: como lo demuestra el gran número de los hallazgos localizados en el hábitat. Respecto de la tumba 111, estas reflexiones podrían ayudar a interpretar el 'vaso' y la pequeña vasija carenada como un inventario funerario 'normal', al cual se asimilaría como 'adición' la gran copa de función posiblemente ritual, y cuya posición muy cerca de la boca del pithos entonces tampoco sería casual.

La tumba 111 era también especialmente rica en hallazgos metálicos, entre los cuales destacan los tres brazaletes cerrados, de bronce, que la difunta llevó en el antebrazo derecho (figs. 9 y 10 s.t.v, lám. 6) ${ }^{11}$. Junto a ellos se encontró una espiral de bronce de cuatro vueltas que tiene el tamaño de un brazalete (fig. 10u). Además hay que mencionar tres espirales más pequeñas, los fragmentos de otra y una sortija de bronce. Las siguientes piezas son de plata: otras cuatro espirales, el fragmento de una quinta, una sortija cerrada y dos sortijas abiertas entorchadas en sí mismas (fig. 10).

Un puñal de bronce, con tres remaches dispuestos en arco, está atacado en particular por la erosión. Sin embargo, parece que la fuerte oxidación contribuía precisamente a la conservación de elementos orgánicos sobre la superficie de la parte inferior de la hoja (fig. 10r). Estos restos orgánicos podrían ser interpretados como fibras vegetales o también como restos de un tejido, que pertenecían a la vaina del puñal o a la vestimenta. En la Cultura de El Argar el puñal es característico tanto en las tumbas de hombres como de mujeres. No obstante, los enterramientos femeninos se definen en general por la presencia de un punzón de cobre o de bronce. Aunque en la tumba 111 falta este elemento, el rico ajuar con alhajas de bronce y de plata habla a favor de un enterramiento femenino, lo que finalmente queda confirmado por las cuentas, a pesar de que esté aún pendiente el estudio antropológico ${ }^{12}$.

10. De aquí en adelante cf. Schubart (2000b: 112).

11. Hasta ahora no se ha realizado un análisis de los objetos de 'bronce' hallados en la tumba 111 de modo que podría tratarse también de cobre o bien de cobre arsenicado.

12. Según las primeras indicaciones del profesor Manfred Kunter (cf. supra nota 8), en la tumba 111 se enterró una mujer joven de entre 16 y 18 años. 


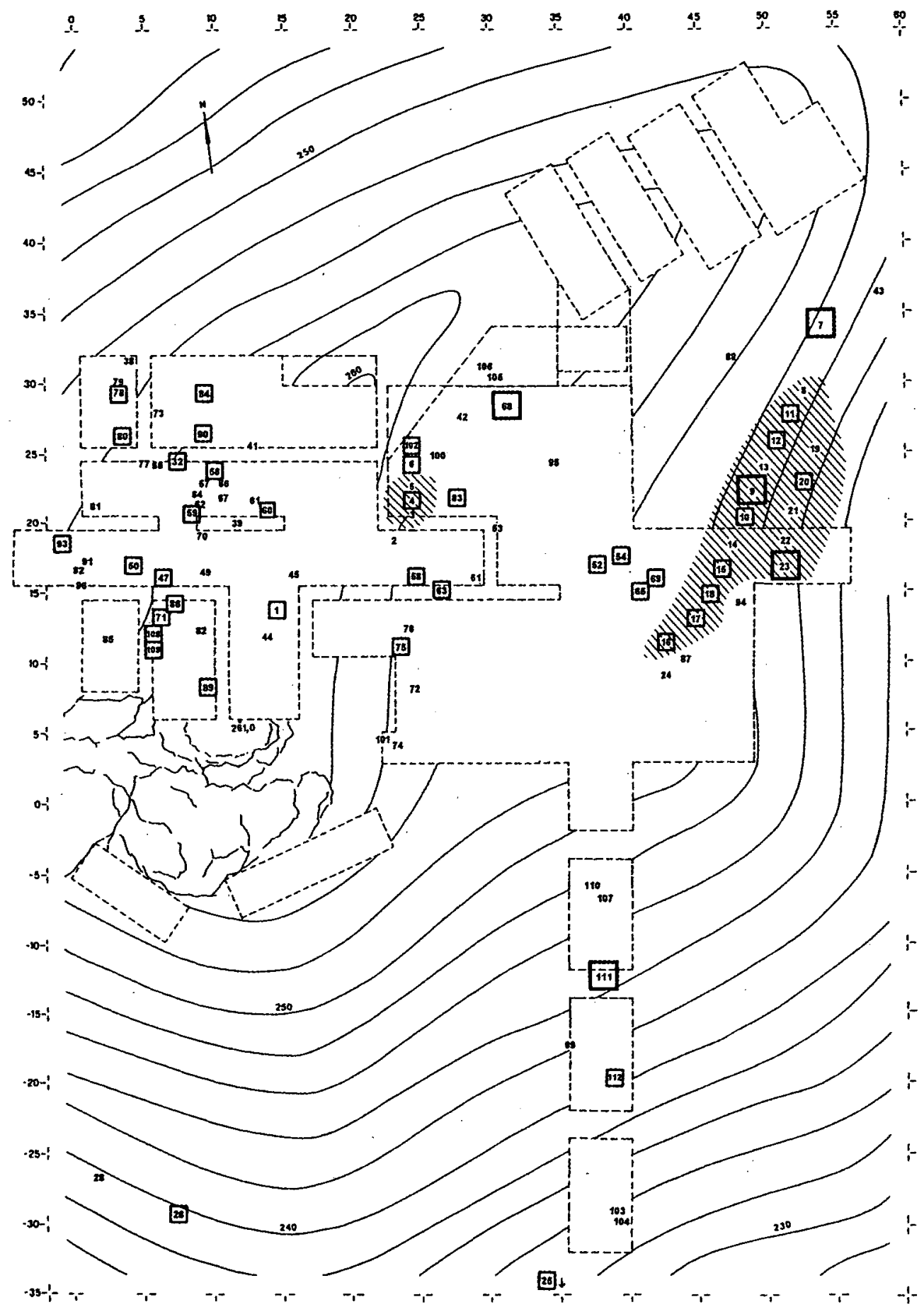

Fig. 13. Fuente Álamo. Distribución de las tumbas con ajuar cerámico. En los sectores rayados se señala la ubicación aproximada de varias tumbas que se encontraron según Siret entre las tumbas 2 y $6(=$ tumbas 2-5) o bien entre las tumbas 7 y 24 ( $=$ tumbas 8-23). Cuadrado pequeño $=1$ o 2 vasijas; cuadrado grande $=3 \mathrm{o}$ más vasijas. 
En la tumba 111 se hallaron más de 50 cuentas aparecidas en su mayoría durante la cuidadosa excavación realizada con una espátula y en parte algunas también recuperadas en la criba. Por consecuencia de las condiciones de conservación antes descritas, las cuentas no se encontraron todas juntas, aunque en su mayoría cerca del cráneo, como, dicho sea de paso, ocurre también con la mayor parte de las espirales. Aquí se reproducen solamente algunos ejemplos de las cuentas (fig. 10a-e) que tienen que ser representativos de las demás aún por estudiar. Además de doce cuentas de plata y dos de bronce predominan las piezas de una piedra verdosa. Entre las cuentas de plata figuran pequeños tubitos que se fabricaron entorchando en sí misma una lámina de plata o elaborando una fina espiral de varias vueltas; aparte hay ejemplares sueltos de cuentas esféricas y alambres de plata formando anillos de una vuelta. Las dos cuentas de bronce son también del tipo 'tubito', una realizada a partir de una lámina y la otra una fina espiral. Todas las cuentas se presentarán por completo en relación con la publicación monográfica de las sepulturas de Fuente Álamo (Schubart e.p.).

Los ricos hallazgos metálicos, en particular las joyas de plata, hacen resaltar la tumba 111 entre la masa de los demás enterramientos de Fuente Álamo, pero no es la única con un ajuar metálico. Poco más de un tercio de las sepulturas de Fuente Álamo incluyen hallazgos metálicos, aunque en su mayoría no más de una o dos piezas (fig. 14). No obstante, tampoco son raros los ajuares que cuentan con tres o más objetos metálicos. En total se conocen doce tumbas de este tipo que fueron localizadas en el caso de la tumba 1 en la cima del cerro, y los restantes once sepulturas todas ellas en la ladera este del poblado. En la ladera sur, aparte de la tumba 99 que contenía un puñal y un punzón constituyendo un ajuar 'normal', la tumba 111 es la única sepultura relativamente rica en hallazgos metálicos.

Antes del descubrimiento de la tumba 111, en Fuente Álamo ya se conocieron objetos de plata procedentes de trece sepulturas, de las cuales doce están situadas de nuevo en la ladera este, mientras que en la ladera oeste sólo el enterramiento en urna de la tumba 86 proporcionó una espiral de plata (fig. 14). También las tres tumbas con hallazgos de oro $(1,18$ y 75$)$ se encuentran en la cima o bien en la ladera este. Aunque no son muy numerosas, confirman la idea, formada en base a los enterramientos con un ajuar metálico rico u objetos de plata, de una concentración de esta riqueza tan característica en el área de la ladera este. Con ello hay que tener presente que en la ladera este y en la cima se ubican en suma 50 tumbas y en la ladera oeste solamente 37, aunque esta proporción numérica no podrá ser definitiva. Así mismo, el número de los enterramientos infantiles, con frecuencia pobres en ofrendas, coincide en un 12:9 respecto de las laderas este y oeste aproximadamente con esta proporción, por lo que parece que no entra en cuenta.

Así pues, el descubrimiento en la ladera sur de la rica tumba 111 significa una verdadera novedad. Por lo demás, el número de cinco tumbas hasta entonces conocidas en la ladera sur era escaso, cuanto más que se trata en parte de enterramientos infantiles que la mayoría de las veces son más pobres (Schubart, Pingel y Arteaga 1993: 7). La tumba 110 que contenía sólo un punzón de hueso y también se diferenciaba en el tipo por ser un enterramiento en fosa, permite considerar que tales sepulturas fueran más frecuentes en las laderas oeste y sur (Pingel et al. 1998: 22 s.). Por lo que la tumba 111 suscita nuevas reflexiones sobre la ladera sur.

Si partimos del supuesto de que los enterramientos argáricos ubicados en el área del hábitat, y aquí en particular las tumbas de Fuente Álamo, se instalaran cerca de las respectivas viviendas, la cima del cerro y la ladera este tendrían que ser consideradas la zona residencial de una población algo más rica, en cualquier caso en una parte. En cambio, en la zona superior hasta ahora excavada de la ladera oeste tendría que haberse asentado una población menos rica, aunque no estrictamente pobre, como lo demuestra la presencia de ajuares cerámicos y metálicos también en la ladera oeste (figs. 13 y 14). Puesto que en los próximos años no continuarán las excavaciones arqueológicas en la ladera sur, el importante dato aportado por la tumba 111 será el único citable en lo que respecta a la por lo visto extensa zona habitada en la ladera sur. Se podría reflexionar respecto de la tumba 111, que por su ubicación en el testigo 39/40 se sitúa en un tramo relativamente alto de la ladera sur, si la misma pertenecía a una zona residencial algo 'mejor' considerada en su rango social, por lo que aún conectaba con la cima y la ladera este; pero esto no sale por ahora de una tentativa especulación. 


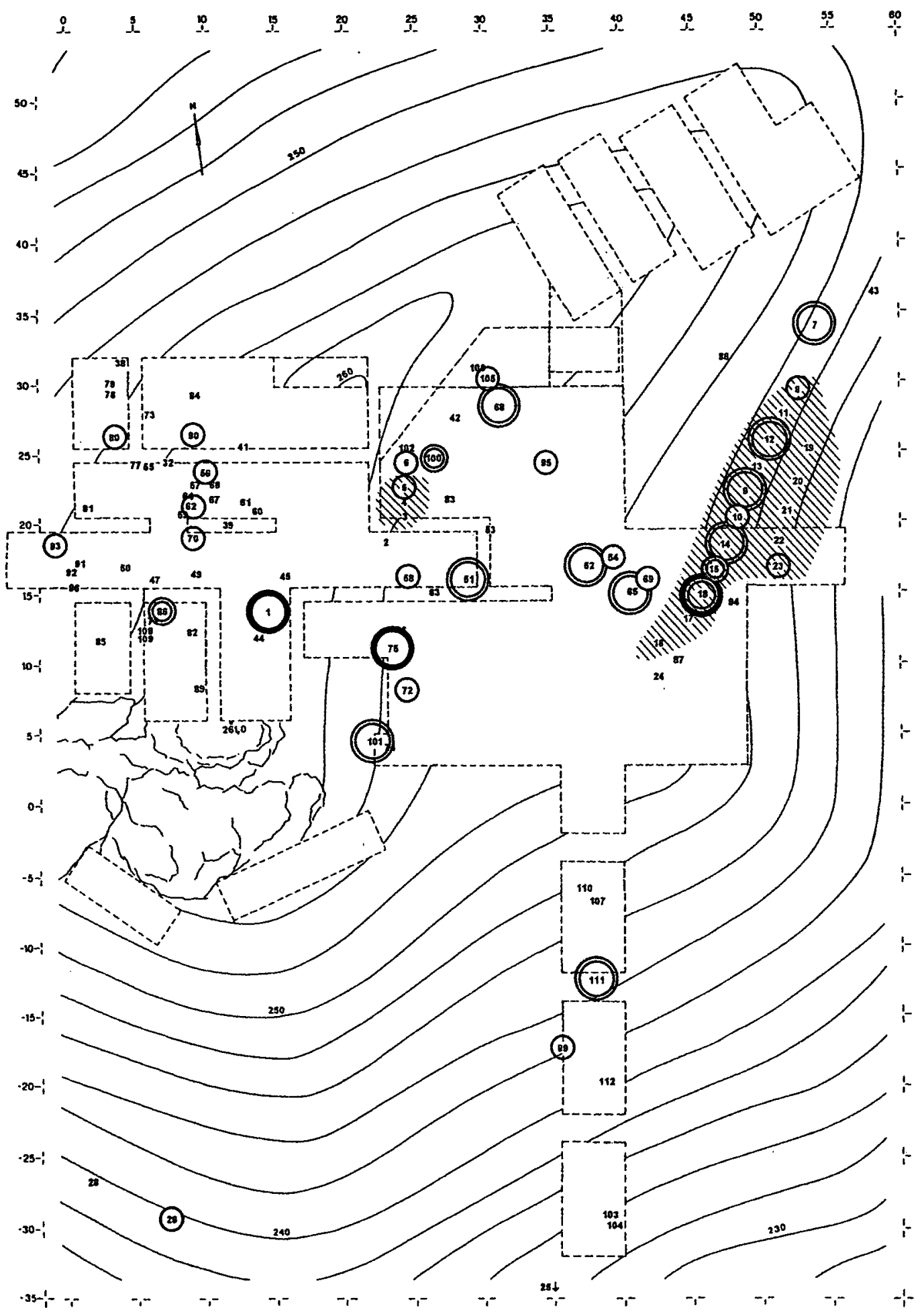

Fig. 14. Fuente Álamo. Distribución de las tumbas con ajuar metálico. Círculo pequeño $=1$ o 2 objetos metálicos; círculo grande $=3$ o más objetos metálicos; círculo doble $=$ plata; círculo negro $=$ oro. 
Así mismo podría ser que la idea de una expansión de esta zona residencial, de la cual formaría parte la rica tumba 111, tuviera su validez tan sólo en una época más tardía de Fuente Álamo. Por lo que antes precedería un hábitat en la ladera sur con unas casas pequeñas, en las cuales se practicaban unas actividades artesanales; en cualquier caso en parte, como confirman un conjunto de pesas de telar y los molinos de mano, lo que podría indicar después un cambio en la función de la zona referida. Sin embargo, los hallazgos y sus contextos son demasiado poco numerosos para permitir unas afirmaciones definitivas. Bajo esta misma expectativa hay que abordar también la cuestión de la datación de las tumbas 111 y 112 como especificamos a continuación.

Sieñdo unos enterramientos en urna, a las tumbas 111 y 112 les corresponde una cronología relativamente tardía dentro de la Cultura de El Argar, ya que las sepulturas en pithos son consideradas como propias del período de El Argar B (Blance 1971: 121 ss.; Schubart 1975: 80 ss.), de modo que quedarían referidas a los horizontes III y IV de Fuente Álamo ${ }^{13}$. La copa y el 'vaso', i.e. el pie reutilizado de otra copa, procedentes de la tumba 111 (fig. 10x.z) pertenecen a la forma $7 \mathrm{~b} 2$ que ya aparece en el horizonte II, pero que se hace frecuente en los horizontes III y IV ${ }^{14}$. Por tanto no facilitan una datación más precisa de la tumba 111 que la señalada de todos modos por el tipo de enterramiento en pithos.

En cambio la cronología de la pequeña vasija carenada (fig. 10y) se puede afinar algo más. Las partes superior e inferior de este recipiente ofrecen una proporción de 3:2, o sea la carena se encuentra en la parte inferior lo que habla a favor de una datación más reciente dentro de la evolución formal de las vasijas carenadas ${ }^{15}$, así como también su forma en general estirada y la parte superior cónica invertida. Al contrario del cuerpo superior más cóncavo de los recipientes del período de El Argar A, en las vasijas carenadas de El Argar B los perfiles tienden a ser más rectilíneas. Para una determinación cronológica también es fundamental la proporción entre la altura del vaso y su máxima anchura. Examinando algunos ejemplares de pequeño tamaño ${ }^{16}$ procedentes de las tumbas de Fuente Álamo se puede observar, cómo la altura aumenta en relación con la máxima anchura. Si la altura es igual a 1, entonces p.ej. el vasito carenado de la tumba 1 de Fuente Álamo perteneciente al horizonte I (su carena se encuentra algo por encima de la mitad del recipiente, el cuerpo superior es cóncavo y el inferior muestra un perfil arqueado) presenta un coeficiente de 1,57 (proporción entre la altura y la máxima anchura). Otras vasijas carenadas de pequeño tamaño ofrecen los siguientes coeficientes: 1,45 (tumba 90 , horizonte I/II); 1,02 (tumba 52, fase $10 \mathrm{~b}=$ horizonte III antiguo); 0,95 (tumba 65 , fase $10 \mathrm{~b}=$ horizonte III antiguo); 1,1 (tumba 9, quizás todavía horizonte III, más bien horizonte IV); 0,74 (tumba 68 , fase $14=$ horizonte IV). El recipiente procedente de la tumba 111 con una proporción de 1:0,78 puede ser clasificado entre las formas tardías. Ante la vasijita carenada de la tumba 52 de Fuente Álamo (Arteaga y Schubart 1980: fig. 9f) con una parte superior más cóncava, la forma del vaso de la tumba 111 es más rígida. Solamente la vasija de la tumba 68 causa la impresión de ser más estirada (Arteaga y Schubart 1981: lám. 10a). Nuestro recipiente de la tumba 111 podría pertenecer todavía al tardío horizonte III, pero se clasifica más bien en el horizonte IV.

Como arriba se expuso, el 'cuenco' de la tumba 112 (fig. 12a) se identifica con la parte superior de una copa de la forma $7 \mathrm{cl}$, aunque con una peana posiblemente más ancha según la forma $7 \mathrm{~b} 2$. Una copa de la forma $7 \mathrm{c} 1$ se dataría en los horizontes III y IV de Fuente Álamo (Schubart 2000b: 107 ss., 112). Así pues, la tumba 112 puede ser adscrita al período de El Argar B sólo en general, y la tumba 111 dentro de este período más bien a una época tardía.

13. Acerca de la concordancia entre los períodos de El Argar y los horizontes estratigráficos de Fuente Álamo cf. Schubart 2000a: 60 s., fig. 1.

14. Cf. supra nota 13.

15. De aquí en adelante cf. Schubart (2000b: 107 ss).

16. Las vasijas carenadas de mayor tamaño dejan ver una evolución formal análoga; no se incluyen conscientemente, de momento, en estas consideraciones. 

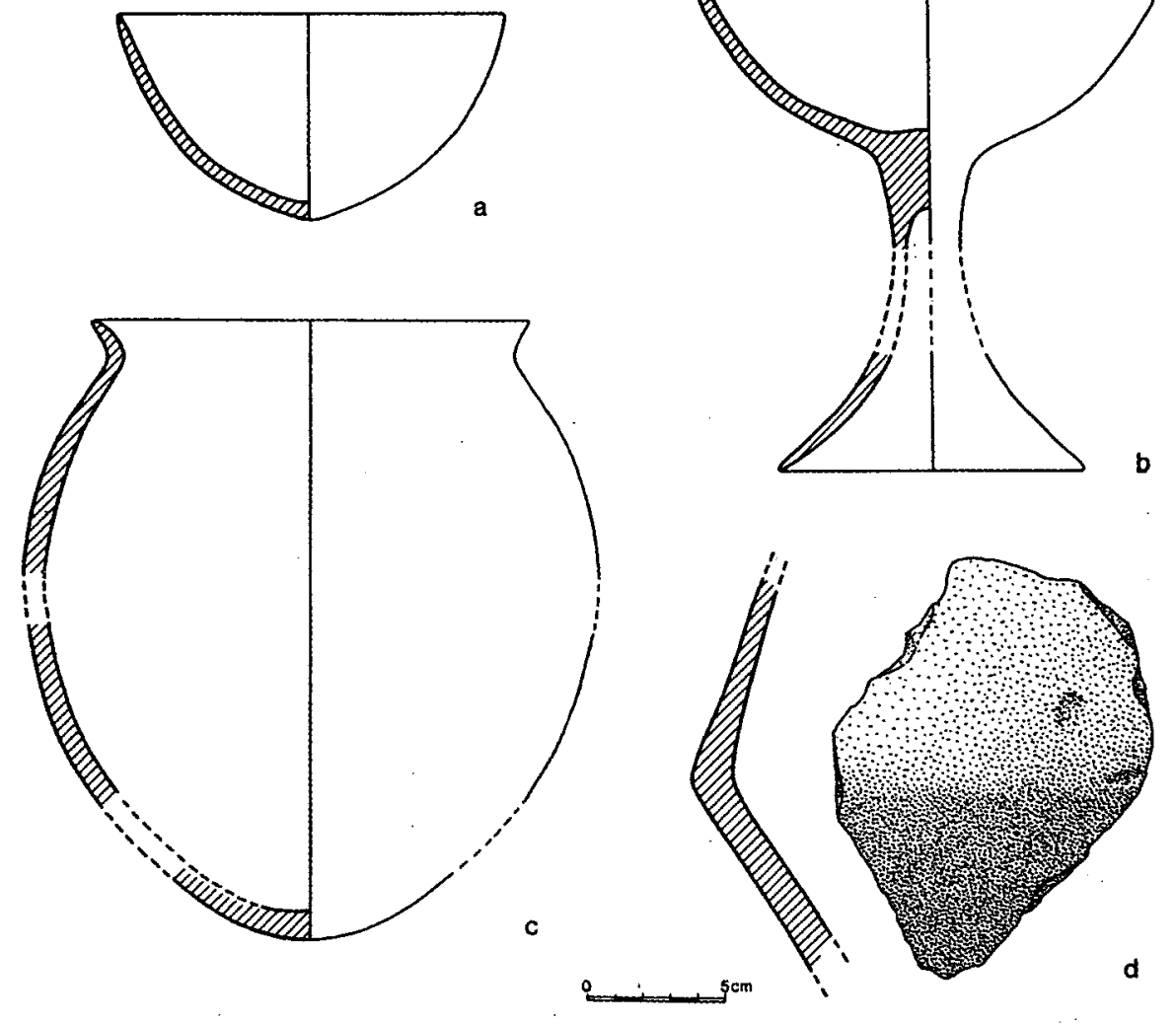

Fig. 15. Fuente Álamo 1999. Corte 39W. Hallazgos materiales procedentes del estrato argárico más superior. a FA 99/4479/2; b FA 99/4479/1; c FA 99/4484; d FA 99/4482.

Si más allá de esta cronología relativa inferida en base a los inventarios funerarios se examina la situación estratigráfica de las tumbas 111 y 112 dentro de los cortes 39 y 40, de nuevo se subraya su datación tardía; y en el caso de la tumba 112 incluso podrá ser definida con una mayor precisión. La fosa de esta sepultura atraviesa un nivel que coincide delante del perfil oeste del corte 40 con un estrato al parecer del horizonte IV de Fuente Álamo. En dicho estrato se hallaron varios fragmentos cerámicos de copas de la forma 7c, entre los cuales se cuenta con seguridad uno de la forma $7 \mathrm{c} 2$ que es la más tardía de este tipo. En lo que concierne a la tumba 111 , en el corte 39 , se puede suponer con mucha probabilidad que su fosa fue excavada desde un nivel que se superpone a los edificios $\mathrm{V}$ y W de $\mathrm{El}$ Argar antiguo, y que este nivel es igualmente más reciente que algunos estratos ubicados detrás del muro mc. Por lo que se hace probable una datación en la época argárica reciente, cuando menos, aunque de momento no se puede aclarar su relación estratigráfica con aquel estrato del cual procede un complejo material tardío que presentamos a continuación.

De los numerosos hallazgos del hábitat argárico, cuyas piezas estratificadas se estudiarán dentro de la publicación monográfica de la ladera sur, se trata aquí solamente el referido al complejo cerámico procedente del estrato argárico más superior de la ampliación oeste del corte 39. Parece que le concierne un carácter especial. Algo detrás del perfil oeste del corte 39 se encontraron todos juntos los fragmentos de tres recipientes cuyas formas pueden ser reconstruidas como sigue: una olla de la forma $4 \mathrm{~b} 2$ (fig. 15c), un cuenco de la forma $1 \mathrm{c} 1$ (fig. 15a) y una copa de la forma $7 \mathrm{c} 2$ (fig. 15b). Las tres vasijas, en particular la olla y el cuenco 
de paredes sorprendentemente finas, destacan por la superficie bruñida de un color negro brillante. Podría ser que se trate de un complejo funerario procedente de una sepultura destruida que se ubicó en este lugar o algo más arriba. En el mismo contexto se hallaron varios fragmentos de una gran vasija de la forma 5 , igualmente de color negro brillante (fig. 15d), que muy bien podría haber sido utilizada como urna, de modo que los recipientes recuperados serían los restos de un enterramiento en urna. En este caso, como de costumbre en los ajuares argáricos se combinaría una olla como recipiente mayor y un cuenco como recipiente menor, a los cuales se añadiría la copa, tal cual se describió arriba respecto del ajuar de la tumba 111; todo ello en el supuesto de que se trate de verdad de un conjunto funerario, entonces con un rico ajuar cerámico. Acerca de la cronología se podría apuntar que la olla de la forma $4 \mathrm{~b} 2$ es característica del período El Argar B (Schubart 2000b: 107), mientras que la copa mostrando una peana con su parte superior maciza, perteneciendo a la forma 7c2, puede ser datada con cierta probabilidad en El Argar B2 (Schubart 2000b: 112).

\section{EL BRONCE TARDÍO POST-ARGÁRICO EN LA LADERA SUR DE FUENTE ÁLAMO}

En relación con la época del Bronce Tardío (Arteaga y Schubart 1980: 268-278) podemos remarcar que los resultados estratigráficos obtenidos durante las últimas campañas realizadas en los cortes 39,40 y 41 (Schubart, Arteaga y Pingel 1989: fig. 2; Schubart, Pingel y Arteaga 1993: figs. 1, 2; Pingel et alii 1998: 15 ss., láms. 2-4) fueron sumamente decisivos para el conocimiento del horizonte post-argárico en este poblado. Como se ha consignado más arriba, abarcaron dichos cortes una buena extensión de la ladera sur de Fuente Álamo (Schubart, Pingel y Arteaga 1993: figs. 1,2). Y por ello mismo, facilitaron la observación de un gran espacio habitado hasta la época del Bronce Tardío (Arteaga y Schubart 1980: 278). Ocupan las construcciones hasta ahora documentadas en la ladera sur del poblado la zona situada en el reborde de la cima del cerro (corte 39) y llegan bajando la pendiente hasta por arriba de la terraza artificial que habíamos apreciado en relación con el corte 16 ya desde la campaña de excavación llevada a cabo en 1977 (Arteaga y Schubart 1980: 255, fig. 4, lám.10b). Los recientes resultados arqueológicos, al continuar poniendo en evidencia que existieron otras terrazas post-argáricas por encima del corte 16, habiendo sido 'cortadas' siguiendo la misma forma sistemática tradicional de la Edad del Bronce en Fuente Álamo, confirmaron plenamente la hipótesis de trabajo que habíamos formulado desde un principio (Arteaga y Schubart 1980: 277 s.) cuando consideramos la posibilidad de encontrarnos ante una continuidad poblacional, sin ningún tipo de hiatus entre la ocupación relativa a la fase más avanzada de El Argar B y la sucesiva ocupación post-argárica relativa al Bronce Tardío.

Como podremos señalar a continuación, hemos conseguido establecer una clara distinción entre los complejos cerámicos del Bronce Tardío que habíamos ubicado en las construcciones post-argáricas localizadas en la cúspide de Fuente Álamo (Arteaga y Schubart 1980: figs. 14, 15; Schubart, Arteaga y Pingel 1985: 78-83) y los complejos estratificados en las terrazas que entonces fueron habitadas en la ladera sur. Poniéndose en evidencia unas diferencias sensibles respecto de la vida cotidiana de quienes ocupaban unos y otros espacios sociales. Las distinciones establecidas entre las diferentes construcciones y los complejos materiales que las acompañan, tanto en la cima como en la ladera, serán estudiadas de una manera detallada en la monografía que sobre el Bronce Tardío post-argárico tenemos en preparación. Por lo que a continuación, para cumplimentar el avance informativo de la campaña de 1999 en Fuente Álamo, daremos a conocer un listado tipológico provisional basado solamente en una selección cerámica procedente de las edificaciones excavadas hasta el momento en la ladera sur. 
En comparación con las ilustraciones que presentamos para tales efectos (figs. 17-24) la cerámica del Bronce Tardío encontrada en dicha ladera sur, cabiendo acusar por ahora la total ausencia de vasijas decoradas (que sin embargo abundan en las construcciones de la cima...), puede quedar clasificada 'formal' $y$ 'funcionalmente' en cuatro grupos de la cerámica cuidada (figs. 17-20) y en otros cuatro grupos de la cerámica común y de cocina (figs. 21-24).

\section{Cerámica cuidada}

\section{GRUPO 1: Fuentes y cazuelas de carena alta y borde relativamente corto}

Suelen presentar superficies bruñidas de muy buena calidad. Cuando la parte del fondo se hace poco profunda, la forma tiene la función casi de un 'plato' (fig. 17a). Las formas intermedias presentan variantes funcionales entre la fuente (figs. 17b) y la cazuela (fig. 17c-e). Y cuando la parte del fondo se hace profunda, la forma adquiere la conocida funcionalidad de una vasija troncocónica de carena alta y borde corto (fig. 17f). Los fondos relativamente curvos pueden llegar a ser aplanados.

GRUPO 2: Fuentes y cazuelas de carena alta y borde alargado

Constituyen una variante del grupo anterior, aunque se diferencian por presentar unos bordes relativamente más alargados, bien sea mostrando una tendencia recta y abierta (fig. 18a), cuando no curvada y más vertical (fig. 18b-e).

\section{GRUPO 3: Cazuelas y ollas de carena alta}

Constituyen la variante intermedia de las dos anteriores. La mayoría tiende a la forma de olla troncocónica de hombro marcado (fig. 19a-c). Y pueden conocer notables distinciones funcionales que se reflejan en sus tamaños (fig. 19a) y capacidades (fig. 19e.f). No todas suelen estar bruñidas.

\section{GRUPO 4: Cuencos de carena alta y borde corto}

Resultan característicos por sus bordes relativamente cortos respecto del fondo variablemente cóncavo, entre las formas menos profundas (figs. 20a-e) y las que sí lo son (fig. 20f). Pueden en estos últimos casos presentar un fondo aplanado y en la carena unos apéndices colgantes para facilitar su suspensión (fig. 20f).

\section{Cerámica común y de cocina}

\section{GRUPO 5: Escudillas, cuencos y ollas globulares}

Aunque algunos cuencos pueden estar bruñidas, los acabados superficiales que más abundan se encuentran alisados y espatulados; y en casos extremos de aspecto más grosero. Las funciones utilitarias incluyen formas de distintos tamaños y capacidades. Cuando las formas concoidales resultan inferiores al cuarto de un círculo, constituyen la capacidad de una escudilla (fig. $21 \mathrm{~h}$ ). Otras que alcanzan la forma del medio círculo adquieren la función del cuenco propiamente dicho (fig. 21f.g). Y cuando cierran hacia el interior, hasta los tres cuartos de círculo, forman el cuenco redondeado y profundo (fig. 21e); que al cerrar todavía más su boca acaba propiamente en la olla globular (fig. 21a-d). 

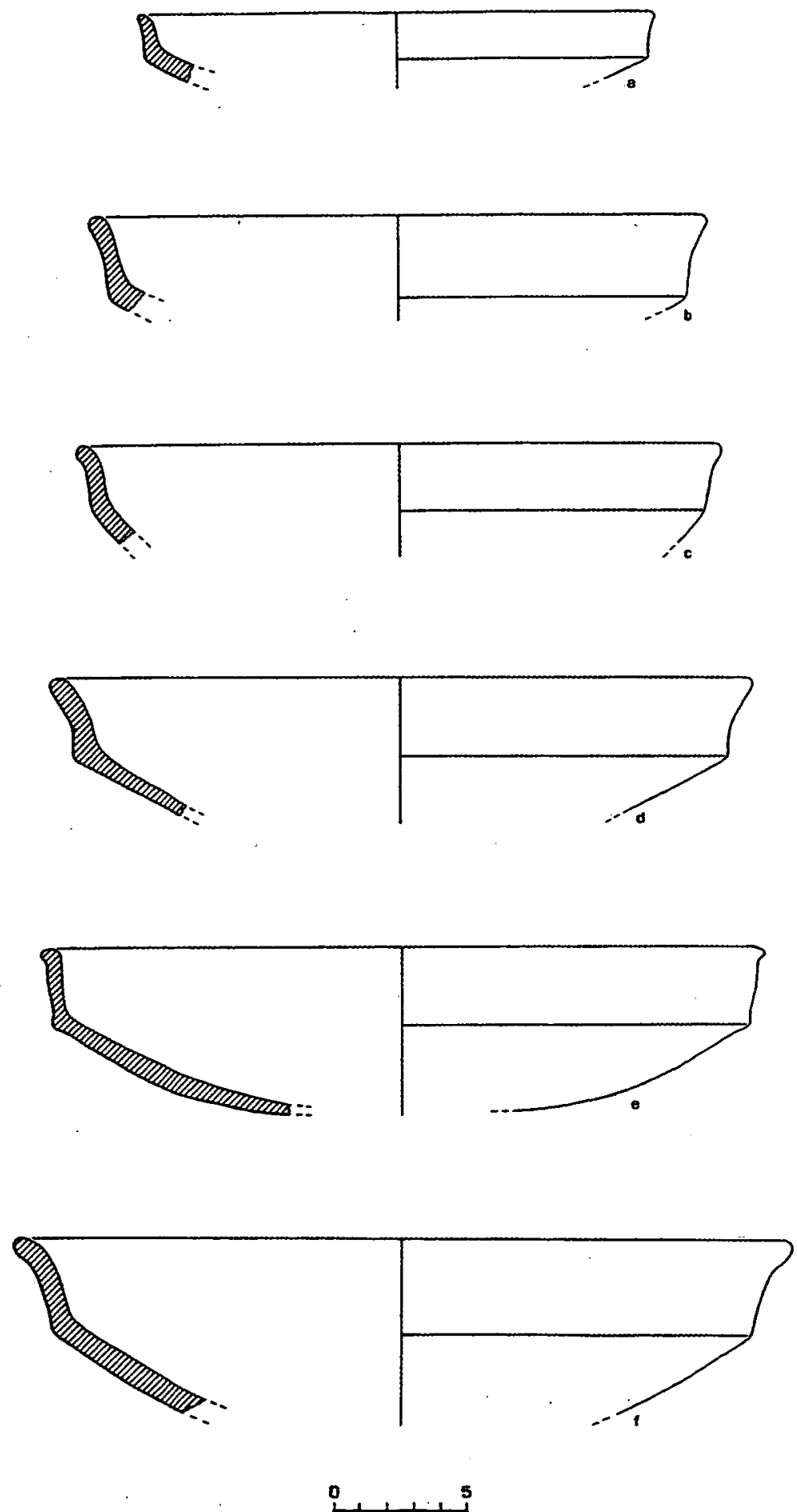

Fig. 17. Fuente Álamo. Ladera sur. Bronce Tardío. Cerámica cuidada: fuentes y cazuelas de carena alta y borde relativamente corto (grupo 1). 

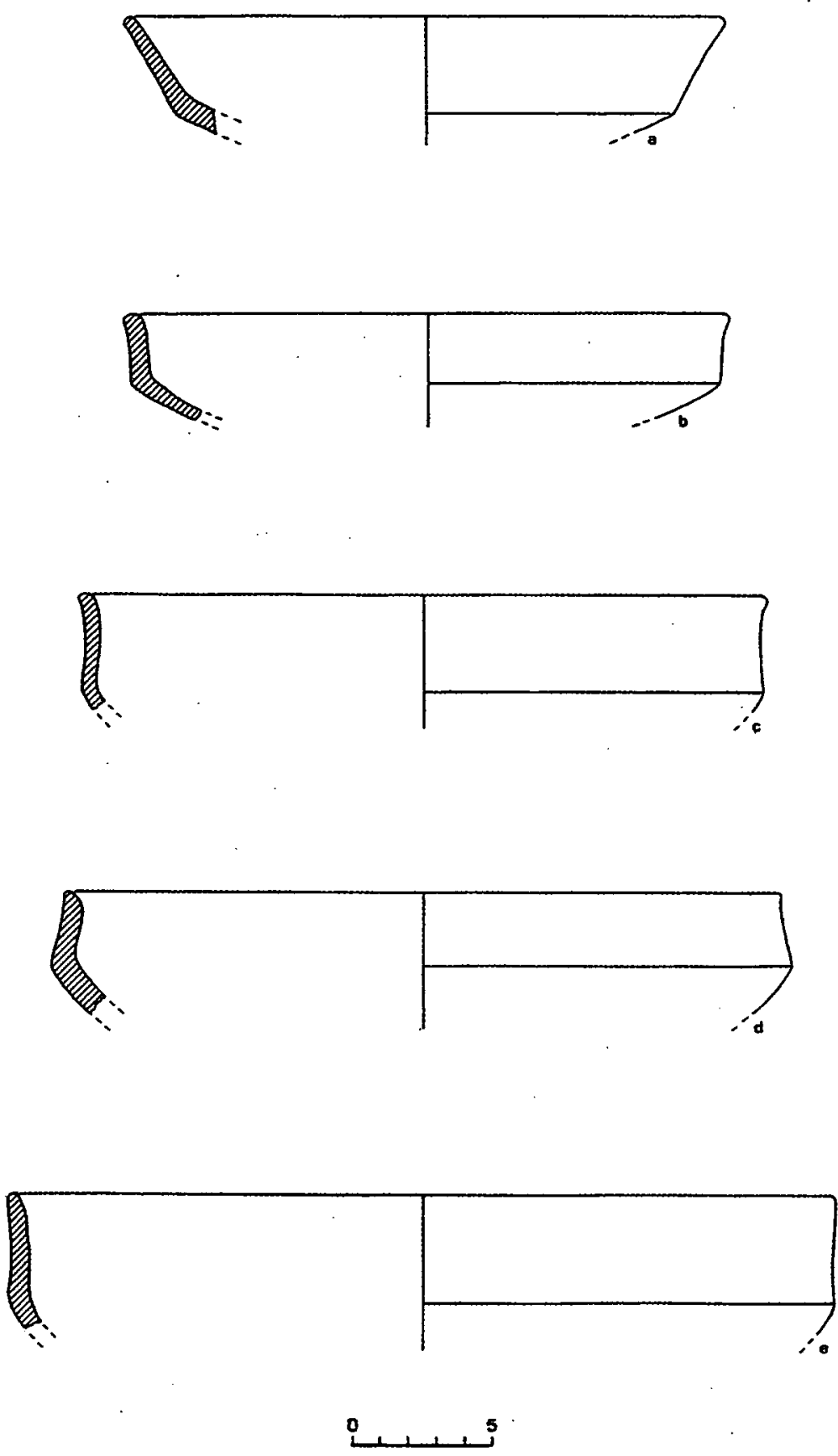

Fig. 18. Fuente Álamo. Ladera sur. Bronce Tardío. Cerámica cuidada: fuentes y cazuelas de carena alta y borde alargado (grupo 2). 

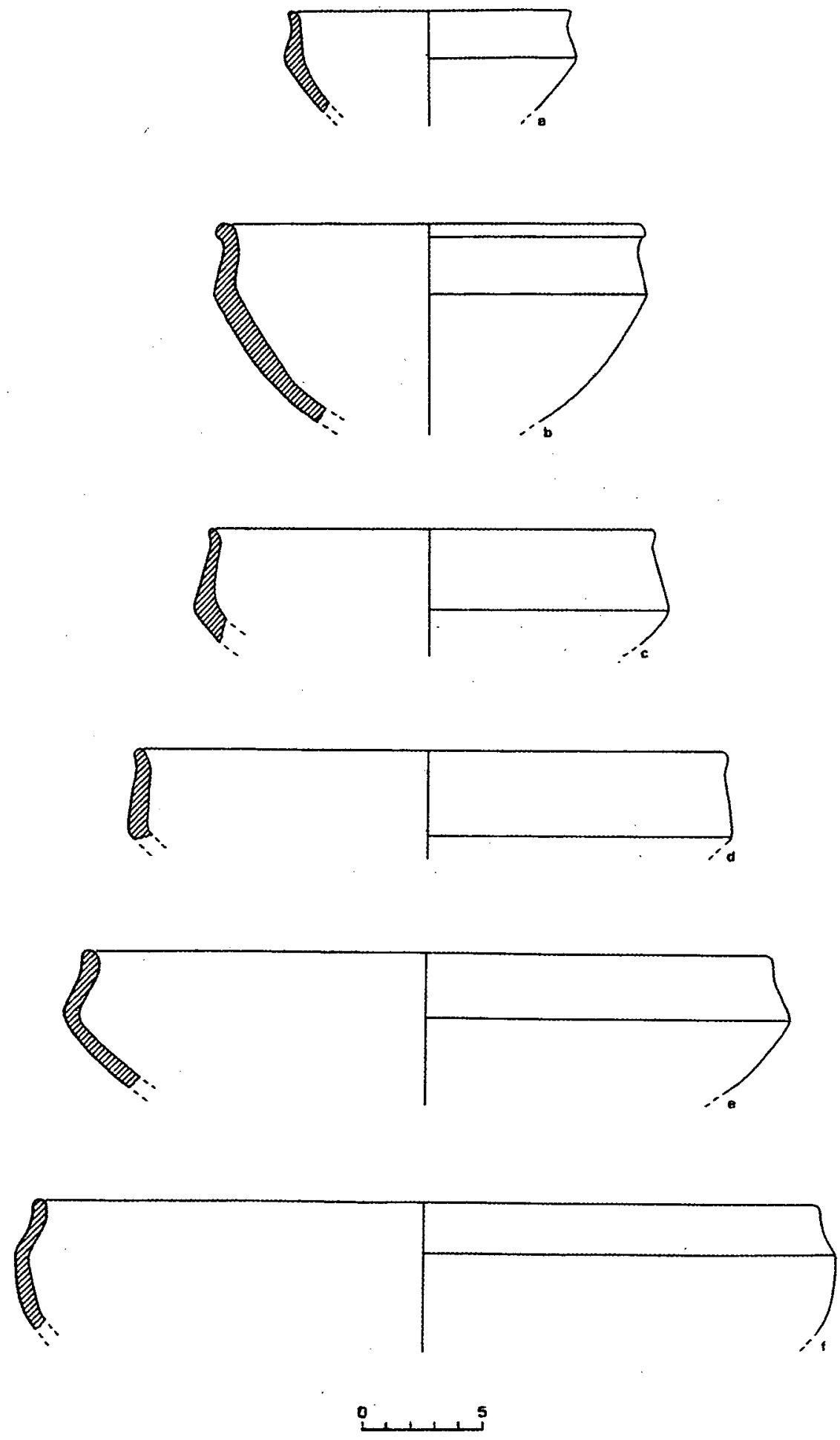

Fig. 19. Fuente Álamo. Ladera sur. Bronce Tardío. Cerámica cuidada: cazuelas y ollas de carena alta (grupo 3). 

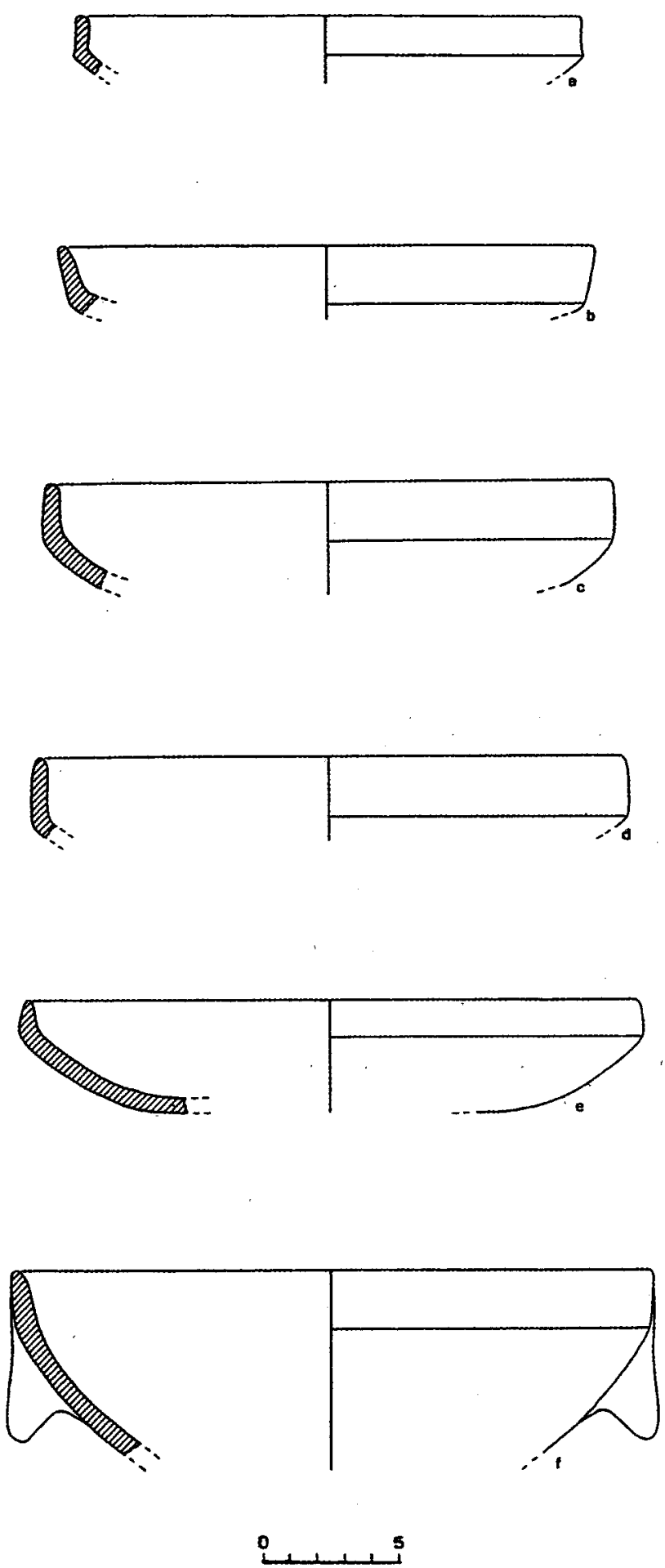

Fig. 20. Fuente Álamo. Ladera sur. Bronce Tardío. Cerámica cuidada: cuencos de carena alta y borde corto (grupo 4). 

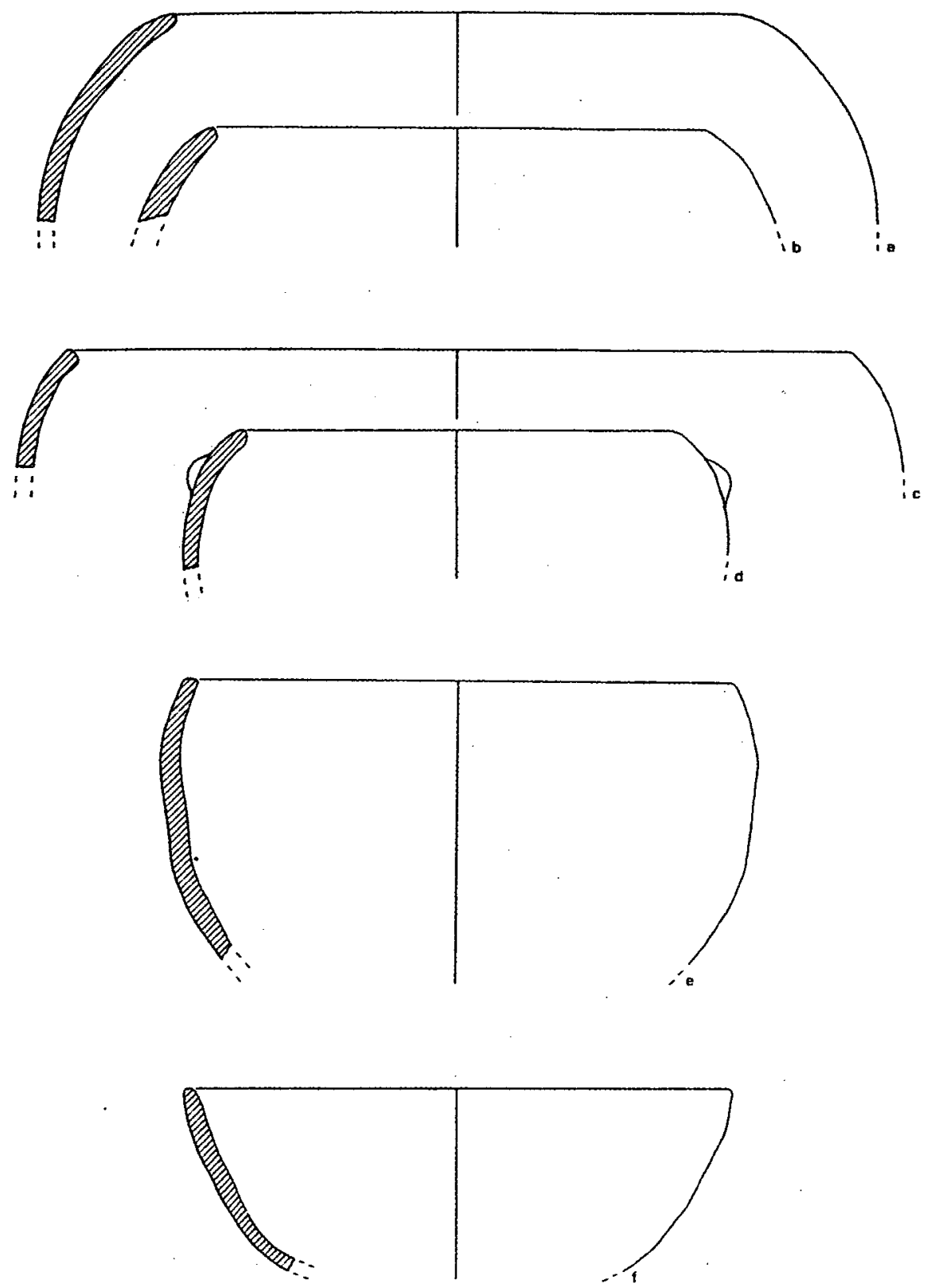

i
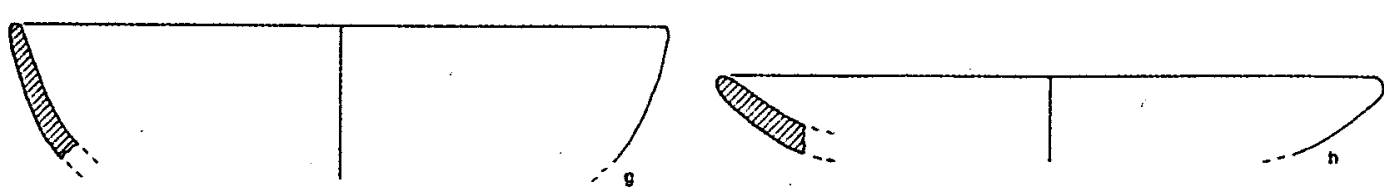

Fig. 21. Fuente Álamo. Ladera sur. Bronce Tardío. Cerámica común: escudillas, cuencos y ollas globulares (grupo 5). 


\section{GRUPO 6: Cuencos, cubiletes y ollas de paredes relativamente inclinadas}

Constituyen variantes del grupo anterior, pero se diferencian por no tener las paredes concoidales. Las distinciones funcionales relativas a sus formas y capacidades se encuentran clasificadas entre los cuencos (fig. 22a) y los típicos 'cubiletes' (fig. 22b), pasando por las ollas de paredes verticales (fig. 22d.e) hasta las grandes ollas de boca abierta (fig. 22f.g).

\section{GRUPO 7: Ollas de perfil en ' $S$ '}

Como variables utilitarias respecto de las ollas y cuencos de paredes rectas del grupo anterior (fig. 23.d) tenemos una inmensa representación de cerámica común de aspecto 'grosero', en la que se incluyen ollitas (fig. 23a.b) y vasijas panzudas con el cuello indicado (fig. 23e-g). Estos recipientes fueron usados sobre todo en las labores de la cocina.

\section{GRUPO 8: Botellas, ollas con el cuello marcado y ollas con paredes verticales}

Constituyen variantes del grupo anterior, pero se caracterizan por la curvatura exvasada del borde. Cuando el cuerpo se hace globular, la forma adquiere el perfil característico de la ollita globular con el cuello exvasado (fig. 24a-d); que cuando su tamaño se hace más pequeño y piriforme, se convierte en la 'botella' típica del Bronce Tardío. El acabado de la superficie puede ser excelente. Las grandes vasijas que añadimos con el perfil en ' $S$ ' y las paredes verticales (fig. $24 \mathrm{e}-\mathrm{g}$ ), más adelante podremos quizás separarlas en un grupo independiente, característico de la cerámica común.

Tomando en cuenta que Fuente Álamo acaba su secuencia prehistórica todavía durante la época postargárica propiamente dicha, este material cerámico 'comparativo' que acabamos de presentar esperamos que pueda pasar a constituir una referencia de primera mano para la definición, cuando menos, de un Bronce Tardío Antiguo en el sudeste de la Península Ibérica. Nuestra primera llamada de atención radica en las dataciones calibradas del Carbono-14 que para el Bronce Tardío de Fuente Álamo (Pingel 2000; Görsdorf 2001) nos permiten abrir y cerrar una oscilación cronológica alrededor de 1500-1300 a.C. Se trata en cuanto a la apertura de dicha oscilación en torno al 1500 a.C. de una datación que, por hallarse referida a la continuidad poblacional de Fuente Álamo hacia la transición post-argárica, entraña para nosotros una expectativa histórica de consecuencia trascendente, porque dicha continuidad poblacional conlleva en sí misma, en el marco temporal indicado, la solución explicativa del 'final' de la llamada 'Cultura de El Argar'. Mostrando con absoluta claridad que dicha cultura se transforma en consonancia con el cambio económico-político que se opera en el seno de la propia sociedad argárica (Schubart y Arteaga 1986; Arteaga 2000a; 2000b).

En comparación con otros ámbitos poblacionales que venimos conociendo como propios del Bronce Tardío en el resto de la Península Ibérica (Arteaga 2000b), la particularidad post-argárica dentro de la cual se integra el poblado de Fuente Álamo permite afirmar que la noción territorial del Bronce Tardío Antiguo en el sudeste y en su entorno deriva políticamente del desmembramiento del Estado de El Argar (Arteaga 2000b). Desde la Crítica de la Economía Política que nosotros mantenemos respecto del ámbito atlánticomediterráneo de la Península Ibérica, desde la Época del Cobre hasta la Época del Bronce (Arteaga 1992; 2000a), cuando hablamos de las contradicciones que se generan en el seno de la propia sociedad argárica nos estamos refiriendo también al desenlace político que desde la desarticulación clasista de las elites dominantes en su Estado pensamos que deriva en la separación antagónica de varios territorios post-argáricos. Y que pasando a constituir unos reinos principescos particularizados, los mismos 'rompen' con el sistema tributario que los articulaba al Estado argárico, y consolidan los dominios poblacionales del Bronce Tardío Antiguo (Arteaga 2000b). 

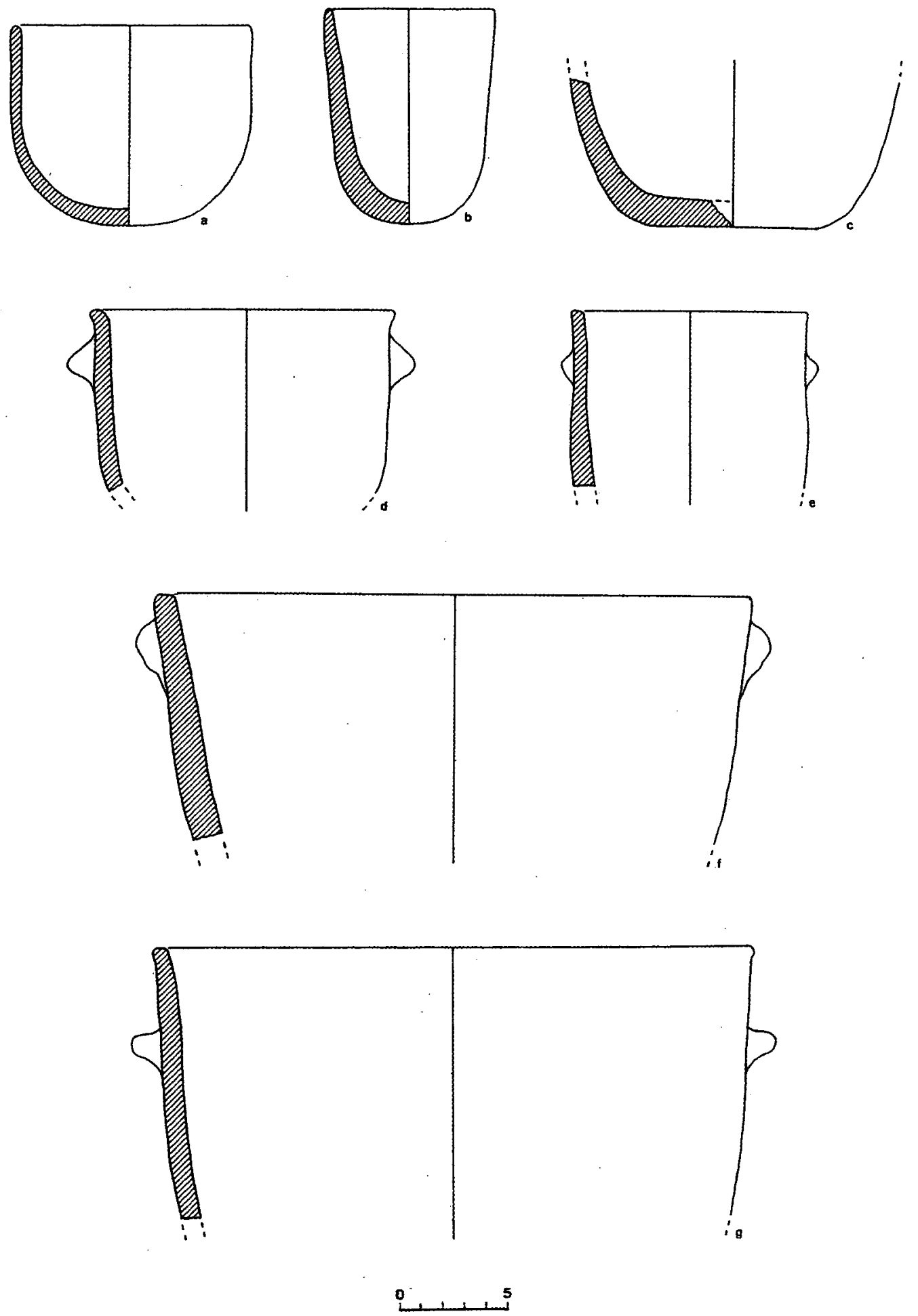

Fig. 22. Fuente Álamo. Ladera sur. Bronce Tardío. Cerámica común: cuencos, cubiletes y ollas de paredes relativamente inclinadas (grupo 6). 

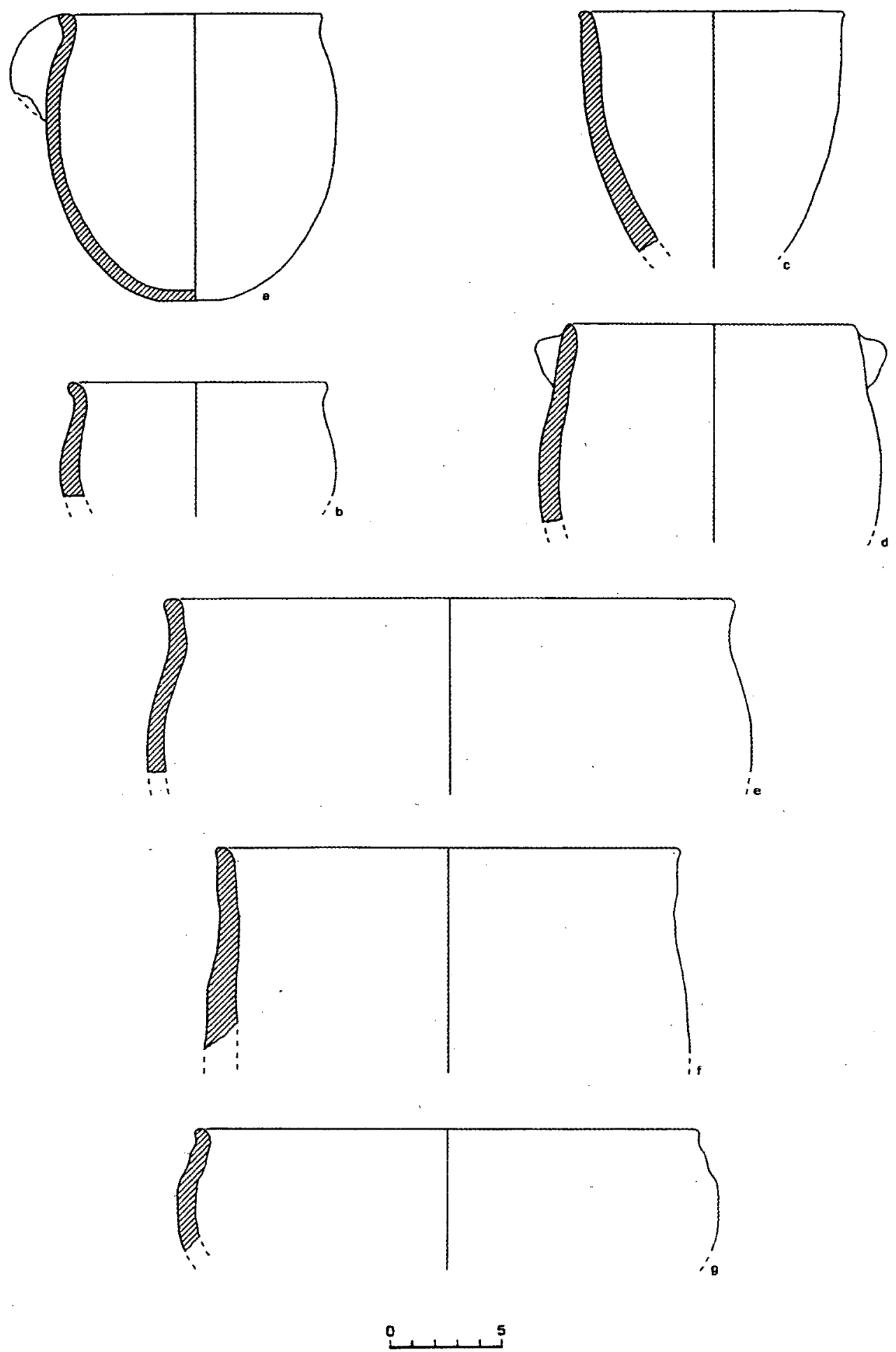

Fig. 23. Fuente Álamo. Ladera sur. Bronce Tardío. Cerámica común: ollas de perfil en 'S' (grupo 7). 

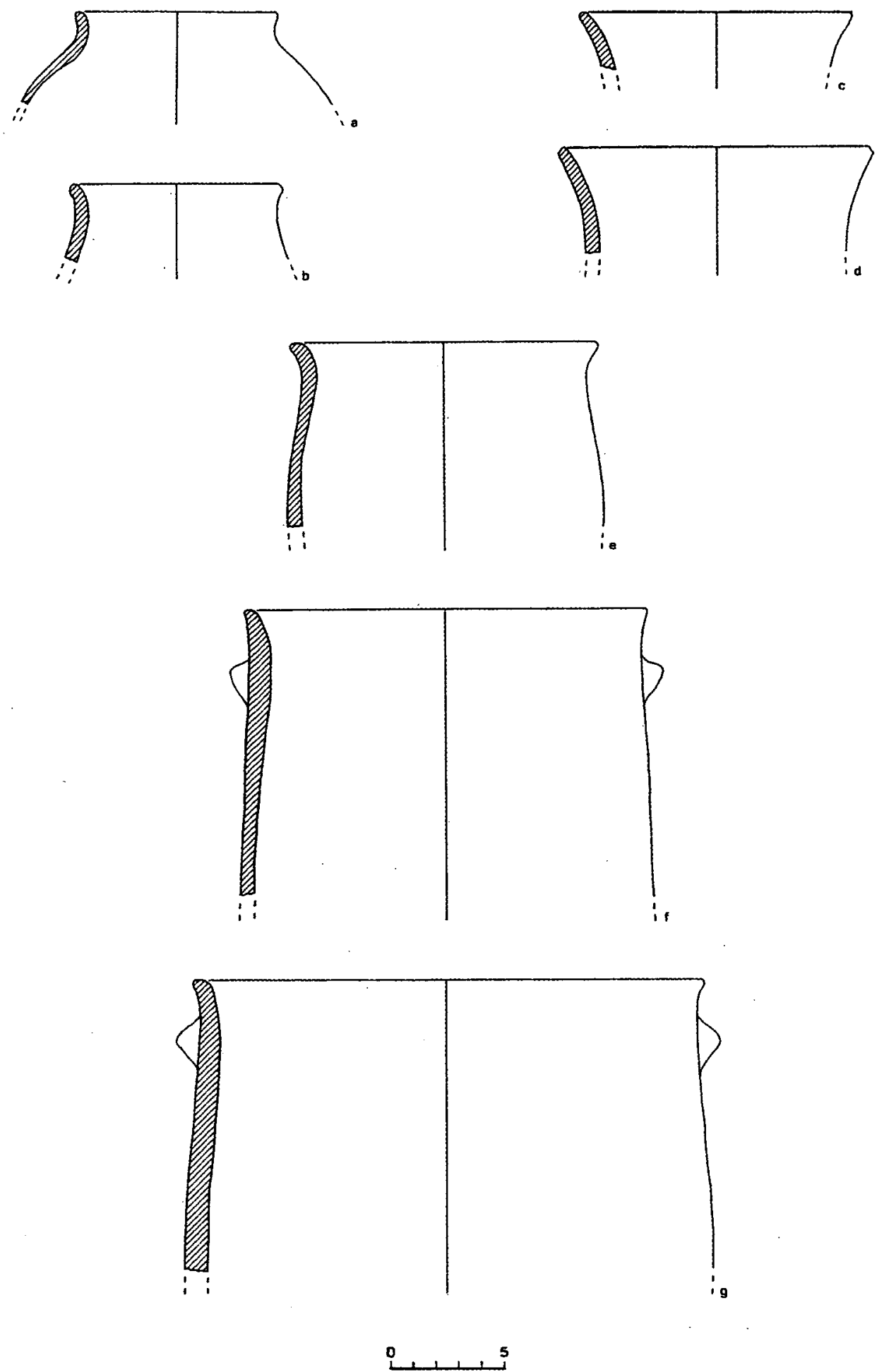

Fig. 24. Fuente Álamo. Ladera sur. Bronce Tardío. Cerámica común: botellas, ollas con el cuello marcado y ollas con paredes verticales (grupo 8). 
Con las nuevas ordenaciones territoriales y las dependencias poblacionales del Bronce Tardío post-argárico, pensamos que alrededor del sudeste y de la Alta Andalucía se conforma la expectativa de una continuidad histórica que todavía sigue siendo para muchos colegas al parecer bastante insospechada; no solamente a la vista de como ellos intentan establecer sus propuestas de periodización, sino también a tenor de como procuran inferir los contenidos históricos de sus respectivos cuadros descriptivos. Una de las maneras más corrientes de llegar a tales 'inferencias' consiste en seleccionar con criterios subjetivos un material 'aparente', para luego buscarle unos 'paralelos' comparativos, y de la similitud 'encontrada' hacer derivar una interpretación concluyente. La interpretación establecida desde el 'exterior', en base a los 'paralelos buscados' y de este modo 'encontrados', suele tener el defecto de no hacer resaltar la importancia de otros materiales 'no selectos', que siendo mayoritarios por lo general tampoco se pueden comparar aparte de los asentamientos que se integran en unos territorios concretos. Y así como pasa con los 'grupos cerámicos' que se toman como más 'significativos', son estos últimos los que se consideran (y no aquellos...) como indicadores del cambio cultural.

Se descuidan, en definitiva, en estas inferencias comparativas muchos de los 'significantes' materiales post-argáricos que realmente se refieren a los modos de vida cotidianos y en cuyo análisis estriba no solamente la continuidad explicativa del cambio material, sino también la posibilidad de acceder a la síntesis general de la cultura, vista igualmente como una expresión fenoménica del cambio ideológico-político (Arteaga 2000b). Las distinciones estratigráficas entre las edificaciones y los complejos materiales de Fuente Álamo obedecen a los cambios operados entre los modos de vida de finales de El Argar y los modos de vida postargáricos, pensamos que en la perspectiva dialéctica de una misma continuidad poblacional solamente podemos atribuirlas al salto cualitativo que se produjo en su propio modo de producción y de reproducción social. No podemos a la inversa hacerlas dependientes de otros referentes poblacionales 'externos' y por lo tanto propios de otros territorios circundantes del sudeste en el ámbito atlántico-mediterráneo de la Península Ibérica.

Lo que acabamos de apuntar pensamos que se puede inferir también respecto de la vida continuada que igualmente observamos en otros poblados prehistóricos que como Fuente Álamo a partir del Bronce Medio muestran unas secuencias estratigráficas que entroncan a todas luces con el Bronce Tardío, y donde, sin embargo, por las razones antes apuntadas este cambio cultural suele quedar interpretado de una manera difusionista. La derivación interpretativa del cambio cultural por difusión suele acabar también en una conclusión más extremada, cuando partiendo de esta inferencia algunos colegas suponen a su vez la existencia de un cambio poblacional. Es decir, cuando introduciendo unos criterios claramente 'invasionistas', conciben por un lado unos movimientos masivos de pueblos 'sin retorno', bajando desde la Meseta hacia las tierras del sur y del sudeste. Y, por otro lado, cuando marchando desde la Alta Andalucía intentan hacer llegar unas poblaciones foráneas hasta la Andalucía Occidental. Para de esta manera, como si aquellas tierras hubieran estado despobladas, procurar rellenar unos hiatos y unos vacíos (las lagunas de la investigación...) que en cuanto al Bronce Tardío pre-tartesio nosotros dudamos mucho que se dieran en el valle del Guadalquivir y en los entornos de su cuenca (Arteaga 1997; Roos 1997).

No podemos descartar que para darse las nuevas ordenaciones territoriales propiciadas durante el Bronce Tardío se hubieran acusado localmente también algunos movimientos y traslados de población; contando siempre con la continuación de aquellos asentamientos que consideramos más estables (Arteaga 2000b). No obstante, las citadas propuestas difusionistas simplifican de una manera demasiado ligera y superficial la complejidad económico-política del referido proceso histórico, ya que la continuidad relativamente prolongada de algunos asentamientos ante el abandono no siempre coincidente de muchos otros durante el transcurso del Bronce Tardío traduce más bien la realidad de una conflictividad acaecida durante varios siglos; y que de esta manera no se puede considerar coyuntural y mucho menos instantánea.

En distintos poblados (como pasaría con Fuente Álamo) la dependencia territorial pudo durar hasta muy poco después del Bronce Tardío Antiguo, cuando parece que algunos asentamientos incluso fueron 
abandonados. En otros asentamientos, a tenor de las fechas radiocarbónicas calibradas, la duración habitacional post-argárica se hizo relativamente mucho más larga; como parece haber ocurrido en La Cuesta del Negro de Purullena, en Granada. Por lo que, a todas luces, resulta evidente que durante el Bronce Tardío tuvieron que llevarse a cabo traslados poblacionales en los respectivos territorios post-argáricos; unas veces para proceder a la ocupación de diferentes emplazamientos igualmente sometidos a la dependencia de los nuevos centros del poder político, y otras veces quizás para aglutinarse en los mismos poblados capitales.

Este fenómeno de aglutinamiento poblacional quizás pueda ser el que se traduzca durante distintos momentos del Bronce Tardío en aquellos núcleos que fueron creciendo de una manera sensible en su mismo espacio de ocupación. Resulta expectante la comparación que en cuanto a sus territorios respectivos pueden permitir establecer unos poblados como los del Cabezo Redondo de Villena, en Alicante; La Bastida de Totana, en Murcia; el propio centro de El Argar, en Almería; el Cerro de la Encina de Monachil, en Granada; el citado poblado de Purullena, en Granada; el asentamiento de Peñalosa, en Jaén; y el poblado de Los Alcores de Porcuna, en Jaén, entre otros tantos conocidos. En definitiva, sin tener que agotar ahora toda la argumentación pertinente, en lugar de concebir una suplantación poblacional nosotros consideramos a tenor del resultado de Fuente Álamo que el desmembramiento del sistema estatal de El Argar no pudo comportarse ajeno al surgimiento del poder de aquellos 'príncipes' post-argáricos que durante el Bronce Tardío 'reinaron' en los 'dominios territoriales' del sudeste y en su entorno (Arteaga 2000b).

La consolidación de unos 'principados' territoriales post-argáricos alrededor del sudeste, durante el Bronce Tardío, hubo de correr pareja con la propia de otros 'principados' territoriales pre-tartesios, alrededor del suroeste de la Península Ibérica. Y como hemos apuntado, difícilmente podemos entenderla sin analizar desde los tiempos del sistema tributario articulado por el Estado argárico (Arteaga 2000a; 2000b) el modo de producción y de reproducción social, según el cual hasta el Bronce Medio, también en todo el ámbito atlántico-mediterráneo circundante, quedaron instituidas por parte de las respectivas elites dominantes las ya subrayadas apropiaciones particulares de las tierras agrícolas, de las tierras de pastos y de las tierras mineras (Arteaga 2000a; 2000b). La emergencia de tales 'principados', en consecuencia, hubo de acrecentar la focalización de los conflictos políticos-territoriales entre los asentamientos y la agudización de los conflictos económicos-sociales en cada territorio. Por lo que en relación con el carácter 'principesco' de los territorios post-argáricos del entorno del sudeste, y de los territorios pre-tartesios del entorno del suroeste, nosotros entendemos que la transición histórica relativa al Bronce Tardío conlleva la condición sine qua non para la explicación 'formativa' de la sociedad aristocrática (Arteaga 1995; 1997) que después conocemos dominando la política económica de la Tartéside, durante el Bronce Final (Roos 1997).

En atención a cuanto venimos comentando pensamos que tampoco faltan evidencias arqueológicas en la Baja Andalucía para argumentar la existencia de un Bronce Tardío pre-tartesio, no solamente contrastable con el horizonte cronológico de las importaciones micénicas localizadas en el Llanete de los Moros en Montoro (Martín de la Cruz 1988). De acuerdo con los materiales cerámicos documentados en la estratigrafía obtenida en el asentamiento de Los Alcores de Porcuna, este Bronce Tardío pre-tartesio se encuentra igualmente representado en Los Alcores de Sevilla, como lo sugieren los hallazgos arqueológicos aparecidos en la ciudad de Carmona (Jiménez Hernández 1994) y que de ninguna manera podemos equiparar con la tipología que muestran los materiales propios del Bronce Final en el suroeste de la Península Ibérica (Roos 1997).

La hipótesis de trabajo propuesta respecto del Bronce Final (Arteaga y Schubart 1980: 275 ss.) considerando al Bronce Tardío como un período prehistórico de transición, pensamos que puede resultar plausible contemplada en la proyección de su propia dimensión atlántica-mediterránea (Arteaga 1995; 1997), sin tener que confundirla con las indudables relaciones e intercambios, marítimos y continentales, que por entonces también sabemos que confluyeron en Occidente, conectando con las distintas y distantes organizaciones económicopolíticas (territoriales) que aparte del sudeste y del suroeste conocemos en el resto de la Península Ibérica. 
La noción atlántica-mediterránea, sustentada arqueológicamente desde la Época del Cobre (Arteaga 1992), pasando por la Época del Bronce (Arteaga 2000a; 2000b), encuentra de esta manera una proyección histórica en la transición del Bronce Tardío (Arteaga 1997; Roos 1997), por lo que pensamos que fue su propio desenlace el que condujo más adelante a la formación de la sociedad tartesia.

No entramos por lo mismo para nada en la discusión (a nuestro entender estéril) de cómo tenemos que 'etiquetar' el nombre de nuestro Bronce Tardío, para no confundirlo con el Bronce Final tartesio; como por su parte quieren hacer algunos colegas, al intentar buscar de una manera mecanicista sus homologaciones esquemáticas siguiendo los dictados de otras terminologías y pautas cronológicas europeas. Para, utilizando las mismas como si fueran las rectoras de unos 'paradigmas' universales, considerar que lo 'correcto' debe ser hablar solamente de Bronce Final; haciendo que las 'siglas' de este último empiecen ya con la inclusión del período post-argárico y pre-tartesio.

Nosotros, por el contrario, preferimos 'separarlo' claramente, para ganar respecto del Mundo Micénico (en el cual se apoyan las secuencias cronológicas europeas) un contraste directo respecto del Mundo AtlánticoMediterráneo del Bronce Tardío occidental. Y, a la inversa, solamente después de establecer el parangón del Mundo Micénico, comenzar a establecer la relación atlántica-mediterránea del Bronce Final tartesio con el Próximo Oriente. Entendemos que la adecuación terminológica y conceptual que de esta forma utilizamos (Arteaga y Schubart 1980: 274 s.), sin tener que derivar de una concatenación terminológica y conceptual ligada al paradigma del Historicismo Cultural europeo, permite ofrecer una coherencia atlánticamediterránea alternativa para la explicación del proceso histórico que en Occidente solamente concierne a la formación de la civilización tartesia (Arteaga 1997; Roos 1997).

La conclusión que podemos resumir de todo cuanto acabamos de exponer, radica en afirmar que los resultados arqueológicos obtenidos en las investigaciones 'post-argáricas' en la cima (Arteaga y Schubart 1980: 268 ss.) y en la ladera sur de Fuente Álamo, pero también en contraste con otras evidencias pre-tartesias obtenidas por nosotros mismos en relación con el Bajo Guadalquivir (Arteaga 1997; Roos 1997), permiten establecer que las relaciones atlánticas-mediterráneas parangonables entre Occidente y el Mundo Micénico, siendo todavía anteriores en varios siglos a la eclosión del Mundo Tartesio, solamente pudieron conectar alrededor del sudeste con la continuidad poblacional prehistórica que nosotros referimos a la consolidación de los 'principados territoriales' post-argáricos, y que como tales hacemos relativos al Bronce Tardío. En consecuencia, la trayectoria milenaria que en Occidente nosotros analizamos para explicar desde el sur (Arteaga y Hoffmann 1999) el proceso histórico de la Civilización Atlántica Mediterránea de la Península Ibérica (Arteaga 2000a; 2000b), encuentra en la definición prehistórica del Bronce Tardío el marco histórico apropiado para a partir de finales del II milenio en adelante comenzar a vertebrar el desarrollo protohistórico de un Bronce Final en la Tartéside.

(O.A. y A.M.R.)

\section{EPÍLOGO}

En lo que concierne a las intervenciones de consolidación y de restauración en Fuente Álamo, que en las anteriores campañas fueron posibles gracias a la aplicación de una gran inversión de fondos, bastante considerables, en la campaña de 1999 solamente era preciso tomar en general algunas medidas complementarias, además de la cubrición de los cortes de la ladera sur. En el corte 35 , el muro situado en ángulo oblicuo muy cerca de la fachada nordeste del gran edificio $O$ estaba minado por la acción de las aguas de lluvia amenazando con derrumbarse. Un avance de la erosión en esta zona tarde o temprano hubiese puesto en peligro la misma pared nordeste del edificio $O$. Por lo que el muro en cuestión ha sido asegurado mediante la construcción de un muro de apoyo, que se contrasta con el muro superior de la Edad del Bronce por una 


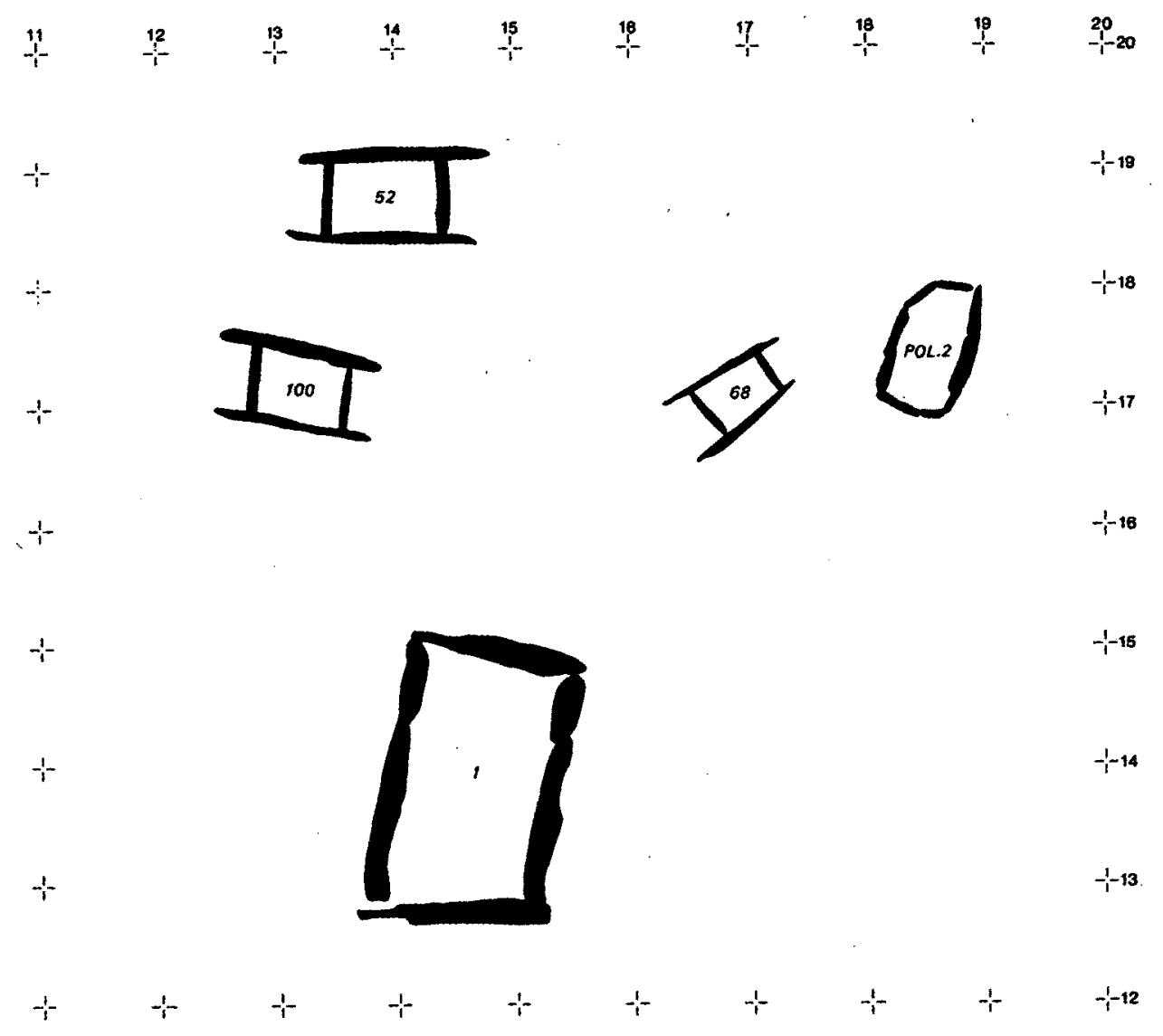

Fig. 16. Fuente Álamo. Ubicación in situ de la tumba 1 en la cima del poblado y, en su cercanía, el actual emplazamiento de las cistas 52, 68 y 100 así como de la 'cista poligonal 2' después de su traslado.

visible línea de separación trazada con finas placas de mármol. Así pues, en este caso el muro más antiguo se halla ubicado excepcionalmente por encima de las placas de mármol; ya que no obstante por todo lo dicho era conveniente marcar en cualquier caso la línea de separación entre ambos muros.

Mientras que en las laderas este y oeste varias cistas de las sepulturas allí descubiertas podían ser conservadas in situ, y además consolidadas (las tumbas 65 y 88 de la ladera este y las tumbas 51,56 y 71 de la ladera oeste), en otras partes del poblado no fue posible conservar varias cistas en su sitio original, como p.ej. las tumbas 68 y 100 que se hallaron ubicadas por completo o en parte por encima del edificio $O$. Las cistas afectadas fueron trasladadas durante anteriores campañas a la cima de Fuente Álamo, y allí han quedado reconstruidas, siendo dispuestas al norte de la tumba 1, a saber: las tumbas 52,68 y 100 así como la 'cista poligonal 2'. Para evitar confusiones en el futuro, en este avance sobre las excavaciones de Fuente Álamo se incluye un plano del así creado 'museo al aire libre' (fig. 16).

Este informe preliminar sobre la campaña de 1999 realizada en Fuente Álamo, entre otros artículos entretanto publicados sobre los resultados parciales de las investigaciones, constituye el último de los siete avances preliminares que llegaron a la luz con regularidad desde el año 1978. Así pues, extendiendo con gratitud una mirada retrospectiva sobre los logros alcanzados en estos 22 años de trabajo, al mismo tiempo cabe mirar hacia adelante con la esperanza de que en un futuro bastante próximo pueda darse una rica cosecha 
de publicaciones sintetizadoras de todo lo aprendido en Fuente Álamo. Al libro general dedicado a la presentación de los trabajos (Schubart, Pingel y Arteaga 2000), le siguen por lo pronto varias monografías (Risch 2002; Schuhmacher y Schubart 2003) ${ }^{17}$ que en los años venideros han de profundizar en los resultados de las excavaciones llevadas a cabo por el Instituto Arqueológico Alemán de Madrid en el poblado de Fuente Álamo durante los años de 1977 a 1999.

Al mismo tiempo también cabe enfatizar que hasta ahora no se lograron todos los objetivos que los excavadores tenían proyectados en 1977 al dar comienzo a las excavaciones, y en particular desde 1988 cuando se comenzaron a proyectar las investigaciones en la ladera sur de Fuente Álamo. Por lo que ahora la determinación tomada sobre la conclusión de las excavaciones sistemáticas sólo puede suponer en definitiva una medida por el momento provisional. Respecto de los trabajos empezados en la ladera sur y en la ladera oeste, pero igualmente a la vista de la ladera norte aún sin tocar, así como a tenor de cuanto aguarda en la zona situada en el nordeste, y también en parte en el sudeste de la ladera este donde se ha dejado reservado un espacio para futuras excavaciones de control, es de esperar que se arrojarán todavía múltiples resultados, cuyo valor informativo, de comparación, y eventualmente de contraste con los conocimientos de los espacios ya excavados, habrá de ser especialmente grande.

La investigación en Fuente Álamo dista mucho de encontrarse agotada. Por esto mismo cabe esperar que los resultados obtenidos inviten a proseguir algún día las excavaciones arqueológicas en el poblado de Fuente Álamo, ojalá que para su fortuna iluminadas entonces por la política cultural de unas mejores estrellas.

\section{BIBLIOGRAFÍA}

ARTEAGA, O. (1992): “Tribalización, jerarquización y Estado en el territorio de El Argar”, Spal 1: 179-208. Sevilla.

- (1995): "Paradigmas historicistas de la civilización occidental. Los fenicios en las costas mediterráneas de Andalucía", Spal 4: 131-171. Sevilla.

(1997): "Las sociedades de la Época del Cobre y del Bronce en el Valle del Guadalquivir", en I Reunión

Int. sobre la Cultura Argárica en el contexto de la Edad del Bronce Peninsular. Cien años después de Siret (Lorca 1997): en prensa.

(2000a): "El proceso histórico en el territorio argárico de Fuente Álamo. La ruptura del paradigma del Sudeste desde la perspectiva atlántica-mediterránea del Extremo Occidente", en Schubart, Pingel y Arteaga 2000: 117-143.

(2000b): "La sociedad clasista inicial y el origen del Estado en el territorio de El Argar", Revista Atlántica-Mediterránea de Prehistoria y Arqueología Social 3: 121-219. Cádiz.

ARTEAGA, O. y HOFFMANN, G. (1999): "Dialéctica del proceso natural y sociohistórico en las costas mediterráneas de Andalucía", Revista Atlántica-Mediterránea de Prehistoria y Arqueología Social 2: 13-121. Cádiz.

ARTEAGA, O. y SCHUBART, H.(1980): “Fuente Álamo. Excavaciones de 1977”, Noticiario Arqueológico Hispánico 9: 245-289. Madrid.

_- (1981): “Fuente Álamo. Campaña de 1979", Noticiario Arqueológico Hispánico 11: 7-32. Madrid.

17. En Preparación: O. Arteaga, Iberisch-römische Siedlungsfunde in Fuente Álamo; O. Arteaga y A.M. Roos, Die Spätbronzezeit von Fuente Álamo und die Frage der Siedlungskontinuität; M. Kunter, Die menschlichen Skelettreste aus den Grabungskampagnen 1996 und 1999 in Fuente Álamo; C. Liesau, Die Knochengeräte von Fuente Álamo; V. Pingel, Die Grabungen 1988 bis 1999 auf dem Südhang von Fuente Álamo; H. Schubart, Die Gräber von Fuente Álamo. Ein Beitrag zur Chronologie und zu den Grabriten der El Argar-Kultur; H.-P. Stika, Paläobotanische Untersuchungen in Fuente Álamo während der Grabungen 1991 und 1996. 
(2000): "Formas de la cerámica argárica de Fuente Álamo", en Schubart, Pingel y Arteaga 2000: 99-106.

BLANCE, B. (1971): Die Anfänge der Metallurgie aufder Iberischen Halbinsel. Studien zu den Anfängen der Metallurgie 4, Berlin.

GÖRSDORF, J. (2001): “C14-Datierungen von Materialien aus der Grabung Fuente Álamo (Cuevas del Almanzora, Almería)", Madrider Mitteilungen 42: 82-84. Mainz.

JIMÉNEZ HERNÁNDEZ, A. (1994): "Nuevos datos para la definición de la etapa final del Bronce en Carmona (Sevilla)", Spal 3: 145-177. Sevilla.

KUNTER, M. (2000): “Los restos de esqueletos humanos hallados en Fuente Álamo durante las campañas de 1985, 1988 y 1991”, en Schubart, Pingel y Arteaga 2000: 265-282.

MARTÍN DE LA CRUZ, J.C. (1988): "Mykenische Keramik aus bronzezeitlichen Siedlungsschichten von Montoro am Guadalquivir", Madrider Mitteilungen 29: 77-92. Mainz.

PINGEL, V. (1991): "Neue Untersuchungen zum bronzezeitlichen Siedlungswesen in Südostspanien Die Ausgrabungen in Fuente Álamo (Prov. Almería)", en Veröffentlichungen des Vorgeschichtlichen Seminars Marburg. Sonderband 7: 1-28. Marburg.

(2000): "Dataciones radiocarbónicas de Fuente Álamo 1977-1991", en Schubart, Pingel y Arteaga 2000: 91-98.

PINGEL, V.; SCHUBART, H.; ARTEAGA, O. y KUNST, M. (1998): "Fuente Álamo. Vorbericht über die Grabung 1996 in der bronzezeitlichen Höhensiedlung", Madrider Mitteilungen 39: 14-34. Mainz.

PINGEL, V.; SCHUBART, H.; ARTEAGA, O.; ROOS, A.M. y KUNST, M. (2001): "Fuente Álamo. Vorbericht über die Grabung 1999 in der bronzezeitlichen Höhensiedlung", Madrider Mitteilungen 42: 33-81. Mainz.

RISCH, R. (2002): Recursos naturales, medios de producción y explotación social. Un análisis económico de la industria lítica de Fuentélamo(Almería), 2250-1400 antes de nuestra era. Iberia Archaeologica 3 , Mainz.

RISCH, R. y SCHUBART, H. (1991): "Las estelas argáricas de Fuente Álamo”, Trabajos de Prehistoria 48: 187-202. Madrid.

ROOS, A.M. (1997): La sociedad de clases, la propiedad privada y el Estado en Tartesos. Una visión de suproceso histórico desde la arqueología del 'Proyecto Porcuna'. Tesis Doctoral, Universidad de Granada.

SCHUBART, H. (1975): "Cronología relativa de la cerámica sepulcral en la cultura de El Argar”, Trabajos de Prehistoria 32: 79-92. Madrid.

(2000a): "La estratigrafía en la cima y en la ladera Este del poblado: Secuencia de los estratos y de las fases", en Schubart, Pingel y Arteaga 2000: 39-61.

- (2000b): "Acerca de la evolución formal de la cerámica argárica", en Schubart, Pingel y Arteaga 2000: 107-116.

_(e.p.): Die Gräber von Fuente Álamo. Ein Beitrag zur Chronologie und zu den Grabriten der ElArgarKultur. En preparación.

SCHUBART, H. y ARTEAGA, O. (1983): "La Cultura de 'El Argar' y las excavaciones en Fuente Álamo (II)", Revista de Arqueología 25: 54-63. Madrid.

-(1986): "Fundamentos arqueológicos para el estudio socio-económico y cultural del área de El Argar", en Homenaje a Luis Siret (Cuevas del Almanzora 1984): 289-307. Sevilla.

SCHUBART, H.; ARTEAGA, O. y PINGEL, V. (1985): "Fuente Álamo. Informe preliminar sobre la excavación de 1985 en el poblado de la Edad del Bronce", Ampurias 47: 70-107. Barcelona.

- (1988): "Fuente Álamo. Informe preliminar sobre la excavación realizada en 1988 en el poblado de la Edad de Bronce”, Anuario Arqueológico de Andalucía 1988-II: 171-178. Sevilla. 
_- (1989): "Fuente Álamo. Vorbericht über die Grabung 1988 in der bronzezeitlichen Höhensiedlung", Madrider Mitteilungen 30: 76-91. Mainz.

SCHUBART, H. y PINGEL, V. (1995): "Fuente Álamo-Eine bronzezeitliche Höhensiedlung in Andalusien", Madrider Mitteilungen 36: 150-164. Mainz.

SCHUBART, H.; PINGEL, V. y ARTEAGA, O. (1991): "Informe preliminar sobre la excavación realizada en 1991 en el poblado de la Edad del Bronce", Anuario Arqueológico de Andalucía, 1991-II: 24-27. Sevilla.

__ (1993): "Fuente Álamo. Vorbericht über die Grabung 1991 in der bronzezeitlichen Höhensiedlung", Madrider Mitteilungen 34: 1-12. Mainz.

(2000): Fuente Álamo. Las excavaciones arqueológicas 1977-1991 en el poblado de la Edad del Bronce. Junta de Andalucía, Sevilla.

SCHUBART, H. y ULREICH, H. (1991): Die Funde der Südostspanischen Bronzezeit aus der Sammlung Siret. Madrider Beiträge 17, Mainz.

SCHUHMACHER, T.X. y SCHUBART, H. (2003): Fuente Álamo. Die Siedlungskeramikder Grabungen 1985-1991. Untersuchungen zur Chronologie und zum Siedlungsschema der El Argar-Kultur. Stratigraphisch geordnete Keramik der El Argar-Zeit aus den Grabungen 1977 bis 1982. Iberia Archaeologica 4, Mainz.

SIRET, E. y L. (1890): Las Primeras Edades del Metal en el Sudeste de España. Barcelona. 


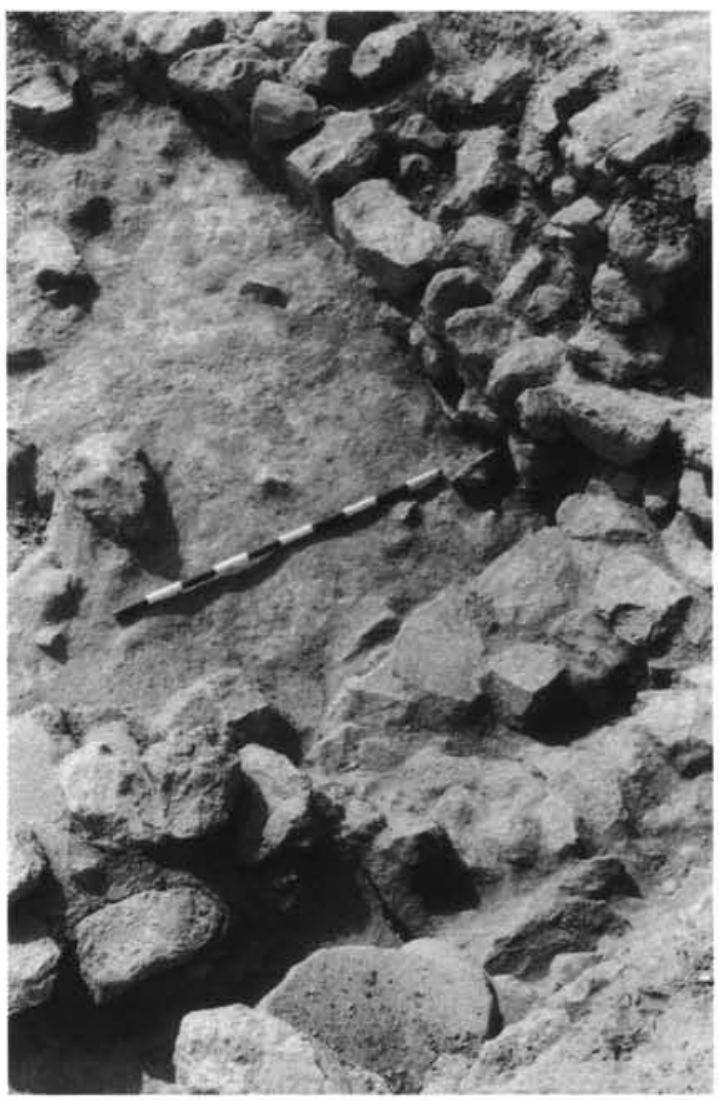

Lám. I. Fuente Álamo 1999. Corte 39W.

Vista del ángulo del edificio $\mathrm{X}$ desde el norte (Foto: DAI-MAD-KB-33-99-30).

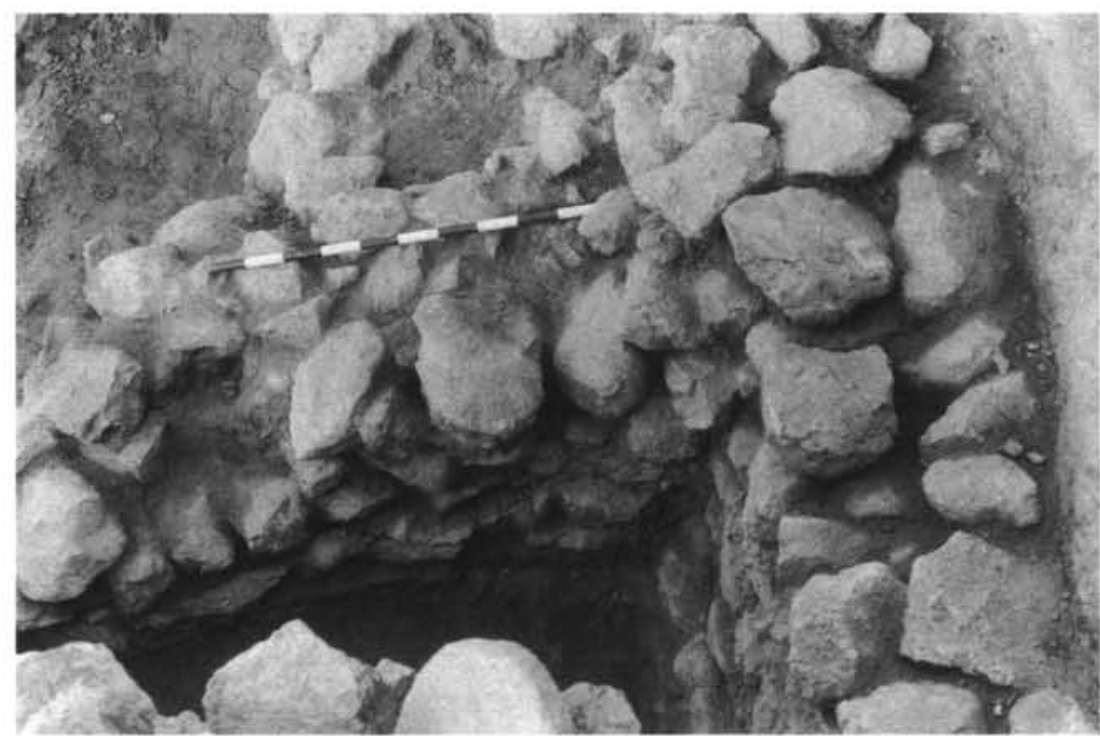

Lám. II. Fuente Álamo 1999. Testigo 39/40. Vista del ángulo del edificio W desde el este. A la derecha muro mf contra el escalón de la roca; por debajo del jalón el muro mi; por delante vista hasta el suelo del edificio y firme geológico. Detrás del jalón fondo de la fosa de la tumba 111 norte

(Foto: DAI-MAD-KB-33-99-27). 
Lám. III. Fuente Álamo 1999. Corte 40. Vista desde el norte. Primer plano a la izquierda muro este del edificio U del Bronce Tardío; en el fondo a la izquierda muro sur del edificio. Por debajo del edificio U un nivel argárico atravesado por la fosa de la tumba 112 (delante del jalón). A la derecha el sector reproducido en la lám. IV (Foto: DAI-MAD-KB-33-99-11).
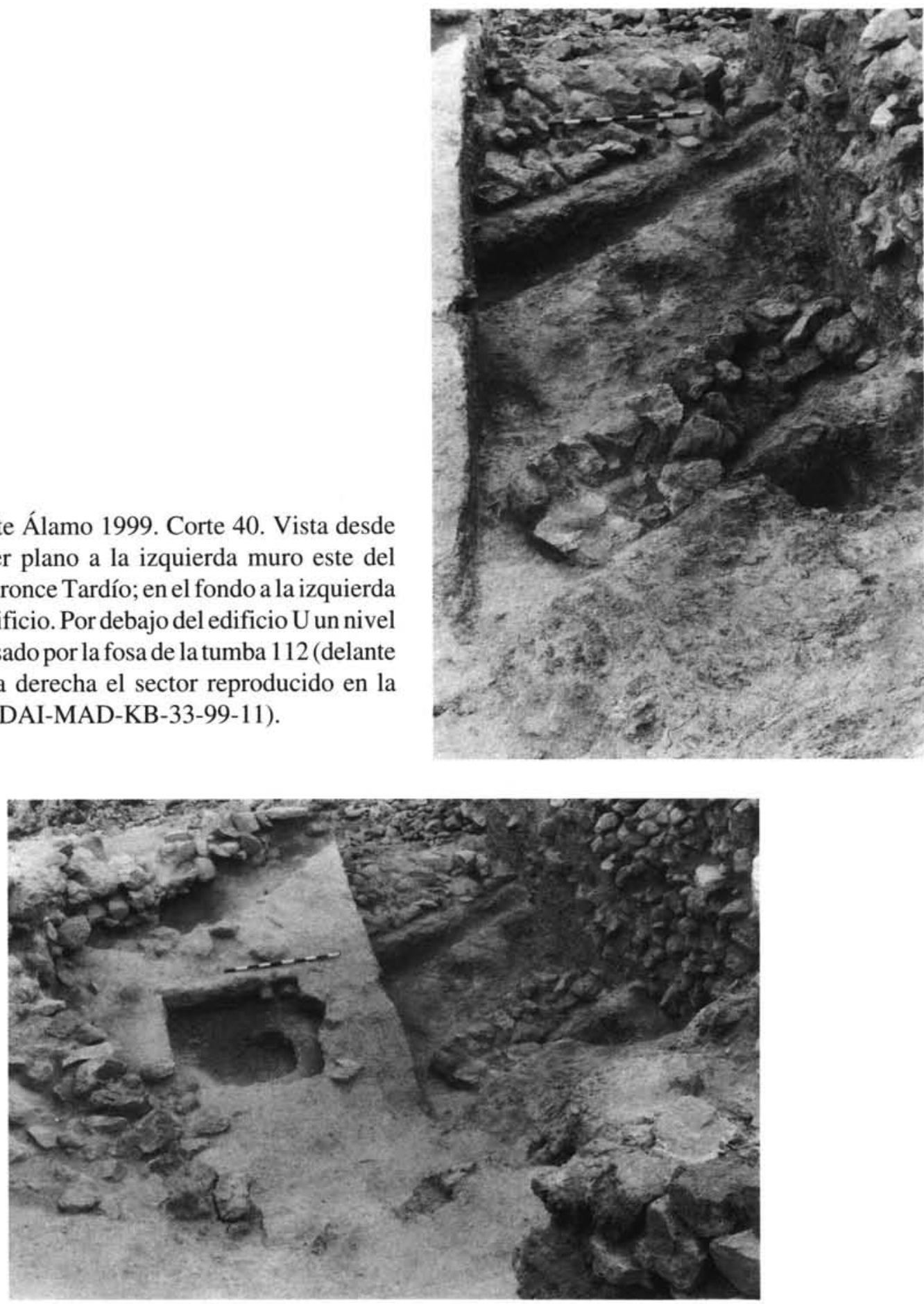

Lám. IV. Fuente Álamo 1999. Corte 40. Vista desde el norte del sector excavado delante del perfil oeste. En primer plano los recortes de la roca en el Bronce Tardío y la época argárica; en el centro un 'canalillo' y hoyos excavados en la roca; además de los muros argáricos mh (bajo el jalón) y me (delante)

(Foto: DAI-MAD-KB-33-99-03). 


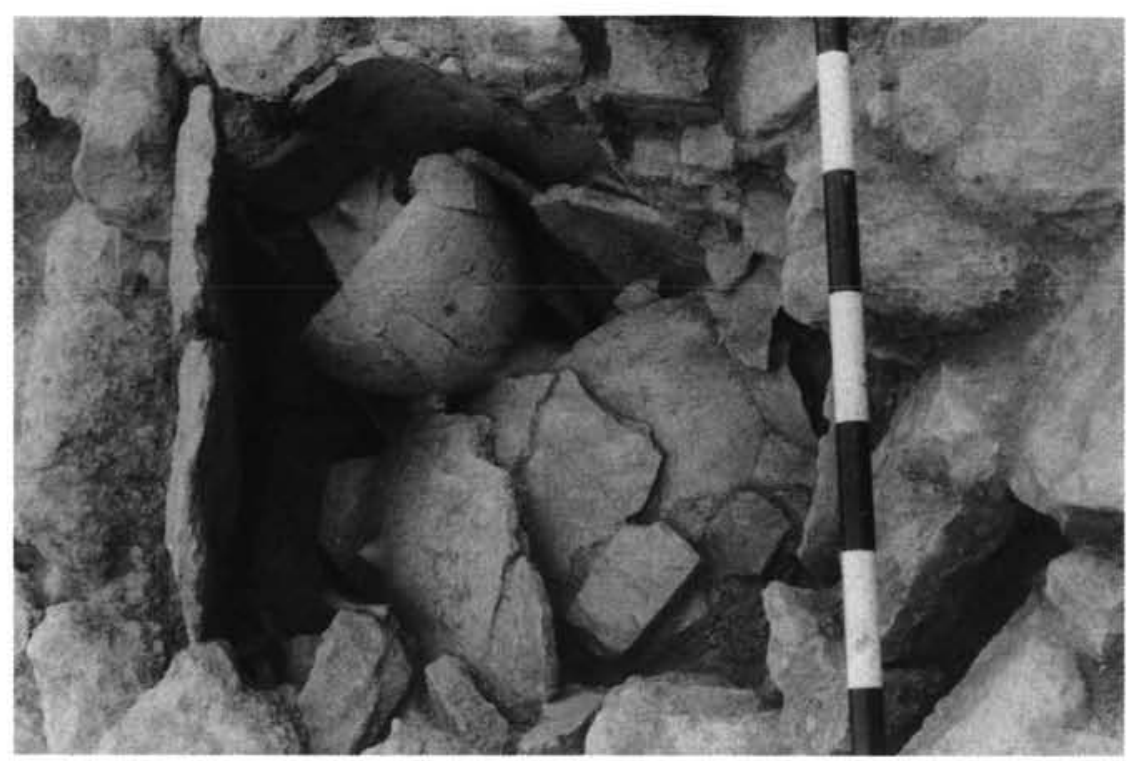

Lám. V. Fuente Álamo 1999. Tumba 111. Vista del enterramiento en pithos desde el norte. A la izquierda la losa de cierre; en el centro los fragmentos de la pared superior del pithos caídos dentro; por encima a la izquierda la gran copa (FA 99/4414/2) (Foto: DAI-MAD-KB-32-99-03).

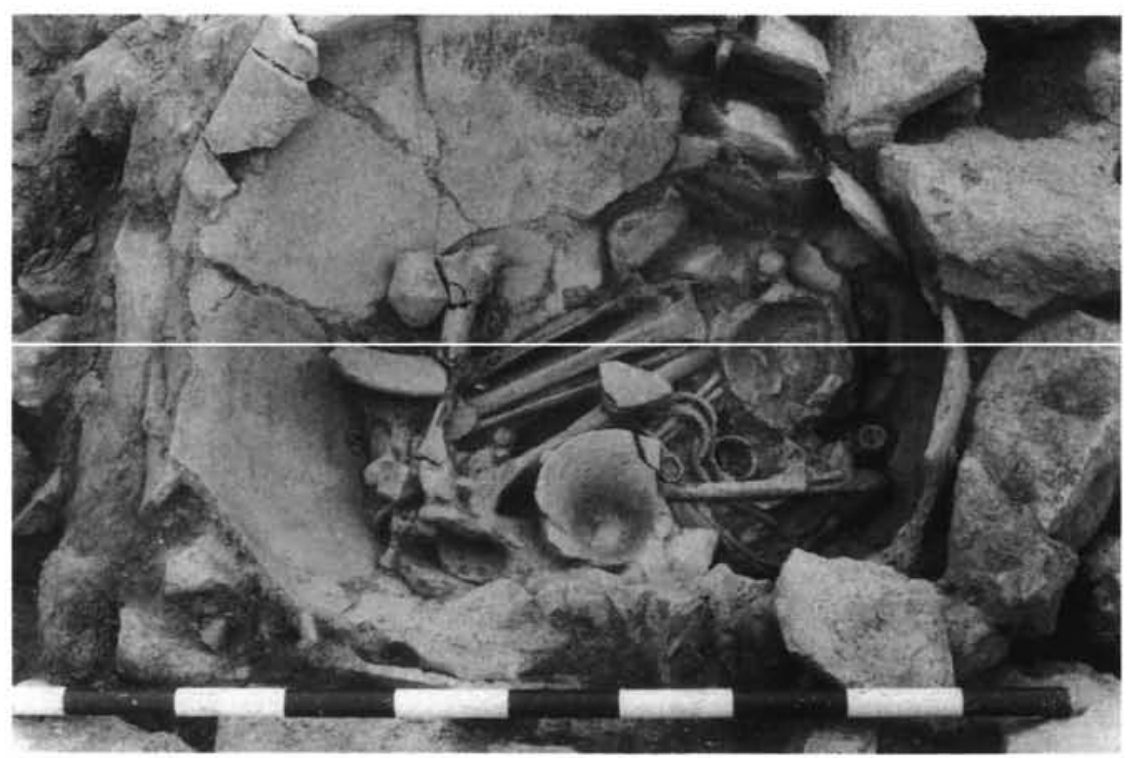

Lám. VI. Fuente Álamo 1999. Tumba 111. Vista del interior de la urna desde el norte. A la izquierda la boca del pithos; a la derecha en el fondo de la vasija el cráneo; en el antebrazo dos brazaletes (FA 99/4414/15 y 16); por debajo a la izquierda el pie de una copa reutilizado como 'vaso' (FA 99/4414/7); arriba a la izquierda pequeña vasija carenada (FA 99/4414/6) (Foto: DAI-MAD-KB-33-99-17). 


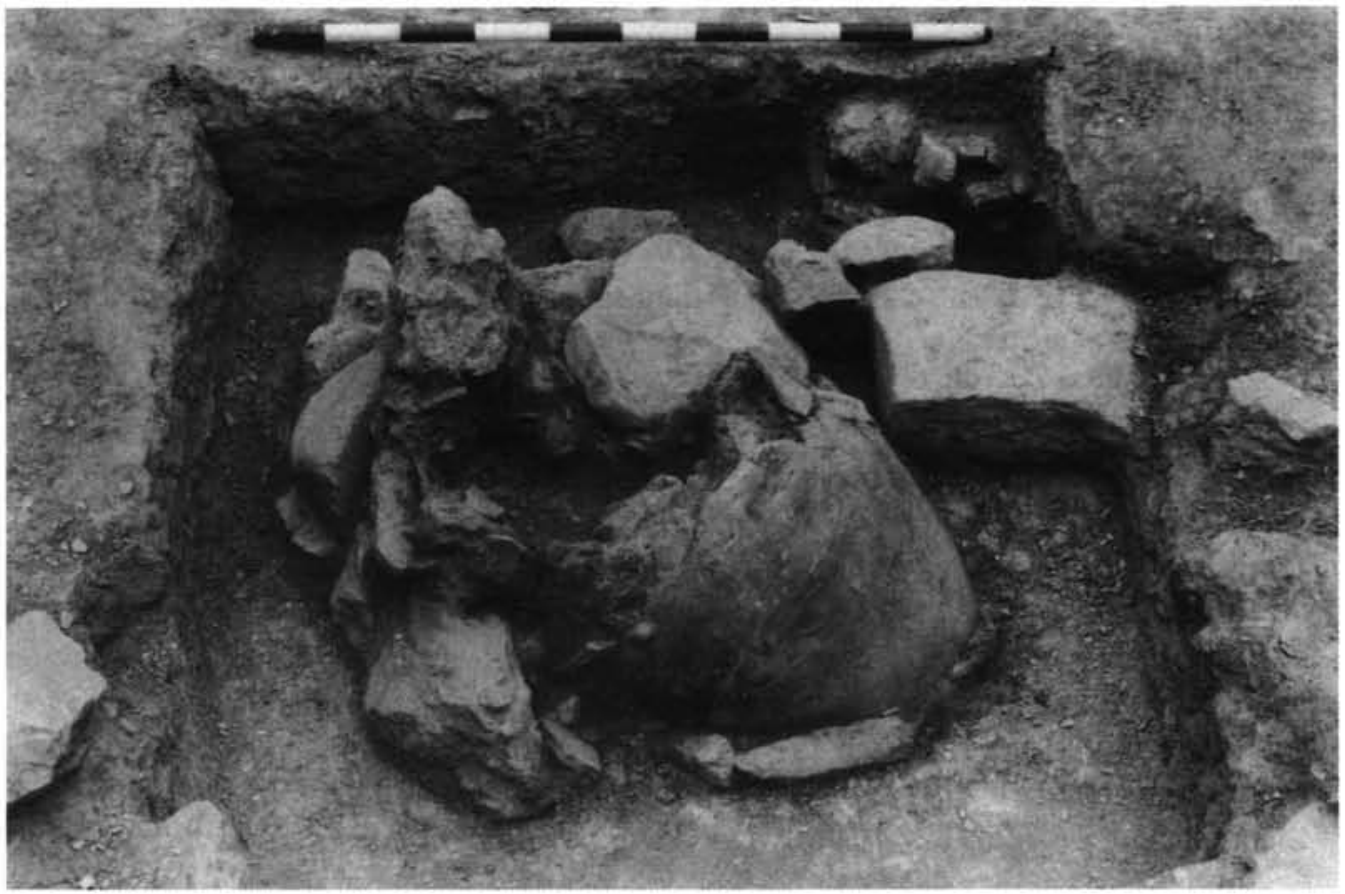

Lám. VII. Fuente Álamo 1999. Tumba 112. Vista de la urna desde el norte, y de las piedras que la acuñaban en la fosa (Foto: DAI-MAD-KB-31-99-35A).

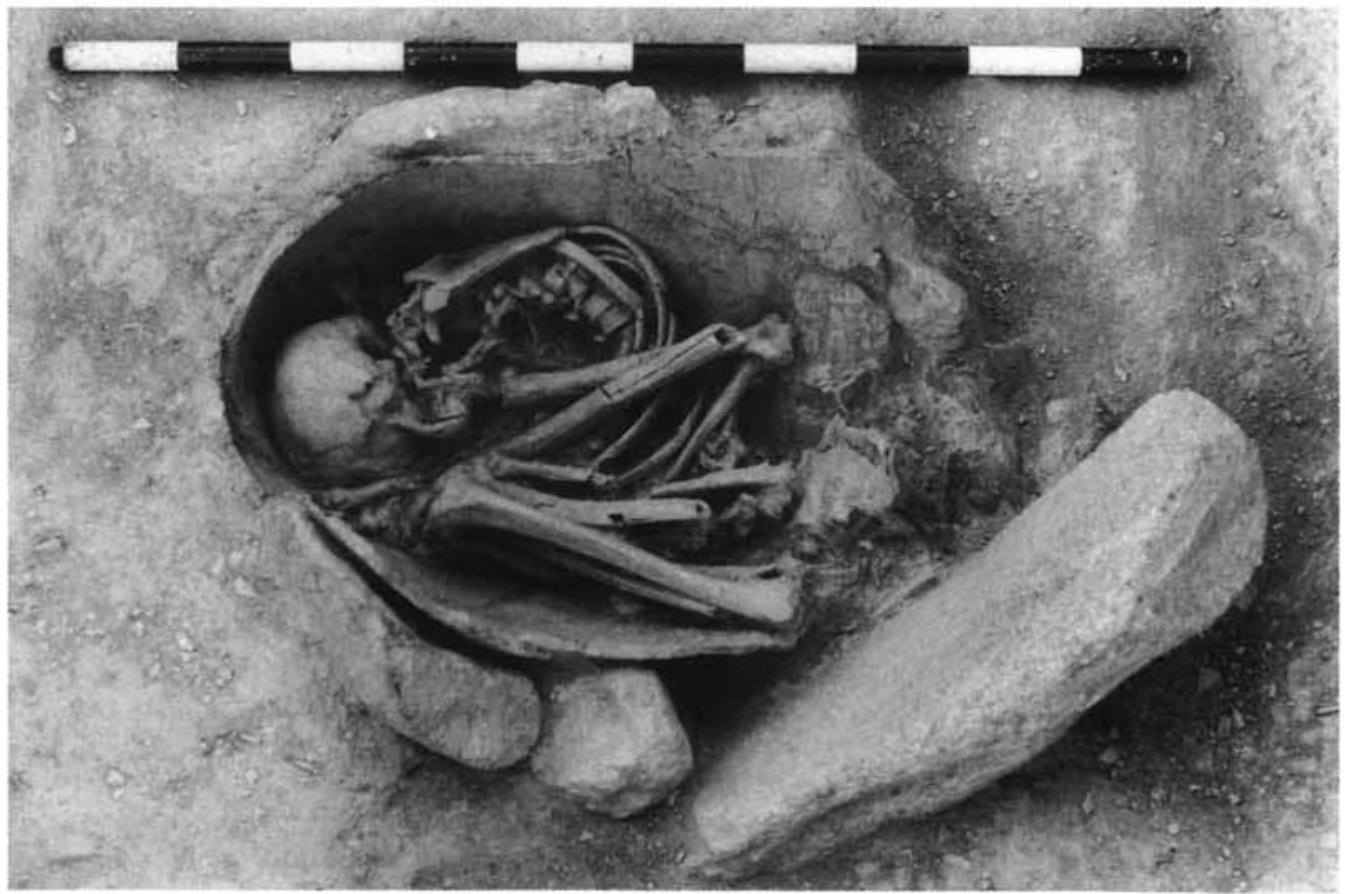

Lám. VIII. Fuente Álamo 1999. Tumba 112. Vista del enterramiento en pithos desde el sur. A la izquierda, en el fondo de la vasija, el cráneo de la difunta colocada en posición fetal (Foto: DAI-MAD-KB-32-99-33). 